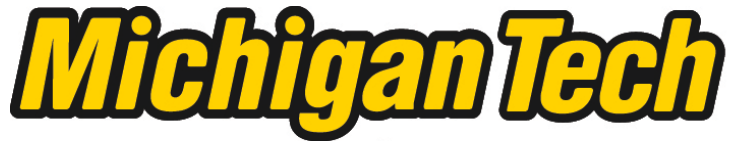 \\ Michigan Technological University Create the Future Digital Commons @ Michigan Tech
}

Dissertations, Master's Theses and Master's Reports - Open

Dissertations, Master's Theses and Master's

Reports

2014

Veteranness : Representations of Combat-related PTSD in U.S.

Popular Visual Media

Diane J. Keranen

Michigan Technological University

Follow this and additional works at: https://digitalcommons.mtu.edu/etds

Part of the Rhetoric Commons

Copyright 2014 Diane J. Keranen

\section{Recommended Citation}

Keranen, Diane J., "Veteranness : Representations of Combat-related PTSD in U.S. Popular Visual Media", Dissertation, Michigan Technological University, 2014.

https://doi.org/10.37099/mtu.dc.etds/814

Follow this and additional works at: https://digitalcommons.mtu.edu/etds

Part of the Rhetoric Commons 


\title{
VETERANNESS: REPRESENTATIONS OF COMBAT-RELATED PTSD IN U.S. POPULAR VISUAL MEDIA
}

\author{
By \\ Diane J. Keranen

\begin{abstract}
A DISSERTATION
Submitted in partial fulfillment of the requirements for the degree of DOCTOR OF PHILOSOPHY

In Rhetoric and Technical Communication
\end{abstract}

MICHIGAN TECHNOLOGICAL UNIVERSITY

2014

(C) 2014 Diane J. Keranen 
This dissertation has been approved in partial fulfillment of the requirements for the Degree of DOCTOR OF PHILOSOPHY in Rhetoric and Technical Communication.

\section{Department of Humanities}

Dissertation Advisor: Diane Shoos

Committee Member: Dieter Adolphs

Committee Member: Eliqabeth Flynn

Committee Member: Patricia Helsel

Department Chair: Ronald Strickland 


\section{Table of Contents}

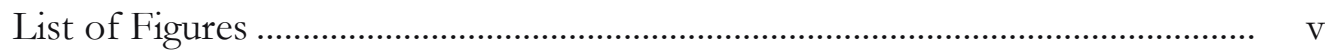

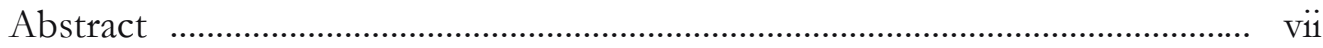

1 Veteranness: Combat-related PTSD in Popular Visual Media.................... 1

Introduction...................................................................................................... 2

Exigency of this Study.................................................................................. 8

Review of Literature: Veteran Representations in Popular Visual Media .......... 12

Critical Framework ............................................................................................. 18

Criteria for Selection of Media Artifacts...................................................... 19

Method and Theoretical Framework ........................................................... 22

Seeing Veteran Myths.......................................................................... 24

Veteranness as a Discursive Unity ...................................................... 31

Uncovering Sociocultural Function of Veteranness........................... 34

Seeing PTSD: Cultures and Symptoms ...................................................... 37

Diagnostic Criteria ....................................................................... 41

Analyzing Visual Media and PTSD Symptom-like Constructs .................... 47

Chapter Summaries ............................................................................................ 48

2 Representations of World War I and World War II Veterans ..................... 51

Introduction: Representations of WWI and WWII Veterans............................. 52

Veteran Discourse in the 1930s, 40s and 50s .................................................... 58

World War I Veteran James Allen....................................................................... 65

Film Synopsis: I Am a Fugitive from a Chain Gang, 1932 ............................... 66

Seeing James Allen as a Combat-affected Veteran ........................................ 72

Veteran Myth from James Allen Representation .......................................... 81

World War II Veterans Al Stephenson and Fred Derry .................................... 86

Film Synopsis: The Best Years of Our Lives, 1946 ........................................... 87

Seeing Al Stephenson and Fred Derry as Combat-affected Veterans ......... 93

Veteran Myth from Al and Fred Representations ......................................... 104 
3 Representations of Vietnam War Veterans ........................................................ 107

Introduction: Representations of Vietnam War Veterans ...................................... 108

Veteran Discourse in the 1960s through the 1990s................................................. 111

Vietnam War Veteran Michael................................................................................. 123

Film Synopsis: The Deer Hunter, 1978 .......................................................... 124

Seeing Michael as a Combat-affected Veteran................................................... 129

Veteran Myth from Michael Representation .................................................... 136

Vietnam War Veteran Private Eriksson .............................................................. 137

Film Synopsis: Casualties of War, 1989 ............................................................... 138

Seeing Eriksson as a Combat-affected Veteran................................................ 142

Veteran Myth from Private Eriksson Representation ..................................... 144

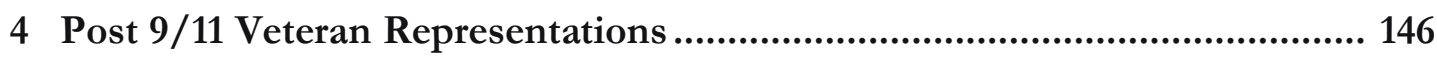

Introduction: Post 9/11 Veteran Representations................................................. 147

Veteran Discourse after 9/11 .................................................................................. 148

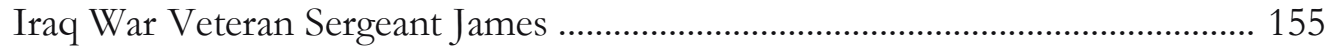

Film Synopsis: The Hurt Locker, 2008 .............................................................. 156

Seeing Sergeant James as a Combat-affected Veteran...................................... 166

Veteran Myth from Sergeant James Representation........................................ 170

Veteran Representations: HBO documentary Wartorn: 1861-2010 ...................... 173

Film Synopsis: Wartorn: 1861-2010, 2011 .................................................... 173

Seeing Noah, Jason, Nathan and Billy as Combat-affected Veterans.......... 175

Veteran Myth from Wartorn Representations ................................................. 184

Epilogue: Sociocultural Functions of Veteranness ............................................. 187

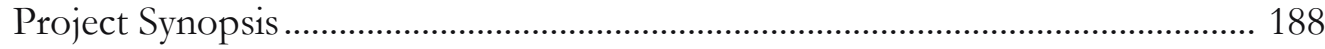

Summary: Veteran Myths after WWI and WWII …………………………........ 189

Summary: Veteran Myths after the Vietnam War ................................................. 191

Summary: Veteran Myths Post 9/11...................................................................... 193

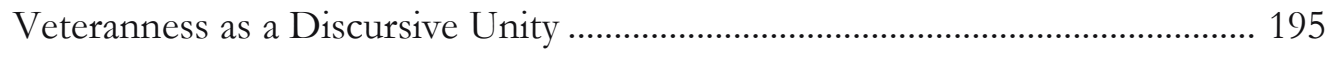

Sociocultural Functions of Veteranness................................................................ 195

Works Cited and Referenced ......................................................................... 199 


\section{List of Figures}

\section{Veteranness: Combat-related PTSD in Popular Visual Media}

Figure 1.1 Photographs of Barnes while fleeing ……....................................... 24

Figure $1.2 \quad$ Illustration of first-order system...................................................... 24

Figure 1.3 Illustration of second-order system.............................................. 28

Figure 1.4 Photograph of Barnes after presumed dead ................................. 32

Figure 1.5 Photograph of Barnes two weeks after death................................ 33

Figure 1.6 Illustration of Veteranness............................................................. 36

\section{Representations of World War I and World War II Veterans}

Figure 2.1 Image of Life magazine's "Speaking of Pictures" pictorial .......... 60

Figure 2.2 Image of Life magazine's "The War" essay .................................... 61

Figure 2.3 First appearance of James Allen .................................................. 67

Figure 2.4 James Allen in his final scene ......................................................... 83

Figure 2.5 First appearance of Fred Derry........................................................ 87

Figure 2.6 First appearance of Al Stephenson ................................................ 89

Figure 2.7 Al Stephenson in his final scene ................................................... 103

Figure 2.8 Fred Derry in his final scene …...................................................... 104

\section{Representations of Vietnam War Veterans}

Figure 3.1 Image of front cover of Vietnam: Reflexes and Reflections ................ 116

Figure 3.2 Image of Reflections (Teter) ........................................................... 119

Figure 3.2 Image of Self-Portrait: The Vietnam Veteran (Suarez)......................... 122

Figure 3.4 First post-war appearance of Michael................................................ 130

Figure 3.5 Michael in his final scene ........................................................... 135

Figure 3.6 First post-war appearance of Eriksson ............................................ 139

Figure 3.7 Eriksson in his final scene ......................................................... 142 


\section{Post 9/11 Veteran Representations}

Figure 4.1 Image of $W$ artorn: 1861-2010 web site ............................................ 151

Figure 4.2 Image of $W$ artorn: 1861-2010 DVD front cover .......................... 152

Figure 4.3-8 Images from "Alone" advertisement ................................................ 154

Figure 4.9 First post-war appearance of Sergeant James ................................. 164

Figure 4.10 Sergeant James in his final post-war scene.................................... 165

Figure 4.11 Sergeant James in his final scene ...................................................... 166

Figure 4.12 First image of Nathan............................................................... 179

Figure 4.13 Nathan in his final appearance ......................................................... 180

Figure 4.14 First image of Billy .......................................................................... 182

Figure 4.15 Billy in his final appearance .......................................................... 183 


\begin{abstract}
Posttraumatic stress and PTSD are becoming familiar terms to refer to what we often call the invisible wounds of war, yet these are recent additions to a popular discourse in which images of and ideas about combat-affected veterans have long circulated. A legacy of ideas about combat veterans and war trauma thus intersects with more recent clinical information about PTSD to become part of a discourse of visual media that has defined and continues to redefine veteran for popular audiences.
\end{abstract}

In this dissertation I examine realist combat veteran representations in selected films and other visual media from three periods: during and after World Wars I and II (James Allen from I Am a Fugitive from a Chain Gang, Fred Derry and Al Stephenson from The Best Years of Our Lives); after the Vietnam War (Michael from The Deer Hunter, Eriksson from Casualties of War), and post 9/11 (Will James from The Hurt Locker, a collection of veterans from Wartorn: 1861-2010.) Employing a theoretical framework informed by visual media studies, Barthes' concept of myth, and Foucault's concept of discursive unity, I analyze how these veteran representations are endowed with PTSD symptom-like behaviors and responses that seem reasonable and natural within the narrative arc. I contend that veteran myths appear through each veteran representation as the narrative develops and resolves. I argue that these veteran myths are many and varied but that they crystallize in a dominant veteran discourse, a discursive unity that I term veteranness. I further argue that veteranness entangles discrete categories such as veteran, combat veteran, and PTSD with veteran myths, often tying dominant discourse about combat-related PTSD to outdated or outmoded notions that significantly affect our attitudes about and treatment of veterans.

A basic premise of my research is that unless and until we learn about the lasting effects of the trauma inherent to combat, we hinder our ability to fulfill our responsibilities to war veterans. A society that limits its understanding of posttraumatic stress, PTSD and post-war experiences of actual veterans affected by war trauma to veteranness or veteran myths risks normalizing or naturalizing an unexamined set of sociocultural expectations of all veterans, rendering them voice-less, invisible, and, ultimately, disposable. 
CHAPTER 1

\title{
Veteranness: Combat-related PTSD in Popular Visual Media
}

\author{
As the train bringing James Allen home from WWI pulls into the station, \\ his mother wonders aloud, "Do you think he'll be wearing his medal?" \\ The young woman waiting with bis mother \\ on the platform excitedly responds, "Why, of course be will." \\ — from the film I Am a Fugitive From a Chain Gang, 1932
}




\section{Introduction}

On Sunday, January 1, 2012, Margaret Anderson, a park ranger at Mt. Rainier National Park in Washington State, was shot and killed. The suspect was 24-year-old Benjamin Barnes, identified in news reports as an Iraq War veteran who had encountered Anderson as he was fleeing into the mountains after a scuffle and shooting at a nearby residence. By January 2, news media were commenting on his military training and deployment to Iraq, mentioning Posttraumatic Stress Disorder (PTSD) and circulating several photographs of Barnes. These photographs included a set in the possession of Pierce County Sheriff's Department. One widely circulated photograph shows the young veteran directly and unemotionally facing the viewer. His hair is military-style short; he displays numerous tattoos on a bare, muscled torso and poses holding two assault-style firearms. On January 3, news media made the announcement, accompanied by a less threatening image of Barnes that he had died from exposure to the elements. Weeks later, the more threatening image of a violent, outlaw veteran re-emerged, reinforcing the growing idea-even though Barnes' military record suggests he was not in combat and not diagnosed with PTSD ${ }^{1}$ - that PTSDaffected veterans exhibit dangerous behaviors (Figure 1.5).

The news articles and photographs of Barnes help define popular notions of Posttraumatic Stress Disorder (PTSD). PTSD is a clinical term for a mental health condition that can lead to "significant distress or impairment in social, occupational, or other important areas of functioning" (DSM-IV 463). Although it is common for people to exhibit stress-related reactions after experiencing traumatic events, only symptoms that do not

1 This progression in the usage of Barnes' image is discussed more fully below in "Seeing Veteran Myths). 
resolve over time and dramatically affect the person's ability to function qualify for a possible PTSD diagnosis (National Center, Public). Regardless of these qualifications, posttraumatic stress and PTSD are terms that dominate popular veteran discourse concerning what are often called invisible wounds — the lasting, non-physical, effects of combat. These notions are also part of a larger ongoing visual discourse that defines and redefines veteran for popular audiences.

Visual media_photographs, film, print magazines and books, Internet content, etc. — are powerful conveyers of ideas about and meanings of PTSD and veteran. My project is an interpretive cultural analysis of visual media representations of veterans and PTSD. I argue that in these representations ideas and meanings about veterans and PTSD are many and varied but they crystallize in a dominant veteran discourse or "discursive unity" that I term veteranness. I further argue that veteranness entangles discrete categories such as veteran, combat veteran, and PTSD along with a variety of veteran myths, often tying dominant discourse about veterans to outdated or outmoded notions that significantly affect how society sees and integrates veterans in society. The following terms, defined below, are central to this analysis:

- Discourse refers to a broad set of sociocultural communication practices in a variety of contexts (entertainment, journalism, information, etc.) and disciplines (popular, professional, military, etc.) that operate along the lines of a "collective consciousness" (Foucault 22); I am especially concerned with the intersection of the combat veteran and PTSD as evidenced in popular visual media.

- Discursive unity (Michel Foucault's, The Archaeology of Knowledge \& the Discourse on Language) refers to seemingly "ready-made" conceptualizations that seem "valid at the outset" (22) and operate, in a circular fashion, through discourse to inform and be informed by ongoing discursive practices that define and redefine veteran for popular audiences. 
- Myth (Roland Barthes' Mythologies) and veteran myth refer to a particular "kind of message” (110) about veterans (e.g. Benjamin Barnes photographs) that overlaps with concepts and ideas about PTSD and appears natural rather than contingent and constructed.

- Veteranness refers to the discursive unity about veterans that is laden with a variety of unexamined veteran myths that have evolved over time and seem reasonable and appropriate.

Discourse is the broadest, most obvious level of communication about veterans. The discursive unity, veteranness, operates in a circular fashion that informs and is informed by concepts that are appropriate for its unity. I argue that veteranness is constituted by a variety of veteran myths that can be distilled from popular discourse by analyzing individual veteran representations that often incorporate PTSD symptom-like behaviors and responses. These representations affect the way all veterans are seen. I conclude this project by examining the broader sociocultural implications of a discourse of veteranness.

Each of the veteran representations selected from popular media and analyzed in the following chapters are endowed with PTSD symptom-like behaviors and responses that seem reasonably applied to the combat veteran representations and their usage in a narrative arc. While three of the selected representations occur within films that include traumatic events from the veteran's combat service, I focus on the post-war construct of the veteran and how it overlaps with PTSD symptom-like behaviors and responses. Ultimately, veteran myths are revealed through each veteran representation as the narrative develops and resolves. Dominant ideas about veteran in popular usage and broadly shared ideas of military veterans in general and combat-affected veterans specifically make veteranness the dominant discursive unity that circulates in popular media. It is veteran myths as they contribute to 
veteranness that then goes on to function in and shape sociocultural practices, making them seem reasonable, appropriate and acceptable.

Stuart Hall notes that representational systems allow producers of visual media to construct not only representations but also the meanings that "regulate and organize our conduct and practices - they help to set the rules norms and conventions by which social life is ordered and governed" (Hall 4). Three sets of sociocultural discourses that establish rules, norms and conventions and that utilize veteranness and veteran myths as broadly understood and circulated meanings in popular media are primary to my discussion: military meanings of strength and veterans affairs (to maintain an effective fighting force and care for the wounded); clinical/professional meanings of mental health management (military and civilian doctors, psychiatrists and psychologists focused on discovery, diagnosis and treatment); and popular culture meanings, which span a variety of sociocultural contexts.

The representations I analyze are selected from the third set of popular culture meanings, but the three sometimes commingle. For example, the HBO documentary $W$ artorn includes interviews with military medical spokesmen who must be attentive to all three of these sets of rules, norms and conventions. James Gandolfini, a highly recognizable television and film actor concerned with veteran issues and the executive producer of the documentary, conducts the interviews. The spokesmen, appearing in military uniform at a military hospital, must show military strength while expressing the Defense Department's concern for the mental health of soldiers. In effect, these spokesmen need to talk about PTSD in ways that address the norms and conventions of all three social segments without violating any of them or the contrasting ideas within the military's own evolving discourse. These discursive conditions produce incomplete or simplified ideas that are generalized and 
outdated and collapse a range of perspectives into naturalized, all-purpose, often distorted images of PTSD, veteran, combat veteran, wounded veteran, soldier and troops. These images help regulate and organize socioculturally appropriate conduct and practices concerning veterans and, as naturalized veteran myths, contribute to veteranness. These practices in turn help establish the norms and conventions by which veterans lives are ordered and governed and help define the parameters of discourse and appropriate and proper sociocultural function of veterans in their, and our, post-war civilian lives.

The object of my analysis is a selection of popular veteran representations in which invisible wounds are a significant component of the veteran construct. Due to the broad appeal of film I have selected for in-depth analysis six representative veteran characters from five popular films and four actual veterans from a documentary film. In order to deepen the historical and social context for these films, I also briefly discuss examples from other popular visual media including art, magazines, television and the Internet from the three periods defined for the analysis chapters. I examine the relationship between these representations and PTSD, the veteranness they suggest, and the ways they thereby inform, reinforce and modify dominant ideas about combat-affected veterans.

Film scholars have examined film representations of veterans from multiple wars (Early, Hale) as well as Vietnam War veterans (Devine, Walker). These studies define a disciplinary focus on veteran representations and establish an important research distinction between the war film and the post-war veteran film. My research is an effort to add to the body of work on post-war veterans by examining realist veteran representations where no physical injury is present or apparent but where the psychological effects of combat are important to the veteran construct. 
Also central to my work here is the PTSD diagnosis from clinical discourse. The diagnostic criteria and symptoms of PTSD form an important interpretive lens for looking at these veteran representations. Veteran representations existed well before PTSD emerged as a clinical diagnosis in the language of veteran discourses and before conversations about combat-related mental illness began making headway into popular discourse. Whether veteran representations pre or postdate contemporary clinical knowledge about PTSD, there are notable patterns that go back to early visual media. These patterns take the form of the troubled former soldier turned outlaw, the biker, the loner, the vigilante, the hunter/hunted (Anderegg, Early, Devine, Walker) and more recently of caricatures in the form of the pretender-vet (e.g. Sergeant Four Leaf Tayback in Tropic Thunder) and the parody-vet (e.g. Walter in The Big Lebowski). That PTSD has emerged as a current, dominant part of filmveteran discourses suggests that a legacy of popular understandings of veteran evolved from earlier representations that incorporated posttraumatic stress symptoms in veteran constructs.

The discourse surrounding the photograph of Barnes introduced above is therefore neither an accident nor an anomaly. A history of juxtaposing outlaw and veteran in representation goes back to early popular visual media. James Allen, in the film I Am a Fugitive From a Chain Gang (see Chapter 2) is constructed from the beginning of the film as a veteran. The film is based on the true story of Robert Burns and adapted from his book, $I$ Am a Fugitive From a Georgia Chain Gang!, and the specifics of Burns' real life lend credibility to the realist construct of the fictionalized James Allen. Allen returns from WWI as a decorated war hero but conflicts arise immediately between the post-war, civilian life he wants for himself and the life others anticipate or expect he will return to. Allen's life spirals 
out of control: jobless and homeless, he is unwillingly caught-up in an armed robbery, convicted, and sent to prison. Now chained to a criminal identity, he escapes and lives his life as a fugitive. The final scene of the film shows Allen disappearing into the darkness and, presumably, from civilized society. Allen moves from being fully present in his life as a returning soldier, to partially present as a fugitive, to missing as a criminal.

The inability of the fictional combat veteran to secure a normal civilian life, followed by a marginalization from society, is repeated in contemporary films. At the conclusion of the 2008 film The Hurt Locker, Sergeant James (see Chapter 4) chooses to leave civilian life, which has become intolerable for him. After he returns from war, he reenlists in his military occupation of bomb technician. The final scene of the film shows Sergeant James' isolation and disappearance from civilian society and bears a striking resemblance to James Allen's isolation and disappearance at the end of I Am a Fugitive from a Chain Gang. Both films incorporate PTSD symptom-like responses and behaviors into the veteran construct and each outcome of total isolation relies on those symptoms as the motivating factors in that isolation.

\section{Exigency of this Study}

What makes this study both particularly pressing and timely is that it examines popular understandings of combat-related PTSD at a time when three interrelated sociocultural conditions within the U.S. are emerging and converging. These conditions include: the return to civilian life of combat veterans from two lengthy wars; increased access to information about PTSD; and a widening recognition of PTSD as a condition with significant impact on veterans, which is in part indicated by an alarming suicide rate among soldiers and veterans. 
The first condition arises from the current need in the United States to cope with the ramifications of several wars. Early wars from the Revolutionary War to the Civil War have framed much of U.S. history. WWI, WWII and the Korean War are quickly becoming part of this history, but the Vietnam War (1964-1974) and the wars in Afghanistan (2001-present) and Iraq (2003-2011) are vividly present for millions of war veterans and their families. Today's U.S. soldiers face unprecedented multiple redeployments with many serving in combat, and women are serving in greater numbers and in higher-risk situations than at any time. The U.S. has been involved in several smaller scale conflicts since the Vietnam War as well, including the Persian Gulf War (1990-1991) and conflicts in Kosovo and Bosnia in the 1990s. According to the 2010 U.S. Census there are about 22 million U.S. veterans (U.S. Census Bureau, 2010 data).

The second condition concerns access to information, treatment and assistance. The Department of Veterans Affairs web site provides a wealth of information about PTSD for both public and professional sectors of the population. Public service announcements and television ads are developed by organizations such as Community of Veterans (CommunityofVeterans.org) to appeal to veterans, speak to their concerns, and encourage them to get help if they are struggling to cope with their post-war situations. For example, the Iraq and Afghanistan Veterans of America (IAVA) and the Ad Council developed television and Internet ads targeted to returning veterans that speak to their sense of isolation and remind them that they are not alone and that other veterans are willing and available to help. Other organizations such as the Vietnam Veterans of America (VVA) work to provide information, support, and legal services to veterans whose struggles with PTSD overlap the before and after dates of the formal clinical diagnosis. In addition, the American 
Psychiatric Association publishes a clinical manual of diagnostic information for professionals in the fields of psychiatry and psychology, releasing its 5th edition in May of 2013.

The third condition is, in some senses, an outcome of the relationship between the first two. PTSD is gaining recognition both in and outside clinical communities as a verifiable, diagnosable disorder. Internet resources are providing opportunities for veterans and their families to learn about PTSD and find treatment, for producers of media to find audiences, and for mental health providers to make knowledge easily available to broad audiences. Prior to the clinical diagnosis of PTSD, a veteran's post-combat dilemmas were attributed to an individual's weakness, character flaw, or simple refusal to leave the war behind. This legacy is countered by clinical research and studies that indicate a disordered psychological functioning in veterans with $\mathrm{PTSD}^{2}$. In addition, veterans are producing visual media and making their own arguments concerning their personal experience and encouraging others to seek help to overcome the effects of combat trauma. In these ways, opportunities are available to popular audiences to learn about veteran struggles with post-combat stress. The terms PTSD and posttraumatic stress are occurring more frequently in popular discourse, and individual veterans and the Department of Veterans Affairs outreach efforts are working to combat the private and public stigma of combat-related PTSD. Crisis hotlines aim to curb a suicide epidemic that averages 18 veteran suicides a day. Paul Rieckhoff, executive director of the Iraq and Afghanistan Veterans of America states, "The suicide rate is out of control it's epidemic proportions right now... and there's a serious lack of national awareness"

2 See Wilber J. Scott's article "PTSD in DSM-III: A Case in the Politics of Diagnosis and Disease," which traces the history of combat related disorders as diagnosable conditions. 
(Hotakainen). In May 2012, during Memorial Day week, numerous major news sources reported that deaths from suicide among active soldiers outpaced deaths from combat and that veteran suicides were continuing an upward trend.

The dramatic increase in the rates of suicide among soldiers and veterans, references to PTSD in popular discourse, and the number of combat veterans in the population demonstrate the urgent need for studies that examine invisibly-wounded veterans and the sociocultural impact of these related conditions. There is a pressing need to facilitate a more clear and accurate understanding of combat-related PTSD and society's expectation of and responses to combat veterans. The affects of posttraumatic stress and PTSD ripple through various sectors of society ranging from the personal and private to public and national interests.

My research also has a personal significance because I am married to a combat veteran of the war in Vietnam. I learned that he was a troubled veteran over a year before I met him. The past twenty-six years have provided me an opportunity to learn about posttraumatic stress and PTSD with an intimacy I know I share with millions of other spouses and family members of veterans.

My analysis is thus designed to add to an existing body of scholarly research on veterans in popular visual media and to broaden existing understandings of veteran and PTSD-affected veteran and their sociocultural repercussions. A basic premise of my research is that unless and until we learn about all of the ramifications of war and civil society's capacity to cope with the lasting effects of the trauma inherent to combat, we hinder society's and our own ability to cope with the responsibilities related to war and war veterans. A society that limits its understanding of posttraumatic stress, PTSD and post-war experiences of actual veterans 
affected by war trauma to veteranness or veteran myths risks normalizing or naturalizing an unexamined set of sociocultural expectations of veterans, rendering veterans voice-less, invisible, and, ultimately, disposable.

The remainder of this chapter consists of a literature review of existing studies on veteran representations in film, a description of the critical framework for my analysis of visual representations of veterans psychologically affected by the trauma of war, and brief descriptions of subsequent chapters.

\section{Review of Literature: Veteran Representations in Popular Visual Media}

As noted earlier in my introduction, one of my goals is to untangle combat veteran from active soldier and non-combat veteran, so I reviewed literature specifically examining combat veteran representations in popular visual media. Two book-length studies focus primarily on war veterans: The War Veteran in Film by Emmett Early and Vietnam Veteran Films by Mark Walker. These studies review hundreds of popular films and the narratives that exist in popular visual media and they periodically mention posttraumatic stress as smaller parts of their overall analysis. They also provide a range of interpretations of veterans as archetypes and symbols that veteran characters in film narratives lend themselves to.

Other scholarly interdisciplinary research that examines cinema in conjunction with sociology, psychology, American studies, and cinema studies has examined the combat veteran and the issue of returning to society. Many of these studies explore issues such as masculinity, identity, race and healing the trauma of war (Fagelson, Karner, Herbison) without directly examining PTSD as a dominant mental health discourse that informs the construct of veteran. 
My review does not include clinical research literature on PTSD because my purpose is not to define PTSD or debate the clinical research of professionals in those fields; I work with definitions of the disorder that are currently in use and accessible to popular audiences. I also avoid literature that focuses exclusively on visual representations of soldiers during war because my work intends to maintain a distinction between war experiences and war traumas as they happen and the combat soldier's post-war experiences. I review studies of PTSD and posttraumatic stress in analysis chapters to provide context and include descriptions of traumatic events when appropriate or available to the veteran representations I selected for analysis. While PTSD is a dominant idea for the discussion of veteran responses to their wartime experiences, I suggest it significantly confines the possible meanings for veteranness in the sociocultural discourses in which the concept of veteran exists and functions for medical or mental health conceptualizations.

The literature I do review consists of explorations at an intersection of clinical, sociocultural and popular visual media. Emmett Early, in his The War Veteran in Film (2003), examines the war veteran as a type of reservoir or symbol of society's collective memories of past wars. According to Early, the stories become a collective memory or a kind of archive that "embodies in the veteran and in those around him the meaning of the sacrifice" (12), thereby, revealing something significant about the cultural values of the time period in which the film was produced and released. Early, who is a psychologist, explains in his introduction that some symptoms of PTSD that are common among veteran film characters are "not uncommon among many veterans who are never diagnosed with PTSD” (12). While he briefly mentions PTSD or posttraumatic stress at least twenty-two times throughout his investigation of veterans in film (as indexed), he leaves the relationship between the veteran 
representation and posttraumatic stress almost entirely unexamined except to the extent that symptoms help to express societal memory of the war.

On the one hand, Early recognizes a problem of generalizing veterans because they are depicted in so many different ways in film. On the other hand, he notes that films, in all their variety, do make statements about veterans that "give us a feeling" (6) for a generalized culture of the veteran. It is this generalized culture that makes it easier to envision veteran archetypes that then acquire a symbolic quality; in other words, the characters and their stories are seen as symbolic statements about the war and the society's response to the war. Early's explanation of the way in which he relates veteran characters to PTSD is quite different from my approach. Essentially, he situates PTSD in what I would call a type of "off screen space" that is not-truly present (because the presence of symptoms does not equate to an actual diagnosis). Symptoms of PTSD are without a definitive purpose or clarity other than to be part of a general feeling of "war veteran" which bears similarity to veteranness (see Method and Theoretical Perspective section above), but which Early does not examine further.

In Early's work, I see a reduction of the veteran representation to a kind of cultural typecasting that is intended to support the film's narrative and contribute to a generalized culture in which PTSD is a complex concept reserved for the more microscopic analysis of mental health professionals. Early's examination is arranged into chapters categorized by a veteran archetype — the wounded veteran; the survivor; the disguised or unrecognizable veteran; the veteran as a social symbol; the man of action (hero, antihero); and as a reflection or looking back at sociocultural history told through veteran memories that have become embodied in and expressed through their behaviors. 
Ultimately, Early concludes that the development of the veteran as wounded, guiltridden, trying to survive, or alienated is symbolic of society's understanding of its own response to the war. Importantly, it is the ability to keep symptoms undetected and "dormant" (240) until triggered that makes them useful in film narratives. For example, Travis Bickle's alienation and irritability in Taxi Driver motivate the main narrative developments of the film. Early's conclusions seem to suggest that Bickle's stress responses are triggered by stressful events and used merely as characteristics to be drawn on in order to add excitement or drama to the overall narrative, which is then symbolic of the alienation and irritability that is at the center of society's collective sense of the Vietnam War. In addition, symptoms associated with PTSD—such as the veteran's sense of having no future, a heightened startle response, nightmares, dissociative flashbacks, and guilt—contribute to the narrative because they add a sense of an "inevitable" (240) action. This action is not only likely to play out in the veteran character, but must play out for the film narrative to be complete. In this way, a film narrative provides evidence of society's response to the war veteran.

Mark Walker, in Vietnam Veteran Films (1991) traces the narrative film image of the Vietnam War veteran and of the changes noticeable in this image over the two and half decades covered in his study (ix). Walker describes his analysis as a genre/myth/system study in which he is attentive to the image of Vietnam veterans historically (both during and since the war) and within and among film genres. In the first part of his analysis, on genre, Walker identifies two categories: order and integration (6). The order genre is defined by a lone veteran protagonist immersed in violent conflicts and includes films such as the biker, vigilante, caper, gangster, police, horror, and war films. The integration genre is defined by 
dual protagonists, the veteran and often a female, and includes comedy and melodrama. In the second segment on myth, Walker relies on Joseph Campbell's work on mythology and the storytelling power of myth, describing an interplay between convention and invention (7) that is the starting point for genre analysis. For Walker, convention has links to sociological mythology, and invention is connected to nature or natural mythology. One fundamental myth used in Vietnam veteran films, Walker says, is that related to life and death (8). He explains the presence of this myth in many order-genre films in which, for example, the veteran, "traumatized by his war experience, must again face that experience in order to be purged of his "wound" (8). In the integration-genre film, "an important mythic narrative concept is compassion, used in the sense of two lovers 'suffering with' each other" (8). In the third segment of Walker's analysis, on system, he describes filmmaking conventions based on genre conventions, noting that genres exist only to the extent they can be described as different from other genres. Walker proposes a system of veteran film genres, reflected in his chapter titles. They include "The Vietvet and the Biker Film" and use this naming pattern for all but two chapters. All other film analysis chapters are titled, “The Vietvet and the [genre] Film" and the following genre distinctions: Vigilante, Caper, Police, War, Horror, Comedy, Melodrama, and Art as distinct genres. In Walker's system, Vietvet ${ }^{3}$ genre films fall under a "supersystem" (11) of veteran films. Presumably, other wars could consist of other systems of organization.

Walker mentions PTSD in relation to individual veteran descriptions only in passing and limits this to terms such as "PTSD-like disease" and "PTSD-like symptoms," but he does

3 "Vietvet" is Walker's abbreviated, and I think unwieldy, shorthand reference to the Vietnam veteran. 
not examine or discuss PTSD as significant to the veteran character in the film. Essentially, Walker's study is a description of a system for classifying Vietnam veteran films rather than veteran representations. Yet it does suggest a diverse body of films that can be defined by a unifying element that helps distinguish them from other film genres. Further, his work moves a step closer to seeing veterans as something other than perpetual soldiers relegated to the war film genre or merely as isolated film characters.

In 1996 cinema studies scholar Barbara Skluth Hale published The Representation of the Veteran in American Film, 1945-1950. Hale analyzes period a selection of representations released during this 5-year period for what they can reveal about the culture of that era. She recognizes several common themes in veteran character films that center on the return of servicemen to civilian society, including "feelings about home, relations with families and friends, anger and frustration about time lost, fear and anxiety about the future and the roles of women in the readjustment process" (186-7). Hale points out how, in the films, "difficulties the soldiers encounter adjusting to civilian life are lumped together with other social ills like alcoholism, racism and anti-Semitism” (5). For Hale, this hints at a naturalized tendency to see the combat veteran as precariously situated at the edge of normalcy and a broad, society-wide adjustment to the returning veterans.

One of the films Hale discusses is John Huston's Let There be Light, a 1946 documentary about the successful treatment and care of psychoneurotic veterans (8). The film, blocked by the Army because it "consider[ed] the topic too disturbing for public viewing" (Hale 9), was not released until 1981. Hale’s work examines veteran’s adaptive/maladaptive conflicts as a society-wide experience that plays out through "the complexity of the issues which the veterans and their families faced" (194). Hale makes no mention of PTSD but, in her final 
chapter, briefly mentions posttraumatic stress syndrome, an alternate nomenclature in use during the debate on whether or not to include a classification for the lasting effects of combat-related trauma in the DSM. The "syndrome" terminology is non-standard today. Hale's study was published sixteen years after the inclusion of PTSD into the DSM-IV, the version Hale briefly cites. Her choice of terminology demonstrates a slow integration of the formal concept of clinical PTSD used in the professional communities into those of academia and scholarly research in disciplines other than psychiatry and psychology and to popular culture and non-clinical discourse. Hale's work suggests that opportunities for the study of combat veterans, society and sociocultural discourses are not limited to or anchored in clinical/psychiatric/psychology research but instead that any "disorder" will more fully be understood by examining society's response to the returning combat veteran.

The aforementioned studies of veterans in visual media differ from my work in that I first explicitly examine the relationship between clinical PTSD and the veteran construct. I go on to examine this construct as a dominant and essential component of veteranness as it is constructed in and by visual media. I then examine the discourses in which these constructs are ultimately deployed and in which they not only signify "veteranness," but also operate and function in ways that affect sociocultural actions and decision-making.

\section{Critical Framework}

My critical framework is broadly informed by visual media studies and more specifically by Barthes' concept of myth and Foucault's concept of discursive unities. It also draws on the disciplines of psychology and psychiatry for clinical and professional information about Posttraumatic Stress Disorder (PTSD). This approach allows for deep analysis of representations of veterans and the discourses in which ideas of veteran circulate. It also 
allows the interrogation of the "effects and consequences of [these] representation[s]" (Hall 6) in terms of how they function in U.S. sociocultural contexts.

I have chosen to focus on lasting psychological effects of war trauma as indicated by veteran representations in film and visual media in three socioculturally differentiated periods. The first period is the early 20th century, characterized by two war veteran homecomings following World Wars I and II. During this period, the awareness that soldiers displayed lasting responses to combat, some very severe, and medical approaches to addressing the problems these soldiers faced were in their infancy. The second period is the return from the Vietnam War of veterans of the 1960s, 70s and 80s. This period was characterized by social upheaval and conflict over, among other issues, attitudes toward this first televised war and the soldiers who fought it. The condition of Posttraumatic Stress Disorder first coalesced into a formal diagnosis in 1980, five years after the end of the Vietnam War. The third period is the post 9/11 period. Since 2011 the clinical discourse of PTSD has been maturing and seeping into popular discourse. PTSD is now an established diagnosis in the discipline of clinical/professional practice and a variety of treatments have been developed, tested and modified over recent decades. In addition, terminology of posttraumatic stress and PTSD as a mental health condition is becoming commonplace.

\section{Criteria for Selection of Media Artifacts}

Selecting veteran representations from film media posed a dual challenge for a number of reasons. First, although the war film is a popular genre, there is not a specific veteran film genre. Veteran characters are present in nearly every other genre, including drama, action/adventure, western/frontier, documentary, etc. Second, veteran characters identified as such number in the hundreds, perhaps thousands, when including supporting characters 
and other visual media (e.g. television, magazines). I developed the following criteria for selecting representations for analysis. In addition to being constructed for popular audiences and circulating within mass media (i.e. film industry, art \& museums, book or magazine publication, Internet, etc.), each veteran visual representation analyzed:

- is a realist construct,

- identifies or reveals the veteran as having combat war experience and situates their war experience as central to the representation,

- centers on a veteran who is without apparent lasting or disabling physical injury.

I define a "realist construct" as a representation that purports to render and is received as a "true-to-life" portrayal of veteran through a narrative that takes place in a plausible setting. For example, the 1946 film The Best Years of Our Lives garnered accolades for being "one of the best films about war veterans ever made" (DVD back cover quoting American Movie Classics Magazine). To win such praise, the film needed to present images of veterans considered by audiences and critics of the time as natural and genuine in terms of psychological and behavioral post-war patterns, including the ways in which the veterans are ultimately reintegrated, in publicly and politically appropriate ways, into civilian society. By selecting realist constructs, I eliminated exaggerated or idealized representations such as action heroes who save the free world or fantastic crime caper heroes or villains.

Two of the veteran representations I examine, James Allen (Chapter 2) and Private Eriksson (Chapter 3), are based on real people. The fictional James Allen is based on Robert E. Burns, who served during WWI, and Private Eriksson, whose real-life counterpart's name remains undisclosed, served in the Vietnam War. My brief analytic glimpse earlier in this introduction at two film characters, James Allen and Sgt. James, illustrates the criteria listed above. Both are representations of people in rather ordinary circumstances as they resume 
their post-war lives. Both veteran characters have been in combat but have no apparent lasting physical injuries, and their responses to their war experience are central to the veteran representations. Their choices and behaviors, triggered by responses linked to their war experiences, are key motivators of the film narratives, a characteristic shared by all of the veteran representations I examine. The incidence, or co-incidence, of veteran and combatrelated effects is sometimes explicit and direct, as in The Hurt Locker, in which most of the narrative consists of traumatic war scenes that set up the choices made after the war, but this is not always the case: for example, in I Am a Fugitive From a Chain Gang we learn little of Allen's combat, and what we do learn is not directly represented but hinted at through the film's dialogue.

Several very notable film representations of veterans are not included in this study. The characters of Ron Kovic from the film Born on the 4th of July (1989) and Luke Martin from the film Coming Home (1978) are examples of veteran representations that fall outside the criteria for my study due to their permanent physical injuries. My choice of criteria is not meant to imply a devaluation of the stresses imposed by physical injury or of veterans who have been physically injured. My aim here is to examine the psychological effects of combat in and of themselves as they play out in popular visual media representations of veterans, and these criteria assist in untangling the psychological from the physical. A brief reference to a veteran's physical injury is sometimes stated or suggested in the selected representations, but physical injury is not a lasting or significant contribution to the veteran construct. Another familiar veteran representation, the Travis Bickle character from the film Taxi Driver, has not been included because this character is not directly identified as a veteran. Paul Schrader's screenplay describes Bickle as 26-year-old, "lean, hard, the consummate loner ... one can see 
the ominous stains caused by a life of private fear, emptiness and loneliness (Schrader). Nowhere in the film is it established that Bickle served in the military and if we infer that he was based on the film's subtext, information about how he served (in combat or in a support role) is absent.

Although other visual media that circulate in a wide popular discourse, such as works of art, are far fewer in number than the available film representations, I discuss several that have been more widely distributed and have explicitly targeted large popular audiences. Online media pose a challenge in terms of the enormous number of available visual media artifacts, potentially available to large audiences, but in actuality viewed by quite small ones.

\section{Method and Theoretical Framework}

My theoretical framework derives from a fusion of visual media studies, Barthes' concept of myth as a natural-seeming connotation, and Foucault's concept of discursive unities as ideas put to use in social practice that regulate in a circular fashion the ways statements inform and are informed by possibilities considered appropriate for discourse. I see Barthes' notion of myth as an entryway into a rich analysis of veteran representations as "a kind of message" (110) or "statement" (Foucault 79) that circulates in U.S. popular media. In addition, I see Foucault's concept of discursive unities, a "ready-made synthesis" or a "collective consciousness" of ideas and meanings that seem "valid at the outset" and familiar to both producers and audiences of media (22) as a means for interrogating the ways veteran representations function when appropriated in sociocultural contexts.

Barthes considers pictures, photographs, or any visual object that acquires meaning to be a type of visual language or visual writing (110-111). Foucault, in his concept of unities, as the natural and reasonable ideas we use every day, is mainly concerned with discourse. He 
does not focus as much on individual constructs but does use such terms as discursive objects or statements to refer to them. He describes these objects or statements with the term formations (Foucault 48) because they are more than mere signs that designate things or ideas but, instead, describe the ways statements, objects or formations are appropriate for and appropriated in discourse.

Both myth and discursive unities are concerned with, here, visual statements/objects that I refer to as veteran representations, used in discourse. The appropriateness of the visual statement is ultimately determined in part by the purpose of the media object (i.e. film, painting, etc.) and what it "says" to audiences about the lasting psychological affects of combat on veterans either directly or indirectly. It is also determined in part by a reciprocal relationship in which the statement informs and is informed by the sociocultural context in which it circulates. Barthes' concepts of myth and a second-order semiological system ${ }^{4}$ of signification help me do a rich analysis of the veteran construct to see the veteran myth it suggests. In myth, the second-order system extends from the first order sign system. The sign becomes myth's form (signifier) and new ideas and concepts (signifieds) are drawn in that synthesize or unite as the myth (signification). This tri-dimensional pattern is important, because meaning is grasped not as "one term after the other, but as the correlation that unites them" (Barthes 113). I then extend that analysis by looking at the ways veteranness (an accumulation of various veteran myths), operating as a discursive unity, functions in sociocultural discourse. The Benjamin Barnes news story and the images circulated with it give a preview of the application of my theoretical framework in the analysis chapters.

4 In the first-order semiological system, the sign is a correlation of a signifier and signified and is the "raw material" (Barthes 114) of myth. A signifier (a word or image) and a signified (the idea the signifier, that word or image, refers to) are correlated as the sign. 


\section{Seeing Veteran Myths}

On January 1, 2012, the online version of the Seattle Post-Intelligencer (seattlepi.com), posted a news report of a shooting in Mount Rainier National Park that was picked up by national, network and cable news sources. The Seattle news source included a slideshow of 18 images, five of Barnes (Figure 1.1). In this news report context, a first-order system, these photographs identify the suspect in the shooting, Benjamin Barnes, the suspected gunman on the run.
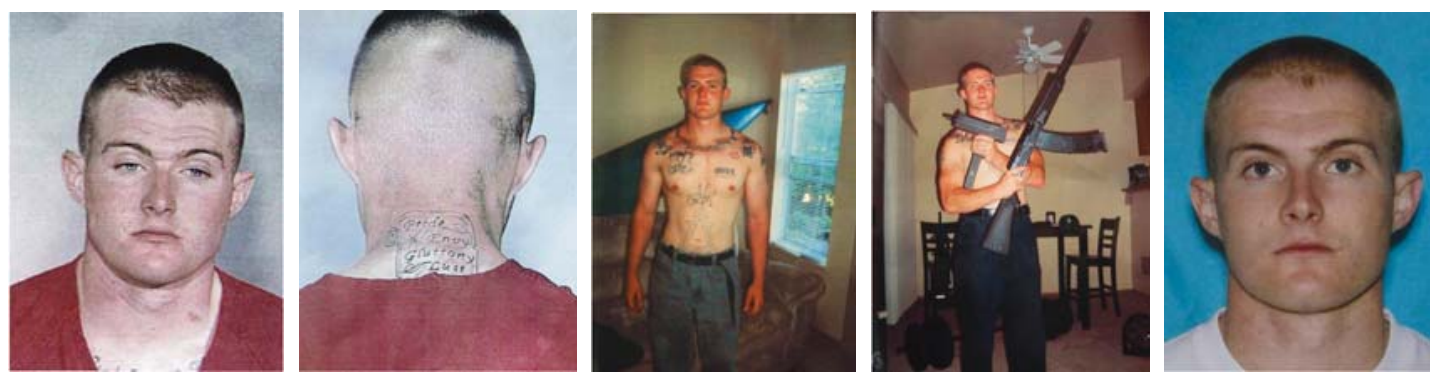

Figure 1.1: Photographs of Barnes published with January 1, 2012 report of the Mount Rainer shooting on the seattlepi.com web site. As noted in the captions, the Pierce County Sheriff's Department had provided all of these photographs. (Seattle Post-Intelligencer, www.seattlepi.com, January 1, 2012.)

Because the photographs acquire a given meaning as signs for Barnes (Figure 1.2), the most obvious meaning is to identify the gunman by showing Barnes’ physical appearance.

\begin{tabular}{|c|c|}
$\begin{array}{c}\text { Signifier } \\
\text { Photograph }\end{array}$ & $\begin{array}{c}\text { Signified } \\
\text { The person, Barnes }\end{array}$ \\
\hline \multicolumn{2}{c|}{ Sign } \\
Photograph of Barnes
\end{tabular}

Figure 1.2: Illustration of first-order system, adapted from Barthes (115).

Myth now has something to work with and can carry out what Barthes describes as a "deformation" (122) of the sign's meaning. The first two photographs of the series show Barnes appearing spaced-out, in a daze; he looks tired or maybe intoxicated and an attitude tattoo (the words "Pride, Envy, Gluttony, Lust" written on a scroll) shows on the back of his neck. The photographs look like mug shots without the identification numbers that typically 
appear across the bottom of the frame. The next two appear to be self-portraits in which he presents a bared upper body scattered with tattoos and brandishing two powerful firearms.

My brief description of the first four photographs in the slideshow series as mug shots, with Barnes looking dazed or intoxicated and brandishing tattoos and weapons, points to concepts that go beyond identifying him as simply the suspect in the shooting. These terms suggest behaviors and character traits that belong to Barnes. The fifth image, a driver license photo, is the most conventional of the group, and its placement in the order is significant. As the last of the five, the ideas suggested by the first four are accomplices to an accumulation of meaning that informs and deforms the more socioculturally conventional image of Barnes. The conventional Barnes, in a most ordinary driver's license image, takes on an appearance of a dangerous Barnes disguised as a typical young man.

Barthes explains that the meaning of the sign is essential to the myth system and myth's deformation of the sign's meaning, its being set aside to make room for other ideas, does not destroy it; instead, the sign's meaning assists the myth by becoming an accomplice of additional ideas or concepts (Barthes 118). Myth retains the sign's meaning (Barnes looks like this) but converts the sign into myth's signifier. This move sets aside (empties) the signifier of its first order meaning and transforms it into the signifier/form that can accept (be filled with) new concepts and ideas (signifieds) in a second-order ${ }^{5}$ system. In the case of Barnes' image, myth's form sets aside "Barnes-looks-like-this" meaning to create room to be filled with signifieds in the form of additional meanings such as: this is the suspect, he is

5 In the second-order semiological system, the signification, the myth, is a correlation of a signifier/form which is the sign, emptied of the sign's meanings or "stolen" (Barthes 125) from the first-order system and the signified(s) that are the new ideas and concepts that fill the form. A form (veteran representation) and signifieds (the new ideas the signifier refers to) are correlated as the signification/myth. 
heavily tattooed, he is the gunman, he brandishes powerful weapons, he has a criminal record, he flouts commonly accepted Christian morals (tattoo details), he drinks/does drugs, he can look like a normal young man, etc. Each of these new ideas arrives already weighted with additional connotations, and an implicit question arises as these ideas accumulate: "What kind of person does these things?" This question suggests a signification that consolidates all of these characteristics into a myth of a disturbing or perhaps disturbed man that extends beyond Barnes to other men with these characteristics.

As myth continues its work, the text (captions and story) introduces additional concepts that reinforce second-order meanings of the photographs. Reading the captions, the audience learns the Pierce County Sheriff's Department provided all of the photographs for the report. The first one-sentence paragraph of the seattlepi.com news story introduces the shooting at the park and pursuit of an armed gunman. The second paragraph reads,

Pierce County Sheriff's spokesman Ed Troyer said late Sunday afternoon Benjamin Colton Barnes, a 24-year-old believed to have survivalist skills, was a "strong person of interest" in the slaying of Margaret Anderson. A parks spokesman said Barnes was an Iraq war veteran. Authorities recovered his vehicle, which had weapons and body armor inside, Troyer said ("Park ranger...”).

Here we see how myth's concept generates from the ideas related to veteran and made available by what Barthes calls a "social usage" (109). In Figure 1.2, I borrow the basic arrangement from Barthes' visual design of the myth system to illustrate and summarize the theoretical framework for my analysis of veteran representations. The illustration is meant to show the close, nearly imperceptible recognition of the tri-dimensional semiotic pattern (i.e. we read the word "tree," the signifier, and have an idea of a tree, the signified, at the same 
time; the signifier and signified are combined in the word "tree" as a sign for the tree we think of). In the case of these photographs in this social usage, to report the breaking news and identify the suspect, both the sign's denotative meaning (to show what Barnes look like) and additional meanings are introduced. Barnes the veteran is an "armed gunman" with "survivalist skills" but he also acquires connotative meanings associated with his tattoos, intoxicated appearance, his brandishing of weapons for the camera, and an ordinariness, pointed out by the in the last, driver's license, photo suggesting an unpredictable personality. These meanings and that weapons (likely similar to those shown in the photograph) and body armor were found in his vehicle attach to his status as a war veteran. That he served in the military in Iraq are highlighted in the headline and article. All of these meanings accumulate in a concept of a veteran myth. The veteran idea now informs the signification and indicates Barnes is more dangerous than an ordinary killer because he is highly-trained and combat-ready (suggesting a popular link to hypervigilance), he handles combat-type weapons with ease (suggesting a popular link to reliving/reexperiencing) and becomes intoxicated (suggesting a popular link to numbing/avoidance). We now have a veteran representation and an evolving veteran myth deformed from that of the sign by visual and textual cues, and it seems as natural (Barthes 124-9) as the sign itself. The addition of the "Iraq war veteran" concept helps answer the implied question in a way that consolidates the first and second order signifieds into a new meaning, a signification: "a combat-affected veteran does these things" in a veteran myth of combativeness ${ }^{6}$ (Figure 1.3).

6 According to Barthes, neologisms are inevitable (121) because the concepts of myth are ephemeral and connections are limited and contingent upon what is known or understood, in essence, contextualized by the reader. For example, "China is one thing, the idea which a French petitbourgeois could have of it not long ago is another: for this particular mixture of bells, rickshaws 


\begin{tabular}{|c|c|}
\hline $\begin{array}{c}\text { Signifier/Form } \\
\text { Photographs of Barnes }\end{array}$ & $\begin{array}{c}\text { Signified/Concept } \\
\text { suspect, tattooed, criminal, veteran, etc. }\end{array}$ \\
\hline \multicolumn{2}{c|}{$\begin{array}{c}\text { Signification / Myth } \\
\text { Veteran Myth of combativity }\end{array}$} \\
\hline
\end{tabular}

Figure 1.3: Illustration of second-order system, adapted from Barthes (115).

Each cue in the photographs and accompanying text is rich with socioculturally shared meanings. Audience members can interpret them in slightly different ways according to what they already know and understand, but the overall interpretive impact of each additional cue or new idea that fills the Barnes form influences the interpretation of the other cues and narrows the interpretive options. Interpretations of being tattooed are subject to matters of taste and style. A similar variation of interpretation takes place for the cues of taking pictures of oneself and of taking pictures of oneself showing off powerful weapons. The social usage of the veteran status of Barnes brings together a naturalized sense of a veteran's ability to readily shoot another person and the shooting of the park ranger. By January 2 , the photograph of Barnes brandishing the weapons and the identification of his veteran status were frequently part of news reports on major media outlets. In the context of news as a commercial enterprise, it made sense to use the most provocative of the available images to draw more interest and more readers, especially in the titillating context of other news reports of soldier suicides and on-base shootings like that at Fort Hood in 2009 and recently in 2014. Associations with posttraumatic stress began to surface in the news coverage, including statements that Barnes' former girlfriend had concerns that Barnes may have suffered from posttraumatic stress (Gast and Pearson). Legal battles stemming from a

and opium-dens, no other word possible but Sinniness [Barthes' footnote to this term also suggests the alternate Sinity]" (121). 
custody dispute between the couple over their daughter also seem to fit easily with other emerging ideas suggesting his combativeness.

It is important to note that it is not certain if posttraumatic stress affected Barnes. His military records indicate he served in a headquarters communications job and was not in a position to come under fire (Horton) ${ }^{7}$. Even if we set aside this military record and assume he did experience a war trauma of some type, "there is no direct, causal link between combat-related PTSD and the type of violence shown at Mt. Rainer" (Horton, quoting VA clinical psychologist Dr. Sonja Batten), yet it is the link between Barnes and PTSD that ultimately prevails as we will later see. What is important here is that the social usage, the linking of Barnes and PTSD, are indicative of preconceived notions operating in news media and circulating in sociocultural contexts concerning military veterans, PTSD and violence.

Barthes states that it is essential to myth that the sign not be destroyed. Retaining the form of Barnes, the real person, lends credibility to the violent-veteran myth. Myth is always able to hide in its form (signifier). It is the "constant game of hide-and-seek between the

7 Horton writes, "Within hours of the Rainier shooting, journalists and writers clamored to mention Barnes' war record, combat stress, and even his duty station in a dizzying effort to find a connection [...] The problem? It wasn't true. ... As more information became available on Barnes, it grew clear that his troubles had little to do with his service in Iraq or his assignment at Joint Base Lewis-McChord. According to The Seattle Times, Barnes was apparently disturbed before he entered the Army-having been expelled from school as a teenager. Additionally, military records show Barnes served in a headquarters communications job in Iraq. A spokesman at Lewis-McChord told the Times there was no record of Barnes having received a Combat Action Badge, indicating he probably never came under fire in Iraq" (Horton). Horton adds an update three days later. "We've received some feedback on this. Some folks took it to mean that a Veteran can't have posttraumatic stress unless they were in direct combat. Of course, that isn't the case. A surgeon inside the wire who deals with horrible injuries or a mechanic who withstands daily mortar strikes can be just as susceptible as any infantryman. A recruit could even be subject to PTSD in the event of military sexual trauma. We don't believe PTSD is an injury that only occurs in combat, but we could've explained that a bit better." 
meaning and the form which defines myth" (Barthes 118) where the meaning of PTSDaffected veteran plays hide-and-seek with the image of Barnes. From this brief analysis of the Barnes photographs, we can begin to see a veteran myth developing that binds ideas about posttraumatic stress to a latent violence that could surface at any time with devastating outcomes.

The ideas of a spaced out, tattooed gunman and a normal-looking war veteran become linked and seem to fit together naturally. In this way, the circularity of images informed by and at the same time informing the viewer about PTSD and Barnes as one of many veterans is completed in the veteran myth. It is the myth, rather than the facts specific to Barnes, that goes on to circulate in the sociocultural collective consciousness as a discursive unity that then shapes society's ideas about and attitudes toward veterans.

Analysis of veteran representations prepares the way for my next stage of analysis, which is to examine the ways veteran myths converge as veteranness, a discursive unity appropriated in sociocultural practices. According to Foucault, discursive unities are outcome of the rules of society. If you are combative, you are on the wrong side of the law. Veteran myths, coalesced as veteranness, are evidence of the sense of the right to speak (or be spoken about), the ability to understand (or be understood), to provide (or restrict) access to already formed statements and the capacity to invest these properties of discourse in the decisions, institutions, and practices (Foucault 68) that shape lives. The already formed visual statements, the properties evident in the photographs of Barnes, point to ideas that already circulate in popular discourse as discursive unities and as veteran myths. 


\section{Veteranness as a Discursive Unity}

As a discursive unity, a broadly-shared sociocultural meaning, veteranness goes on to inform and be informed by sociocultural practices. The photographs of Barnes, whether they were the only images available or if they were selected from many, made sense and seemed proper, or appropriate, in both contexts of identifying him in the news coverage and deepening the meaning of Barnes-the-veteran in our collective consciousness. The unspoken rules for concept formation of discursive unities operate "at a kind of preconceptual level" in which existing and "recurrent elements of statements" can and do "reappear, dissociate, recompose" (Foucault 60) in ways that are logical according to those rules. These rules characterize a discourse (Foucault 60) and define the parameters of that discourse. If Barnes was a murderer (he was) and a veteran (he was), the other ideas signified by the photographs also seem sensible. The Barnes photographs help create veteranness in the context in which they are used. They appear and recompose at a preconceptual level as already formed, sensible concepts. The rational and natural meanings of PTSD-affected veteran are evidence of a logical structure of a discursive unity and a property of discourse. We can see this formation in the ease by which the veteran myth develops. The news sources did not need to justify identifying Barnes' veteran status or endorsing the connection to posttraumatic stress, the connection was already reasonable even though unproven and unlikely.

After Barnes' body was found in the park on January 2, different logical structures became available through the acquisition of "new semantic contents"(Foucault 60), in this case his death. This change in the imminent danger posed by Barnes changed the sensibilities of proper and appropriate visual discourse. Compare the photographs of Barnes distributed before and after his death. The set of photographs used by local Seattle news the night of the shooting (Figure 1.1) were distributed when Barnes was still alive and on the run. The 
photograph distributed nationally and internationally by the Associated Press (Figure 1.4), a global news source, after the discovery of Barnes' dead body is a cropped section of one of the images from the five that were originally released.

\section{Benjamin Colton Barnes, Iraq War Veteran Suspected Of Killing Park Ranger, Reportedly Found Dead}

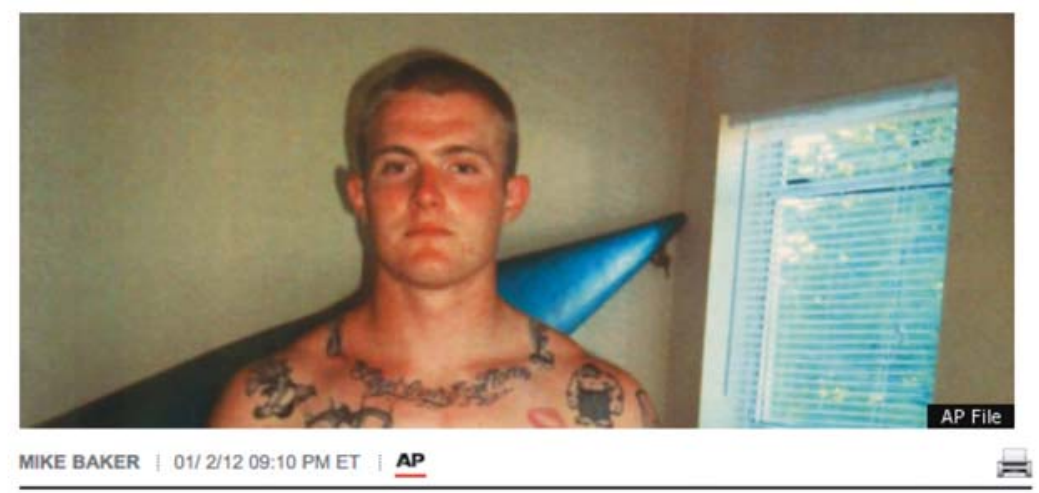

Figure 1.4: The Associated Press selected this photograph, one of the five shown in Figure 1.1, to identify the suspect Benjamin Barnes after a body, presumed to be his, was located by aerial search. Officials had not yet confirmed it was Barnes because inclement weather delayed ground personnel from reaching the body (Internet screen capture, Huffington Post, www.huffingtonpost.com, in Crime section, accessed December 10, 2012).

The change in context influenced the choice of photograph used to accompany the

news coverage. The day of the shooting it seemed appropriate to construct a dangerous image of the veteran Barnes, but the same dangerous construct was no longer necessary the following day. Not only was the selected photograph of Barnes the one in which he has the least intimidating facial expression, it is also cropped to include a kayak instead of guns and a window letting in light rather than the entire dark and cramped room. However, the connection to his veteran status remained strong, second only to his name in the headline.

The Mount Rainier shooting story continued to develop over the two days between the shooting and the discovery of his body and in the weeks following. The visual representation of Barnes reverted to reinforcing the signification of the veteran whose violence, fed by 
PTSD, should concern us. A veteran myth of combativity became part of the Barnes-theveteran construct as ideas of PTSD and violence accumulated with Barnes' image. Figure 1.3 shows a cnn.com news report headline and photograph from January 17. Barnes' Iraq War Veteran status has been incorporated into the headline in a generalized way that constructs and reinforces the violent Barnes of the shooting as a symbol for all veterans and combatrelated PTSD. The reality of the Barnes incident lends credibility to the myth and the headline, which cites experts as pointing to a relationship between veterans' PTSD and a growing problem of violence.

\section{Experts: Vets' PTSD, violence a growing problem \\ By Ashley Hayes, CNN \\ updated 5:02 PM EST, Tue January 17, 2012}

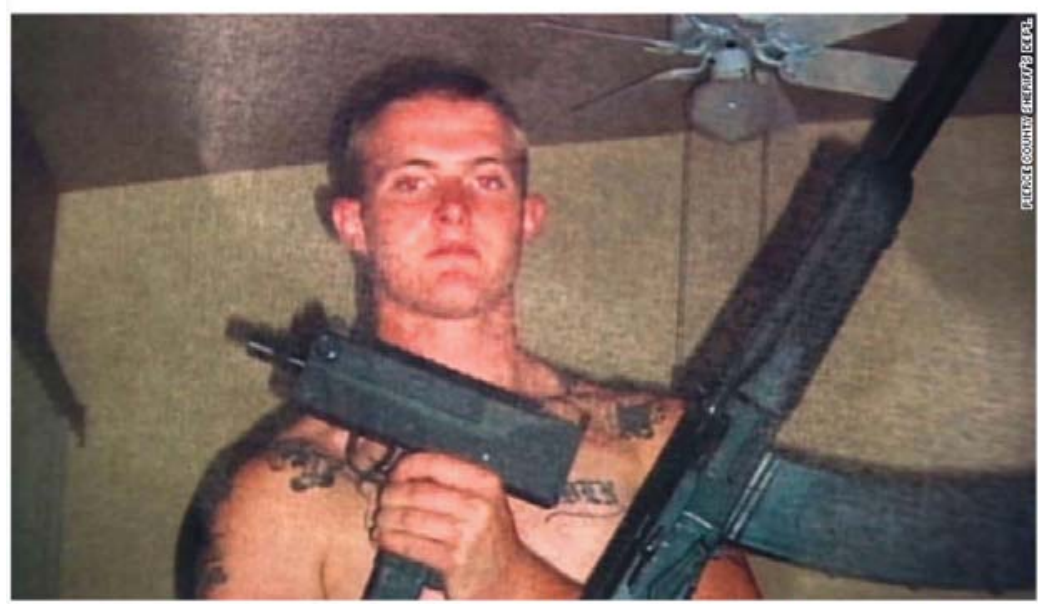

Veteran Benjamin Colton Barnes, 24, is suspected of killing a park ranger at Mount Rainier National Park on New Year's Day.

Figure 1.5: Headline and photo of Benjamin Barnes dated 1/17/12 (Internet screen capture, www.cnn.com, accessed February 1, 2012).

In selecting the photograph (Figure 1.5) for the popular press' follow-up news story, media producers relied on a fully formed myth. This signification seemed an appropriate choice, rhetorically, for this usage in the sociocultural context of a follow-up news story. Both the producers and audiences needed to access an already unified visual statement— the 
mentally unstable, dangerous war veteran myth—drawn from a naturalized dominant veteran discourse that already recognized the legitimacy of the connection. Alternative discourses were possible concerning Barnes, but the unstable, PTSD-affected, violent war veteran discourse prevailed.

Barthes points out that myths are seen not as motivated, but as reasoned. This difference gives the signification, i.e. veteranness, an escape from its true/unreal duplicity by naturalizing it "in the eyes of the myth consumer" (Barthes 120-30). In essence, news media outlets did not need to act in a motivated manner to force together the ideas of violence, veteran and posttraumatic stress as seen in Figure 1.3. They simply operated within the conventions that already define veterans in this way using collective understandings, already formed as existing discursive unities, of veterans that, at the same time, incorporate myths.

\section{Uncovering Sociocultural Functions of Veteranness}

Using an image of a veteran not diagnosed with PTSD to construct representations of a mentally unstable, dangerous war veteran affected by the disorder is an indicator of the representation's social function. Such constructs reinforce the naturalization of veteranness and help normalize the social conventions in which they are used. Foucault notes that this power to construct naturalized representations is "in fact confined (sometimes with the addition of legal sanctions) to a particular group of individuals" (Foucault 68)—in this case, news editors, journalists and the experts referenced in news articles. Such visual statements made about veterans and PTSD in popular media "seem to belong in a natural way" (Foucault 60) to the logical development of the story (Figure 1.5) and help regulate "ways ... of practicing the possibilities of discourse" (70), in this case of popular veteran discourse, through its norms and conventions. Figure 1.5 exemplifies the discursive power of the news 
outlets where the "experts" are given the authority to link "vets' PTSD" to the "growing problem" of violence exhibited by Barnes.

However, as we can see in the comparison of the images of Barnes before and after his death, sociocultural expectations can influence these practices by declaring what is appropriate and proper for a given discourse. Barnes does not need to appear threatening when no threat is present. This circular influence is not uncommon. For example, the campaign to reduce smoking creates parameters for visual media's use of images of people smoking cigarettes and regulates advertising strategies to appeal only to adults. Its function is to change naturalized attitudes about smoking. In more recent advertisements for the new ecigarettes, the function is to reframe a traditional smoker's experience in a context where imposing second-hand smoke on those around you becomes unacceptable. As formal and informal rules change, the function of the advertisement changes. It upholds one set of standards (maintaining the smoker's personal experience of smoking) while challenging another (smoking is not a shared experience). In another example, other formal rules regulate the incorporation of sexual content, expletives and graphic images considered to be in excess of broad conceptions of acceptability, and the representations governed by these rules function to uphold social conventions such as decency or morals. Other rules are less formal and media producers will consider contemporary sociocultural shifts in audience attitudes to construct representations that can function to reinforce, challenge or reframe attitudes. Identifying, deconstructing, and critiquing veteran myths can serve as a first step in uncovering popular sociocultural attitudes that reflect social conventions and norms through the representations. When used in popular visual media, these representations can also justify more formal rules governing sociocultural practices related to veterans such as protocols for 
treating PTSD-affected veterans or punishing presumed or real PTSD-related behaviors.

Figure 1.6 (below) illustrates the development of veteran myths, their appropriation into a discursive unity of veteranness and then into discourse through their usage in popular media.

My analysis of veteran representations aims to reveal veteran myths in popular visual media and the concepts that inform them that are grounded in posttraumatic stress and PTSD symptom criteria but infused with connotations or mythologized in a way that seems natural and appropriate. I then go further to propose what these findings suggest about the function of veteranness in sociocultural practices.

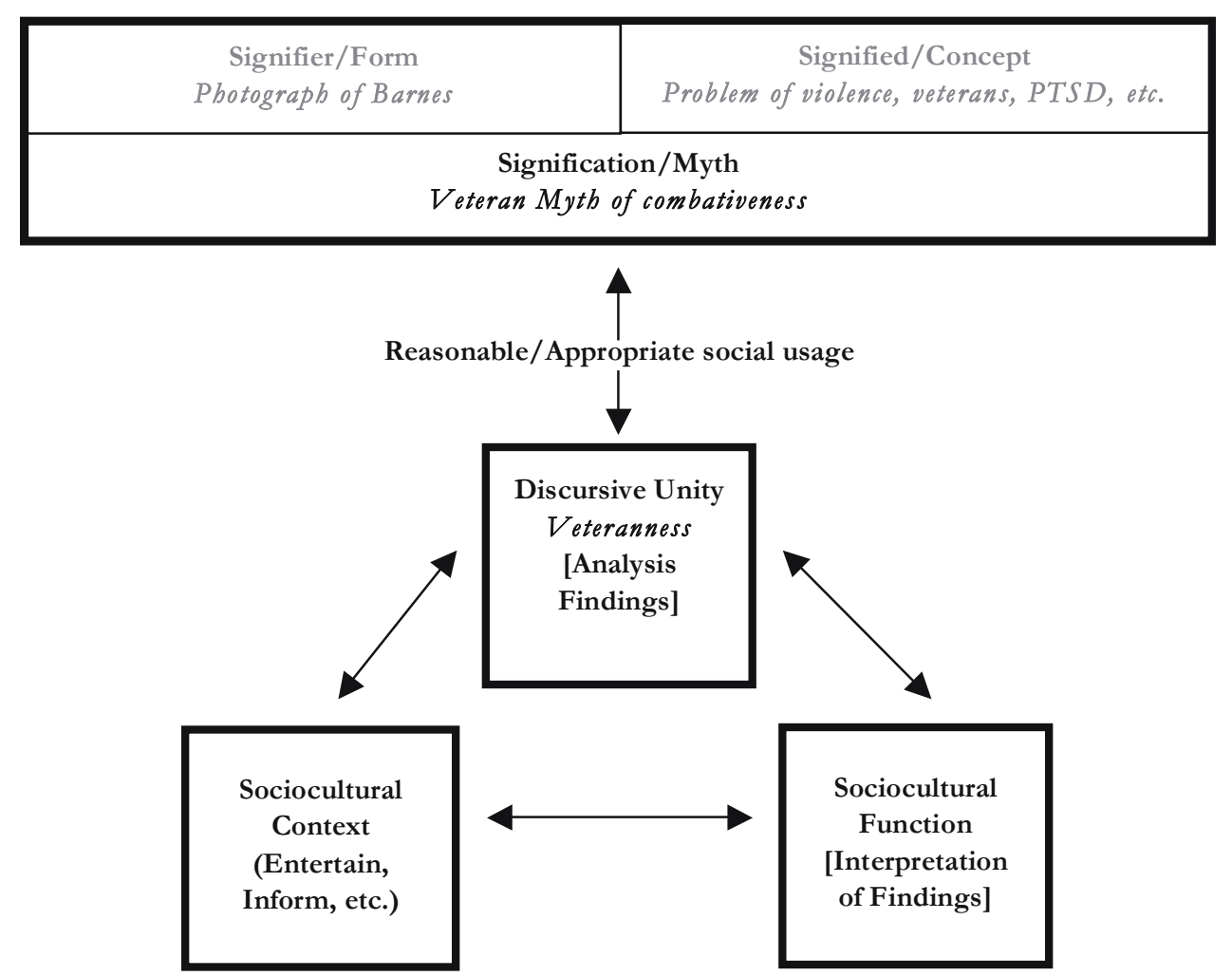

Figure 1.6: Illustration of Veteranness circulating and functioning in sociocultural discourse, (top Signification/Myth portion adapted from Barthes (115).

The lower portion of Figure 1.6 indicates the circular influence between shared ideas about veterans used in discourse and their function in everyday life and reminds us of the 
necessity for studies like this one that examine these reciprocal influences. As Horton remarks, "We must step out of the feedback loop that both feeds and informs the stereotype of the broken, mentally unstable Vet" because it does a disservice to veterans (blogs.va.gov). The veteranness of Barnes functions in this example of an evolving story in popular news media to reinforce a myth of the mentally unstable war veteran by providing a seemingly indisputable image and clear example appropriated as a discursive unity in a dominant veteran discourse.

A close examination reveals, however, how veteran myths are perpetuated by hiding in plain sight. Barthes says readers of myth are in a position to reveal myth's function (129), and Foucault points out the informative loop of discursive practices that reinforce a collective consciousness (22). In this project, I act as a reader of veteran myths and analyze representations of combat veterans to expose the mythology circulating in popular media as veteranness. Uncovering the sociocultural functions of veteranness can become a catalyst for interrupting naturalized ideas and challenging the status quo, the collective consciousness of veteranness and then revealing the functions that sociocultural contexts reinforce. My efforts contribute to an existing body of research on veteran representations in visual media and provide a critical definition and assessment of veteranness and veteran discourse. My hope is to influence the sociocultural rules, norms and conventions regarding combat-affected veterans and the roles we assign to them.

\section{Seeing PTSD: Cultures and Symptoms}

PTSD is a prominent part of contemporary veteran discourse, as the Barnes example shows. Of the images available to news media sources, it was the most intimidating, dangerous-looking image of Barnes that ultimately prevailed in the context of popular news 
coverage of veterans and PTSD. The strength of the lasting connection between Barnes and PTSD was made not by a diagnosis or a failed treatment history but instead by accusations in police and court documentation suggesting he might have suffered from posttraumatic stress disorder. This connection indicates the ease with which popular media, in a news context here, eagerly associates the violence of Barnes' actions and PTSD.

Veteran discourse occurs in two primary sociocultural segments or subcultures in the U.S. One is a professional, clinical culture where PTSD is a diagnosis of a mental disorder with formal, structured treatment approaches in the fields of psychiatry and psychology. The terms Posttraumatic Stress Disorder and PTSD circulate within this subculture as formal and clinical language. The other subculture is popular culture where terms like posttraumatic stress are a continuation of a legacy of terms like shell shock and battle fatigue that circulate outside the professional subculture but sometimes include clinical PTSD. Popular discourse refers broadly to invisible wounds of war leading to problems readjusting to civilian life, as in the marketing message on the front DVD cover of the HBO documentary, Wartorn: 1861-2010: "In every war, there are invisible wounds." Common to both subcultures is the notion that the veteran's soldiering duties and experiences have brought on psychological challenges or mental illness. I suggest there are other, less prominent subcultures, for example, the subculture of diagnosed combat veterans themselves as clinical patients, or a community of veteran "brothers" who understand each other in a way that outsiders cannot. I suggest that further study is needed of these and other veteran discourse cultures to demystify and demythify veteran perspectives. In my work here, I use the professional, clinical terms primarily when cued by discussions of symptoms, diagnosis and treatment. I use the popular terms primarily when cued by discussions in popular settings where the participants in the 
discourse likely do not have the education, training and diagnostic resources or experience of the professional clinician.

For information about PTSD, I draw from two widely recognized sources. One is the National Center for PTSD web site (www.ptsd.va.gov). The other is the American Psychiatric Association's (APA) Diagnostic and Statistical Manual of Mental Disorders (DSM), fourth and fifth editions. The APA's manual is the standard for clinical practice of psychology and psychiatry, and the Center focuses on research and outreach to trauma survivors and is an extensive resource for both professional and public audience. The DSM is part of the Center's body of information research.

While I rely on these sources for clinical information and descriptions of PTSD and its symptoms, I remind the reader that my research is not a clinical study of PTSD but is rather a study of popular media representations of veterans and the dominant ideas that inform them. I make no claim to diagnose the veterans represented in my selections, whether they are based on real veterans or purely fictional. I rely on clinical information to recognize when and how the diagnostic criteria of PTSD overlap or coincide with popular visual media constructions of veteran. When referring to symptoms exhibited by a veteran film character, I use terms such as symptom-like response/responses or behavior/behaviors instead of the more clinical language.

My other professional source is The National Center for PTSD, which is a research and education entity started in 1989 to "conduct cutting edge research and apply resultant findings to advance the science and promote understanding of traumatic stress" (National Center, "About Us"). Housed on the Department of Veterans Affairs (DVA) web site, it addresses all types of trauma in addition to the trauma of combat or military service. The 
Center's web site includes links to two sections, Public and Professional, which parallel the two subcultures I mentioned above that relate to my usage of terms. The Public section is addressed to lay audiences who want to learn about the disorder such as trauma sufferers who seek treatment and life management and friends and families of trauma sufferers who seek information. It is a vast and authoritative source of information for non-professionals that only recently became easily accessible through the Internet. The Professional section is geared toward mental health researchers and therapy providers. Most of this section falls outside the scope of my dissertation except for the descriptions of symptoms of PTSD. Both the Public and Professional sections of the web site contain "PTSD Overview" pages and each of these pages contains a "Symptoms of PTSD" link. These are my primary informational sources from the Center's web site.

In addition to providing information, the Center is also a source of veteran representations. An outreach project, AboutFace, designed to speak directly to veterans about PTSD, is accessible from the Center's pages. Make the Connection, another outreach site, is housed on a separate website. Both of these sites contain still images and videos of veterans talking about PTSD.

The American Psychiatric Association (APA) publishes the Diagnostic and Statistical Manual of Mental Disorders (DSM). The fourth edition, DSM-IVTR ${ }^{8}$, and fifth edition, DSM-5, are the primary information sources for mental health service providers and the National Center for PTSD. The DSM-IV classifies PTSD as an anxiety disorder with six distinct

8 Hereafter, the abbreviation DSM will designate DSM-IV TR, which is the current official version at the time of this dissertation's completion. DSM-IV was published in 1994. The TR indicates the edition contains text revisions made since the edition was first published. DSM-IV TR came out in 2000. Other versions will be noted with their edition number (DSM-I, DSM-II, DSM-III, and DSM$I V)$ and the appropriate TR designation if required for clarity. 
criteria. The DSM-5, recently released in May of 2013, removes PTSD from the anxiety disorder classification into a newly created classification of "trauma and stressor-related disorders" (National Center, Announcement). It also eliminates one of the diagnostic criteria, A2 (see below), and makes some modifications to the arrangement of symptom lists. Because DSM-5 is recently released, I rely more heavily on the diagnostic criteria of the $D S M-I V$, which has a much longer history of usage among professionals and a greater likelihood to have filtered out to the general population. I note differences between descriptions of diagnostic criteria between the editions when relevant to my analysis.

\section{Diagnostic Criteria}

The six diagnostic criteria of PTSD in DSM-IV are: exposure and response to trauma; persistent reexperiencing of the trauma; persistent avoidance of associated stimuli or numbing of responsiveness; persistent increase in arousal symptoms; duration of the three persistent disturbances; and significant impairment in important areas of social functioning (DSM 463-468; National Center, "Professional"). The public section of Center web site rewrites these criteria for its popular audience and presents the criteria as four types of symptom clusters that correspond to the DSM's list of three persistent symptoms: reliving or re-experiencing; avoidance; numbing; and feeling keyed-up which is also known as hyperarousal (National Center, "Symptoms").

The following is a synthesis of symptoms drawn from the DSMs and the National Center for PTSD. This list arrangement parallels the symptom listing in DSM-IV and the Center's Professional section to utilize the rigor of the Manuals. In addition to symptom descriptions, I provide an example to demonstrate how the symptom can be seen as part of a veteran construct. While I will discuss cinematic and other media-specific techniques in 
more depth in the analysis chapters, in this section my goal is to identify places in the films' narratives that visually represent or suggest symptoms of PTSD.

Stressor (Criteria $A 1$ and $A 2)$

A stressor is described as exposure to a traumatic event (A1) that involves actual or threat of death or serious injury or a threat to the physical integrity of self or others and the person's response (A2) to the event in the form of intense fear, helplessness or horror. The DSM-5 eliminates the A2 criterion. Under DSM-IV a veteran was required to meet both of these criteria. The Center's Public section does not include this exposure and response criterion in the list of symptoms, presumably because there is an assumption that the reader understands that trauma has been experienced.

In film, traumatic experiences are often part of the narrative in which we see the character experience and respond to combat events. Sgt. James in The Hurt Locker (see Chapter 4) experiences numerous exposures and responses to intense and traumatic events. In one of these scenes toward the end of the film, Sgt. James arrives at the threat location to find a bomb padlocked around the body of an Iraqi civilian. As viewers, we have been accumulating an awareness of the preparations and procedures taking place as James works to control the threat. His diligence and concentration are visually apparent through cinematic and acting techniques. We watch his control and determination deteriorate to a desperate helplessness as time runs out and he is forced to abandon both his task and the terrified man. As viewers, we watch a process in which Sgt. James' intensity in carrying out his training successfully is replaced with his personal, emotional intensity when he realizes it is impossible to succeed. This visual representation of Sgt. James' war experience allows us to see the stressor/response criterion. 


\section{Intrusive recollection (Criteria B)}

Intrusive recollections are recurrent (persistent) and distressing memories that break through the person's normal thoughts. Intrusive recollections go beyond ordinary memories in that there is an aspect of re-living the trauma rather than simply recalling that the event happened. The DSM lists five types of recurring, intrusive recollections: distressing recollections of the traumatic event (includes recurring images, thoughts or perceptions); distressing dreams of the event; acting or feeling as if the event(s) were recurring (this includes having a sense of reliving the event, illusions, hallucinations or dissociative flashback episodes that may occur when waking up or intoxicated); intense psychological distress when exposed to internal or external cues that resemble or even symbolize some aspect of the traumatic event; or distress responses that are physiological rather than psychological (DSM-IV 468). The Center summarizes these symptoms as a cluster of reexperiencing symptoms that includes having nightmares, having a flashback that feels like you are going through the event again, or having something in your environment trigger a sense of reliving the event.

As diagnostic criteria, these are different ways of reexperiencing the trauma. Only one of the five need be present to qualify toward a diagnosis of PTSD. In film, we may often see them run together. For example, a veteran character could be shown dreaming a flashback triggered by something they see. The film Casualties of $W$ ar (see Chapter 3) provides an example of this blurring of distinct diagnostic symptoms. Nearly all of the film takes place in a series of dream-like flashbacks triggered after Vietnam veteran Eriksson notices a Vietnamese woman seated a few rows from him on a city bus. He dozes and dreams or flashes back through the film's recreation of a traumatic series of events that take place within one mission. Only short segments occur in the film's present (August, 1974). 
Cinematic techniques highlight Eriksson's psychological and physiological distress over the flashbacks and provide a visual interpretation of intrusive recollection, re-experiencing or reliving the trauma criterion.

\section{Avoidance/numbing (Criteria C)}

These two criterion are presented together in the DSM but are separated on the Center public audience web page. This criterion is indicated by a veteran's persistent avoidance of stimuli associated with their war trauma and a numbing of their general emotional responsiveness. To qualify as PTSD symptoms, these responses would not have been present before experiencing the trauma. The DSM lists seven indicators of this symptom and at least three must be present to qualify for diagnosis (468). The symptoms of this criterion include: trying to avoid thoughts, feelings, or conversations associated with the trauma; trying to avoid activities, places, or people that lead to recollections of the trauma; having an inability to recall important aspects of the trauma; having a markedly diminished interest or participation in activities once enjoyed; feeling detached or estranged from other people; having a limited or restricted ability to feel emotion; or having a sense of a foreshortened future or life events (i.e. the veteran might lack normal expectations regarding marriage, family, career, or lifespan).

For lay audiences, the National Center for PTSD makes a distinction between behaviors of avoidance and of emotional numbness. Presumably this separation makes it easier for general audiences to grasp both aspects of this complex diagnostic criterion. On the Center's web site, the avoidance cluster gives examples such as avoiding crowds or keeping busy to avoid thinking about the event. The numbing cluster emphasizes significant difficulty with expressing and/or experiencing emotion. Examples in film include James Allen in $I$ Am a 
Fugitive from a Chain Gang (see Chapter 2), Michael in The Deer Hunter (see Chapter 3). These veteran characters avoid talking about their war experiences by changing the subject when others ask about the war. These brief examples suggest avoidance of situations that could trigger memories. Further analysis in later chapters will more fully discuss examples of emotional numbing.

\section{Hyperarousal (Criteria D)}

The DSM describes hyperarousal as: having difficulty falling asleep or staying asleep; being irritable or having outbursts of anger; having difficulty concentrating; being hypervigilant; or having an exaggerated startle response. To qualify as PTSD, these symptoms would not have been exhibited prior to the trauma and two or more of the five indicators would need to be present. The Center describes this criterion, for popular audiences, as a symptom cluster of feeling keyed up, jittery, always alert for danger, or quick to feel angry or irritable. Always being alert to danger might lead the person to appear to be defensive or a loner, and they may not want to leave themselves in exposed situations: for example, they may want to keep their back guarded by always facing crowds.

Many of these responses are easily represented in film: the veteran startles at the sound of a car backfiring or dives to the ground for cover; the veteran quickly loses his temper to seemingly innocent or naïve comments by non-veterans; etc. For example, in I Am a Fugitive from a Chain Gang, James Allen is being shown to his office on his first day back to work when we hear an explosion in the near distance. Allen flinches, ducks down, and begins to raise his arms for protection, visually scanning his surroundings. Realizing his boss reacted very differently, Allen jokes that the blast had him 'lookin' for the nearest dugout." They share an uneasy chuckle and the boss points out a construction site visible from Allen's 
office window. Hypervigilance can be more difficult to show because the term refers to the attention paid to one's surroundings, whether the surroundings are real or perceived. The Allen example, however, shows an exaggerated startle response that is included in the hypervigilance criterion.

\section{Duration - (Criteria E)}

Duration is a reference to the length of time the symptom has been present and is a key element of the previous three criteria described as "persistent": reexperiencing (B), avoidance (C), and hyperarousal (D). The duration of a symptom is generally longer than one month. Duration is not included in the list of symptoms for the Center's lay audiences. Instead, a duration-of-symptoms description is placed immediately below the list of the three clusters of persistent symptoms to better help readers to recognize the duration distinction.

When symptom-like responses or disturbances are included in a visual representation, they often have or are assumed to have a representational value. In a two-hour film, it might not be possible to show more than one or maybe a few variations of a symptom. The presence of a symptom in visual media, regardless of whether this medium is temporal, as in film and video, or is still, as in photographs or paintings, is a strong indicator to viewers that the symptom is not an isolated response and is significant to the veteran's life experience.

\section{Functional significance (Criteria F)}

The final DSM criterion is that of significant impairment in important areas of functioning, including social and occupational functioning. To qualify as symptomatic of PTSD, the impairment must cause "clinically significant distress or impairment" (DSM-IV 468 ) in these areas. This diagnostic criterion is not included in the Center's symptom information for popular audiences. These evaluative determinations would be made by 
professionals in a formal diagnosis process and include determinations of duration (less than three months would be "acute" and more than three months would be "chronic") and onset (“delayed onset" would mean the symptom appeared at least six months after the trauma event).

The photographs of Benjamin Barnes (Figure 1.1 above), for example, not only depict a veteran, they also depict a man whose behaviors are outside the cultural norm of acceptable, adequate functioning. His actions, over time, lead to the violent death of a park ranger and ultimately to his own death. Whether he was diagnosable for PTSD or not, the image brings together the ideas of a significantly impaired social functioning and Barnes' veteran status. This is one way we can recognize the criterion of functional significance in visual media.

\section{Analyzing Visual Media and PTSD Symptom-like Constructs}

In Chapters 2, 3 and 4, I analyze veteran representations for the ways they overlap with PTSD as a dominant characteristic of the veteran that motivates key changes in the narrative. My selection process, in that the veteran representation is of a combat veteran, presumes the stressor/response criterion has already been met. The duration criterion will also be presumed for the same reason. This means that most of my analysis will focus on the persistent symptoms—-reliving, avoiding, numbing, and hyperarousal—and the functional significance criterion.

The Benjamin Barnes photographs introduced above provide a dramatic example of a PTSD-affected veteran in news media that includes posttraumatic stress not only to create a more compelling story, but also to continue using the image in contexts outside of the story of the shooting. By taking a closer look at this and other images and the way they represent veteran, I show how we can recognize a relationship between PTSD and the veteran 
constructs as they contribute to veteran myths, veteran myths as they contribute to veteranness, and veteranness as it circulates as the dominant, popular veteran discourse and contributes to socioculturally shared meanings of veterans through their appearance in popular visual media.

\section{Chapter Summaries}

While visual media can be used to convey the trauma of war and the veteran's post-war experience, the actual experiences of veterans are often constructed from understandings that are dominant in our popular discourses. In my analysis, my focus is always on the representation of the returned veteran as separate from the soldier, but I sometimes refer to war experiences of either real or a fictional veterans when available and warranted.

As noted, my three analysis chapters (Chapters 2, 3 and 4) are defined by periods differentiated by historical and sociocultural contexts. These periods might be conceived in an alternate manner, yet I maintain my organization is useful in that it is grounded in significant sociocultural trends related to recognition of the lasting effects of combat on veterans. While home photography and video technology were available throughout these periods, distribution was limited to small audiences. Unless these personal media were repurposed for television, film, or magazine, they are not included in the sample of representations I examine here.

The veteran representations in Chapter 2 are selected from the early and mid 20th century when Hollywood film and print were the dominant modes of early mass media with top-heavy creative control held by studios and publishers. In Chapter 3, my selections of representations are drawn from popular media after the end of the Vietnam War and the social and political upheaval of the time when counter-culture and protest voices found their 
way into popular venues. The veteran representations in Chapter 4 are selected from post 9/11, contemporary media in which PTSD is clinically established and continually developing, and the signs of lasting and damaging effects caused by combat stress are increasingly present in popular media. The final chapter presents my conclusions about the ways veteranness functions in terms of sociocultural practices as they relate to posttraumatic stress and the combat-affected veteran.

\section{Chapter 2: Representations of World War I and World War II Veterans}

In order to provide additional context for the films I analyze in this chapter, I begin by discussing a photograph collection from a May 1949 issue of Life magazine. Presented as a two-page spread of 68 photographs of the last surviving American Civil War veterans, it was printed 84 years after the war and accompanied by a short article titled "The War." My indepth analysis is of three veteran representations selected from two critically acclaimed films: James Allen, a WWI veteran from I Am a Fugitive From a Chain Gang (1932), and Fred Derry and Al Stephenson, WWII veterans from The Best Years of Our Lives (1946).

\section{Chapter 3: Representations of Vietnam War Veterans}

My discussion of the sociocultural context of this era focuses on works of art by Vietnam War veterans, including: Hi Mom... I'm Home (1994) a painting by Ned Broderick used on the cover of a book of veteran artists; Self Portrait: The Vietnam Vet (1985), a painting by Benjamin Suarez; and Reflections (1988) a painting by Lee Teter. My in-depth analysis is of two Vietnam War veteran representations selected from two critically acclaimed films released after the end of the Vietnam War: Michael, from The Deer Hunter (1978) and Private Eriksson from Casualties of War (1989). 


\section{Chapter 4: Post 9/11 Veteran Representations}

The sociocultural context of this period includes the ever-increasing presence of social and online media and I discuss the ways veteran representations are finding new audiences. My sociocultural context discussion looks at the ways HBO marketed their film $W$ artorn and a PSA produced by Iraq and Afghanistan Veterans of America (IAVA) and the Ad Council. The veteran representations examined in-depth in this chapter are: Sergeant James, a multi-

deployment veteran of the wars in Afghanistan and Iraq from the film The Hurt Locker (2008) and a collection of Iraq and Afghanistan War veterans from the HBO film documentary Wartorn: 1861-2010 (2011).

\section{Epilogue: Sociocultural Functions of Veteranness}

In this chapter, I give a synopsis of my project, the analysis chapters and the veteran myths revealed through my analysis. I follow these summaries with a discussion of veteranness as discursive unity and disclose my findings on the functions of veteranness in sociocultural discourse in the United States. 
CHAPTER 2

\title{
Representations of World War I and World War II Veterans
}

\author{
"T'm different now. I've been through hell. ...I'm out of step" \\ -James Allen
}




\section{Introduction: Representations of WWI and WWII Veterans}

In this chapter, I analyze three veteran representations selected from two films that were products of the Classical Hollywood era of filmmaking. During this period, a handful of major studios dominated an entertainment industry that produced films for large audiences. Producers and audiences shared in two major sociocultural events. The nation was fighting its way up from the economic depths of the Great Depression and was bringing home two generations of soldiers from the First and Second World Wars. This era thus felt the effects of two groups of war veterans returning to civilian life: one who fought "the war to end all wars" and the second who fought their battle twenty-six years later.

While these homecoming events played out, the popularity of film was on the rise, and this popularity raised concern over the film industry's apparent profiting from indecent content and the negative effect it could have on society. The outcry of religious, civic, and political organizations motivated the film industry to create a self-imposed code initiated by the Motion Picture Producers and Distributors of America (the MPPDA, which later became the Motion Picture Association of America or MPAA). Implemented by the Hays Office this code was to assist the film industry in avoiding governmental intervention and regulation through self control to "become mature enough to bear censure, conservative enough to value goodwill, and shrewd enough to advocate middle-class morals" (Leff and Simmons 5). Constraint was called for in use of profanity, nudity, sexual acts and perversions, drug trafficking and more (Leff and Simmons 7), but the resulting "nambypamby" (Leff and Simmons 6) films could not compete at the box office with the uncensored films. By 1934, the weak enforcement of a self-regulated system did not alleviate concerns over sexual, criminal, and violent film content and more diligent controls were 
imposed. The "Production Code" was created and enforced and a film would now first need to be approved by the Production Office before being released in theaters (Bergman and Asimow, Doherty). Three principles were basic to the code:

1. No picture should lower the moral standards of those who see it.

2. Law, natural or divine, must not be belittled, ridiculed, nor must a sentiment be created against it.

3. As far as possible, life should not be misrepresented, at least not in such a way as to place in the mind of youth false values on life (Leff and Simmons 10).

Determining the exact or probable influence of the production code on an individual veteran representation is outside the parameters of this dissertation. However, the existence of the code provides concrete evidence that a particular film would have been influenced to the extent that it needed to meet the code's criteria. This tells us that the film veterans of this time period would have been constructed to either adhere to the code or cleverly subvert it, that they were considered reasonable constructs and acceptable for broad audiences. Essentially, the film characters passed for acceptable veteran discourse during this period of filmmaking. Leff and Simmons note that "those who produced them were bound to produce 'correct entertainment' for the mass audience, ... [they] must not pander to that mass audience but honor the moral responsibilities of the motion pictures" (10). These responsibilities led producers "to condemn criminality; to sanctify the marital vows and 'not infer that low forms of sex relationships are the accepted or common thing; to shun vulgarity, obscenity, and profanity; to clothe characters properly; to respect religion and national feelings; and to carefully treat 'repellent subjects'..." (Leff and Simmons 12). Both of the films selected for analysis in this chapter adhere to the code quite well: the 
criminalized veteran has an ill-fated story and the successful veterans shed the characteristics that put them outside acceptability.

The first veteran representation I analyze is James Allen, who returns from WWI in the film I am a Fugitive from a Chain Gang ${ }^{9}$. Released in 1932, thirteen years after the end of war, the film is based on the autobiography I am a Fugitive from a Georgia Chain Gang! by Robert E. Burns. James Allen, played by Paul Muni, is the film interpretation of Burns and the film adaptation closely resembles Burns' written account of events of his post-WWI life, but with an exaggerated military record that helps strengthen the veteran status of the Allen representation. The film focuses on an ordinary person fighting the giant and impersonal forces of society. Indeed, the film was one of the few Hollywood films directly associated a distinct social change in the form of elimination of the chain gang prison system (Green 9, Minchew). At first the film was considered a risky business decision (Green 43), but it was a huge success for Warner Brothers, and national news headlines of Burns' escapes and subsequent captures brought it additional attention. Burns actually appeared on the set of filming as an advisor while he was a fugitive, but only for a short time because of the risk of being captured (Black 135). He was arrested again only weeks after the release of the film, but was able to avoid extradition to Georgia. In 1945, thirteen years after the film was released, Georgia's governor pardoned Burns (Minchew). Allen's story, however, ends a year after his second escape.

9 Directed by Mervyn LeRoy and starring Paul Muni, the film was a nominee for three Academy Awards: Best Picture, Best Sound Recording, and Muni for Best Actor in a Leading Role. The film won the National Board of Review award in 1932, and was added to the National Film Registry in 1991 by the National Film Preservation Board (imdb.com). 
Although both Burns and Allen were in or near combat, there are notable changes made in the film to Allen's military service ${ }^{10}$ to make it more heroic and to his post-war employment and fugitive career ${ }^{11}$ to lend to the continuity of the film's overall narrative. Allen's post-war behaviors and responses continually put him at odds with others' expectations at critical moments of his life and lead to his distancing and ultimate exclusion from all but the darkest margins of personal and societal relationships. Ultimately, Allen-theveteran becomes Allen-the-fugitive in a myth-building operation that emphasizes the contrast between the success of his wartime experiences and the failure of his civilian experiences. This is accomplished by using his posttraumatic stress responses in ways that create the quickest route to his criminalization. I associate the term criminality with the veteran myth constructed through Allen, whose PTSD symptom-like responses and behaviors are essential to bringing him to his criminal and fugitive phases.

The second and third representations I analyze are WWII veterans Fred Derry (Dana Andrews) and Al Stephenson (Fredric March) from the film The Best Years of Our Lives, released in 1946, less than a year after the end of the war. With numerous cinematic awards

10 Burns served with a medical detachment of the 14th Railway Engineers regiment that was stationed at the front where he attended to wounded soldiers and to burial of the dead (Burns 11). The character of Allen serves in an Engineering Corps where he did construction work.

11 Both Burns and Allen face employment difficulties after they return home. Burns did not have a job waiting for him, as Allen did, and felt that being an ex-service man was a hindrance to finding one. While a fugitive after his first escape, Burns went into publishing, developed The Greater Chicago Magazine and after "months and years he managed eventually in 1929 to build this magazine into a place of importance in the business and real-estate circles of the great city" where he "held a position of high public trust in the life of Chicago" (Burns 13-14). In the film, Allen also builds a highly respected career, but as a civil engineer. After his second escape, Burns writes his book, determined to destroy the chain-gang system. 
and nominations ${ }^{12}$, the film's portrayal of three veterans-Fred, Al, and Homer Parrishreturning to a small town, each to a different situation, was a critical and box office success (Affron and Affron 164). Given the time of the film's release, about a year after the end of the war, the film's fictional characters and individual stories paralleled the return of real military veterans who were also readjusting to civilian life. Homer ${ }^{13}$ and Fred are a generation younger than Al. Fred, a soda jerk in a drug store before the war and a bombardier during the war, had hastily married his "girl" only weeks before going overseas. Al has been married for twenty years, and he and his wife have two teenaged children. A banker before the war, $\mathrm{Al}$ served as an Army Infantry Sergeant and uneasily returns from the battlefield to both his home life and an employer who immediately promotes him at the bank. Mindful of censorship guidelines that influenced the moral parameters for scripting "social, political, and sexual themes" in major motion pictures (Black 168), the narrative of The Best Years of Our Lives is one of great success in the war overseas and of the veterans at home as they reintegrate into happy, fulfilling, and productive lives.

12 Directed by William Wyler and starring Fredric March and Dana Andrews, the film won numerous awards. Its seven Academy Awards include Best Picture, Best Actor in a Leading Role for Fred March, Best Actor in a Supporting Role for Harold Russell, Best Director, Best Writing in a Screenplay, Best Film Editing, and Best Music Score. The Academy honored Russell and presented him with an Honorary Award for his portrayal of Homer Parrish "for bringing hope and courage to his fellow veterans" (imdb.com/title/tt0036868). Russell, a navy veteran and double amputee who lost both hands during the war, was not a professional actor. The film also earned many other national and international awards including: BAFTA Award for Best Film from any Source; Bodil Award for Best American Film; Cinema Writers Circle Award for Best Foreign Film, Golden Globe for Best Motion Picture and Special Award for Harold Russell for Best Non-Professional Acting; Karlovy Vary International Film Festival Award for Best Director; National Board of Review for Best Director; New York Film Critics Circle Award for Best Director and Best Actor.

13 The film's story follows the three veteran's stories and the ways they intertwine. Parrish lost both of his hands during the war. His permanent physical injuries disqualify the representation from close analysis here based on the selection criteria established for this examination. 
The PTSD symptom-like responses exhibited by both $\mathrm{Al}$ and Fred are integral to their individual stories and woven through the narrative as temporary post-war hurdles easily overcome by these veterans' decisions to battle their inner demons and put the war behind them. I consider the veteran myth constructed in this film to be a myth of psychosimplicity that links two essential components. The first part of the term, psycho, refers to both clinical and popular social recognition of combat stress, referred to in the film as "nervous out of the service" by Fred, as a real and potentially lasting effect of combat trauma. This idea parallels the development in medical and clinical disciplines that were beginning to define and treat combat stress as a psychological condition. Simplicity refers to the narrative's treatment of posttraumatic stress as something easily overcome by making a choice to do so and then following through on this choice. In the film, psychosimplistic battles are waged by all three of the main veteran characters. Al grapples with what he knows about banking and what he knows about soldiers. He fights to legitimate the soldier's strength of character as an asset that makes him a better lending risk and in so doing, participates in popular sociocultural notions of the ways veterans are assets to the economic recovery of the nation. Fred grapples with mistakes made as a youth and military trainee that affect his post-war move to civilian adulthood. His dilemmas eventually drive him to flee his hometown, but just as he is leaving, circumstances provide him opportunities to purge his memories of combat and to fight for a job by reinforcing his determination to put those memories aside. Homer eventually accepts his girlfriend Wilma's love after she proves, to his satisfaction, that she has the courage to handle his prosthetic limbs and assist him with what he cannot do for himself when his prosthetics are off. 


\section{Veteran Discourse in the 1930s, 40 s and 50 s}

At the time when the representations discussed in this chapter were produced and distributed, popular discourse concerning war veterans did not include the degree of clinical language that today is used to refer to posttraumatic stress or PTSD. It did, however, use language that remarked on changes exhibited by both soldiers and war veterans, and this language began a legacy of ideas that carried forward to later periods.

Before the early period of mass media, several terms were in circulation. During the Civil War, terms such as nostalgia, homesickness, malingering, soldier's heart and irritable heart described or noted changes in the emotional condition of soldiers when no physical cause was apparent or known. During WWI, terms like shell shock, battle fatigue, combat exhaustion and war stress shifted the attention to physical origins of causation such as the sound and forceful impact of explosions endured in combat and the emotional and physiological toll of this combat experience. Shortly after the war and throughout the WWII era, shell shock was still in common usage, but military psychiatry was shifting to include a vocabulary that described psychological origins of the condition. The psychoanalytic approach generated terms like battle neurosis, combat neurosis, war neurosis and psychoneurosis and these changes spurred a growing interest in analysis as treatment therapy. Let There Be Light, the third installment of a threepart documentary film series about WWII soldiers produced by the army in 1946, documents the treatment of psychoneurotic war veterans, but was not released until 1981 due to disturbing content (Hale 149). The film shows images of former soldiers, some of whom were physically incapacitated with involuntary shaking or were unable or barely able to communicate verbally, and others undergoing electroshock and psychotropic drug treatments. In 1952 the American Psychiatric Association (APA) published the first edition 
of the Diagnostic and Statistical Manual (DSM). It contained an entry for gross stress reaction that helped classify combat-related conditions (as well as stress reactions) that could occur even in people who did not have a history of other mental disorders.

Along with these military and clinical usages, a veteran discourse was developing in popular film and print media. One example of veteran discourse in this era appeared in the May 30, 1949 issue of Life magazine. The collection of photographs reveals how natural and normal it was to present veterans as an icon of American history and Americana. The timing of the pictorial in a Memorial Day context also allows us to see a sociocultural practice of situating veterans in a particular social role and the ease with which a veteran myth assisted the practice.

In recognition of Memorial Day, the magazine published a pictorial of Civil War veterans in a rare collection of every living veteran from a war. The pictorial appeared 84 years after the end of the Civil War, 17 years after I Am a Fugitive from a Chain Gang, and three years after The Best Years of Our Lives. The pictorial references three combat veteran groups in various stages of readjustment: a historical group consisting of aged combat veterans from the Civil War; a mature group of WWI veterans; and the newly returned veterans of WWII. It is the status of these three groups of veterans as real individuals that lends credibility to what I refer to as a veteran myth of monumentality. A similar reliance on realist characteristics is an essential part of the film representations analyzed from this period. The Civil War pictorial provides insight into the dominant veteran discourse of this period and highlights a veteran myth that was part of this discourse in the early to mid-1900s.

The war veteran pictorial, which appeared in the "Speaking of Pictures" section of the magazine, was a two-page spread (see Figures 2.1 and 2.2 below) accompanied by an essay 
on a third page that adds the author's personal memories of the veterans he encountered as a young boy to the broader, national memories constructed through the pictorial pages.

Together, the pictorial and essay construct a veteranness that honors, celebrates, and reveres the sacrifices made by the veterans pictured. Nostalgia and promise intertwine in gestures honoring both a historical and future United States. In this monumentality myth, respect for the individual sacrifices made by veterans for the benefit of America's past, present, and future masquerade as broadly shared, unified memories.

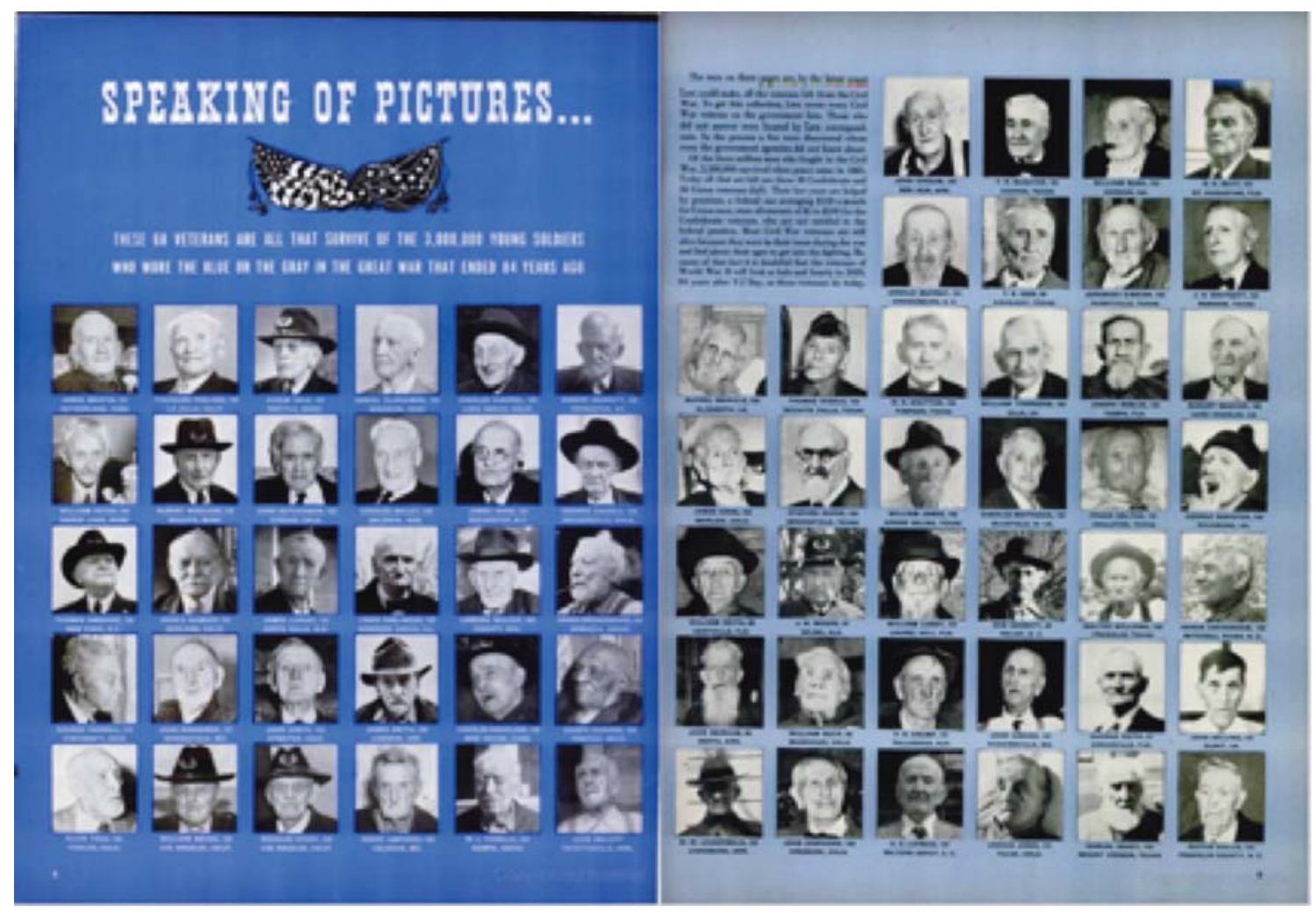

Figure 2.1: "Speaking of Pictures," Life, May 30, 1949, pages 8-9. The introductory text read: "These 68 veterans are all that survive of the $3,000,000$ young soldiers who wore the blue or the gray in the Great War that ended 84 years ago." (Internet screen capture, books.google.com, accessed October 24, 2013). 


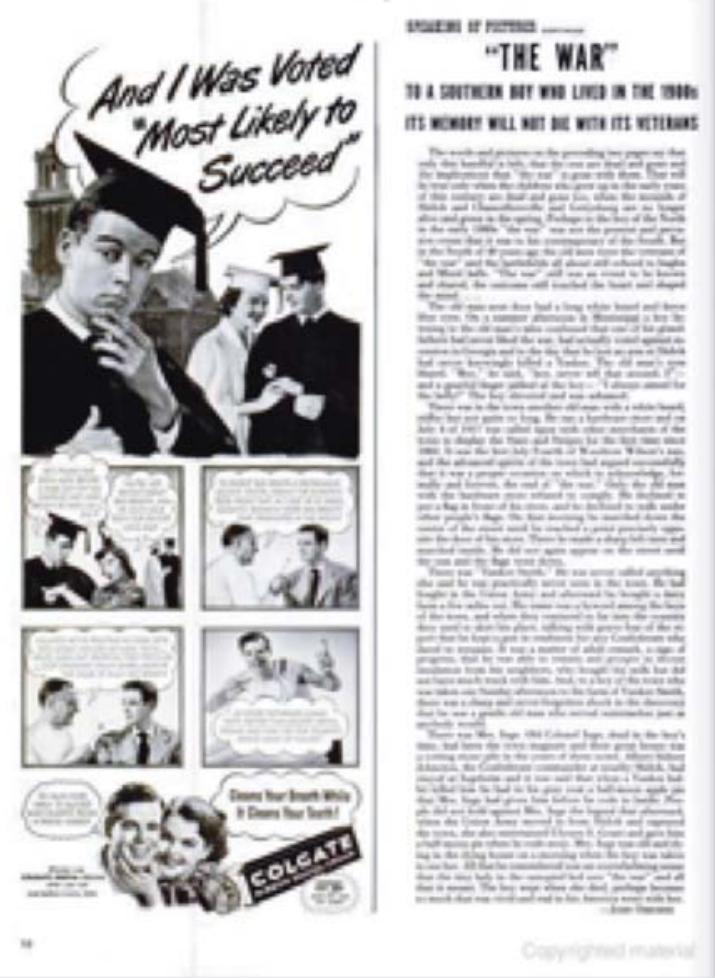

Figure 2.2: "Speaking of Pictures," Life, May 30, 1949, page 10. Titled "The War," the two lines of lead-in text read: "To a southern boy who lived in the 1900s / its memory will not die with its veterans" (Internet screen capture, books.google.com, accessed October 24, 2013).

Looking at the pictorial we can see that each of the 86 photographs of a veteran is captioned with his name, age, hometown and state. Whereas each photograph is a sign for the individual veteran depicted, the entire collection of sixty-eight images also is a sign with a public meaning: these are the last surviving veterans of America's Civil War. In Barthes' terms, these pictures provide myth with what it needs: a sign with a meaning that can be modified without being destroyed, one which neutralizes the politics of war by emphasizing the need to honor the warriors and uphold the value of American history for a future America. Within this realist visual veteran discourse, then, a veteran myth of monumentality is revealed: the veteran as a signification of the remembrance of American victory, sacrifice, honor, and history and a promise that the United States will continue to exist into the future. 
To neutralize the divisive politics of the Civil War, the pictorial neither valorizes winners nor diminishes losers. Both Union and Confederate veterans are presented with equal visual weight. The background colors of the pages also evoke the idea of neutrality. The Union page has a vivid blue background and the Confederate page a pale blue rather than gray background, which would have created a more striking visual distinction. In addition, both the Union and Confederate flags are present in one design element. These visuals suggest that what matters most is not the historical divisions that resulted in the Civil War, but the historical unity that resulted from ending the war. Life magazine's pictorial sets aside the meaning of the differences of the individual men for a meaning of their sameness. The meaning of the individual's personal wartime sacrifice serves to emphasize the value of both side's sacrifice. In a veteran discourse valuing national sacrifice, the veteran's differences are set aside to merge under a unified idea of sacrifice-for-country implying or connoting that every U.S. war's veterans are national sacrifices and a national investment made to ensure its own future.

Textual cues reinforce the visually presented ideas that point to a hard-fought American history, one with continuity, begun in the past, present today (1949) and expected to extend well into the future. To indicate the passage of time between then (after the Civil War) and now (after WWII), each veteran's age (most of the veterans are a hundred years old or older) accompanies a recent photograph to help readers "see" that much time has passed since these men were young soldiers. The small size of the collection also emphasizes how few out of the many veterans are alive; these are "all that are left" (9). They are a singular embodiment of the Civil War. Their rarity increases the value of what they represent. Additional textual reinforcement of this visual embodiment accompanies the pictures in the 
short paragraphs cueing Life's readers to look ahead to the year 2029 (84 years from then) and to wonder if the newly returning WWII soldiers "will look as hale and hearty" (9) as the pictured veterans and to consider whether these veterans will be alive in 84 years. In this way, these photographs help construct a myth that merges ideas of history and valuable rarity, associates this group of Civil War veterans with the individual veterans of WWII, and invites readers to look at new veterans from a similar perspective: as already a part of a preordained national history communicated through a powerful national visual discourse.

The publication of this pictorial in the context of Memorial Day as veterans from WWII were reintegrating into society both reflected and reinforced a dominant, naturalized discourse of a tradition of honorable sacrifice. Joining together the pictorial with a short essay on the following page further reinforces this discourse. The essay is not about any of the pictured men, but supports a myth of monumentality constructed through the pictorial by elaborating on a realist interpretation of a journalist's reminiscences about war veterans during this period. The essay's title is “The War," a popular way of referring to the Civil War in 1949. The essay echoes ideas the editors expected would, or should, resonate with the magazine's audience, including PTSD-like symptoms of hyperarousal and avoidance. The author describes his personal observations of lingering effects of wartime combat, but he writes of them not as problems for the veterans, but as nostalgic reminiscing of his boyhood. He writes of a Confederate veteran's "fierce blue eyes," which give the impression that he is always watching and combat-ready, and describes the solitude and hypervigilance of a Union veteran known as "Yankee Smith" as someone who was rarely seen in town and rumored to keep "a gun in readiness for any Confederate who dared to trespass" (Life 10). The author's nostalgic tone suggests these descriptions are not his own but a shared, normal and expected 
way to think about these veterans. He writes of a young boy's excitement to see for himself the mysterious Yankee Smith who lived "in decent insulation from his neighbors" and describes how he experienced "a sharp and never-forgotten shock in the discovery that he was a gentle old man." He then switches topic and talks of Old Colonel Inge's dying widow. She, and the memories she stirred "was 'the war' and all that it meant;" he states that he "wept when she died" because what "was vivid and real in his America went with her." His closing sentence does not attempt to shine a light on the isolated and misunderstood veterans; it emphasizes the loss of historical artifacts, which merely serve as triggers for his own memories. Neither the veterans nor the widow are fully their own persons to the author; instead, they are monuments to American history.

The essay helps reinforce a veteran myth of monumentality in other ways as well. The essay's lead-in text, "To a southern boy who lived in the 1900s/its memory will not die with its veterans," suggests the veterans pictured on the previous pages and imagined through the essay belong to the war rather than their families and society. They are "its veterans." The remembrance of the fighting soldiers evoked through the essay is equivalent to remembrance of "the War" into which they are absorbed. They are no longer individual men who were soldiers; in myth, all veterans are united in a discourse that seems "natural" and "taken for granted."

The Life pictorial is a visual media artifact that came out of a popular veteran discourse of the mid- to late-1940s and into the 1950s. It also informed that discourse by using real veterans from the Civil War to consolidate, modify and reinforce ideas about veterans of WWII and turn them into a visual, historical statements/artifacts in a broad national discourse about veterans. Both groups of pictorial veterans, Union and Confederate, are 
merged into one that sets aside each individual veteran to become, collectively, a signifier of a national history. The essay also suggests veterans live out their lives in a forever-thewarrior state of mind, a normal state for both the veteran and the civilian, an idea that helps support a discourse that wants to remember them for the soldier phase of their lives. A veteran myth of monumentality belongs properly and appropriately to a discursive unity. The sociocultural function of the myth is to treat military veterans as a monument to history and to reinforce remembering a collective sacrifice and a collective history. Essentially society sacrifices the veterans' individuality for its own historical support system. The value of what, rather than who, survives disguises what was lost—-the fallen and combat-affected soldiersand makes all that is left, the lost and gained remnants of war, a "real America," the ultimate signification of the magazine pictorial.

The remainder of this chapter presents analyses of three popular film representations of veterans that appeared earlier than the Life pictorial and that construct other veteran myths of criminality and psychosimplicity that circulated along with monumentality in a normalized veteran discourse in the World War I and II periods.

\section{World War I Veteran James Allen}

I Am a Fugitive from a Chain Gang begins at the end of WWI and James Allen's military service. The opening sequence establishes Allen as a successful, capable, returning soldier, a man full of promise. It also introduces his personal post-war expectations and reveals key character traits that are essential in constructing a veteran myth. These traits resemble PTSD symptom-like behaviors and responses and they resurface throughout the film to motivate key developments in his story. After he arrives home, conflicts instantly arise. Allen's personal post-war goals differ from those his family and boss envisioned for him, and as he 
actively pursues his preferred career path to "be free" and out from "under orders," his troubles intensify. While PTSD symptom-like responses and behaviors do not lead directly to Allen's arrest and conviction, they lead to a situation where he becomes embroiled in a crime. These behaviors and responses are triggered at decisive moments that transition him from the successful persona on board the ship carrying him home to a wanderer, convict, then fugitive, until ultimately he is completely marginalized from society. The film's overall perspective is quite sympathetic to Allen, a perspective that intensifies the film's emotional tension and suspense. Allen's actions, even those that resemble his heroic wartime acts, become problematic in his personal relationships and the criminal justice system.

A veteran myth develops from Allen's PTSD symptom-like responses that, at crucial turns, drive him further from society's norms. It is part of the normative discourse of this era to use Allen's respectable veteran status and combat wartime experiences to create the dramatic sense of suffering and personal loss that eventually helped change the prison system's chain gang practices. Significantly, it is not Allen's veteran status alone that creates the dramatic difference in him from the beginning of the film to the end. It is the symptomlike behaviors that coincide with what we today call PTSD that motivate the changes in the story and that lead to what I call a veteran myth of criminality.

\section{Film Synopsis: I Am a Fugitive from a Chain Gang, 1932}

The opening shot of the film is of a large military ship carrying soldiers from the army ${ }^{14}$ infantry's Sunset Division home from the war. We are introduced to Allen in the film's first scene, which takes place in a cramped, below-deck space. A close-up view of a scuffed-up

14 The Sunset Division is the name of the 41st Infantry Division of the Army's National Guard (www.history.army.mil). 
enemy combat helmet, a soldier's souvenir, emphasizes the idea that these men were in or very near combat. In the background, we hear joyful commotion and the camera tracks down to show a cluster of soldiers playing dice. Allen soon enters from an upper deck (Figure 2.3).

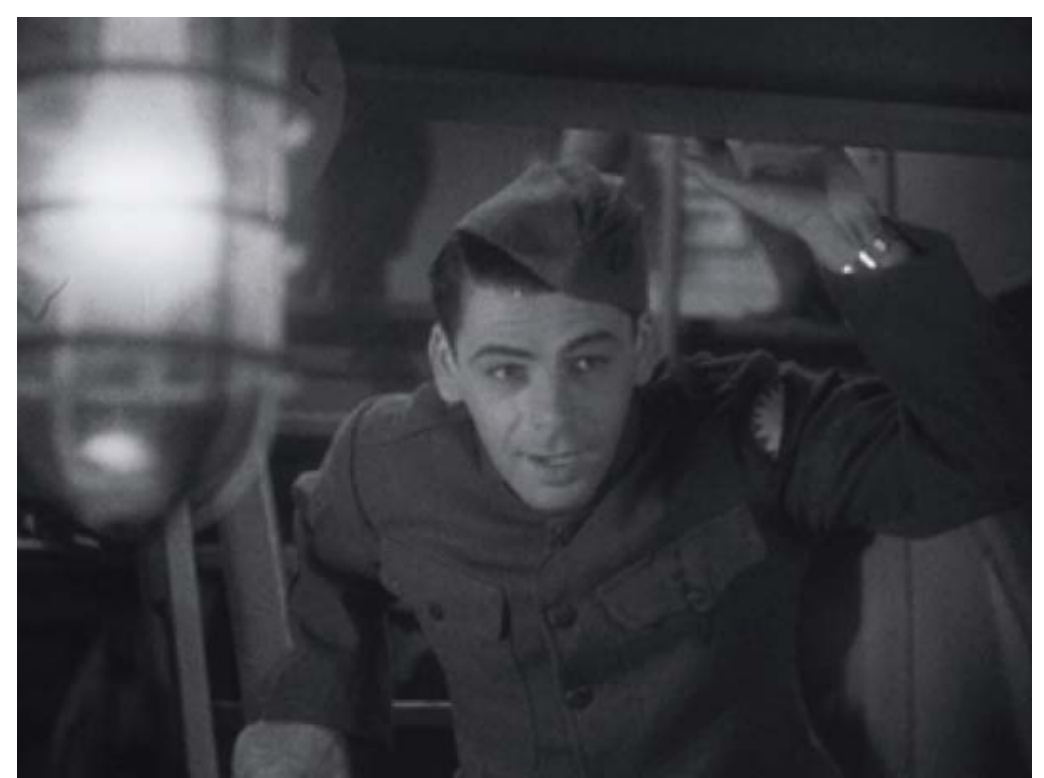

Figure 2.3: First appearance of James Allen in $I A m$ a Fugitive from a Chain $\mathrm{Gang}$, as he enters the scene from the deck above (DVD screen capture, $I \mathrm{Am}$ a Fugitive From a Chain Gang).

In this introductory shot of Allen, the Sunset Division shoulder patch is clearly visible on his uniform, reinforcing for us that he is attached to this combat infantry unit. His actions and demeanor tell us he has a leadership role, which appears to be a comfortable one for him. Allen remains on the steps and never fully enters the space with the other men. This framing creates a contrast between Allen and the men due to his position of authority. Another contrast is created by their respective appearances. Allen is in uniform and well groomed. The other men appear rumpled and in various stages of undress, and several display tattoos on arms and chests. After sitting on the steps, Allen engages in a relaxed conversation with a small group of men about their post-war plans. Allen speaks highly of 
the construction experience he acquired while he was stationed with an engineering corps and explains that he will be making the most of his military service by getting a construction job.

The film cuts to scenes showing large victory parades and celebrations, emphasizing the grand welcome and apparent acceptance of the returning solders. As his train nears the station, Allen's mother, brother Clint, girlfriend Alice, and former employer Mr. Parker await his arrival. Allen's mother and Alice are giddily eager to see him and wonder aloud if he will be wearing his medal, later identified as a Belgian Croix de Guerre ${ }^{15}$, awarded for heroism. Allen steps off the train wearing an ordinary, civilian suit and hugs his mother who rushes to him. Allen's facial expression and tone of voice suggest he is quite happy to see Alice. She returns his admiring glances noting, "you look different, too." That she recognizes that he has changed appears to please him, but Allen is caught by surprise when she adds, "I think it's the uniform I miss." His smile fades, but Alice continues, pointing out that the uniform made him look "taller, and more distinguished."

Allen moves on to acknowledge his former boss, Mr. Parker, and shows appreciation and surprise that Parker has come to the station. Clint is quick to explain that Allen ought to be thankful that Parker is going to rehire him back into his old job at the factory. Allen resists expressing the obligatory thanks to Parker for the job as Clint continues an enthusiastic explanation that Parker "feels that after all you've been through, we owe you something." Before Allen has time to respond, his mother interrupts, unable to contain her

15 The Croix de Guerre, or War Cross, medal could only be earned by foreign nationals for acts of heroism performed on Belgian soil (firstworldwar.com). 
joy at having her son home. Allen, his facial expressions and body language conveying that he is overwhelmed by the unforeseen reactions, suggests they go home.

At home, Allen tries to get his plan back on track by asking Clint to talk to Parker about not taking the job. Clint insists that Allen has a "duty" to accept Parker's offer and his mother explains how she looked forward to Allen working at the factory again. The scene fades out and Mr. Parker's shoe factory sign quickly fades in, signifying Allen's decision to put aside his personal goals and return to his old job. Inside the factory we see Allen, slouching and shuffling his feet as he surrenders his post-war self and attempts to take on an older version of the pre-war persona that he is expected to resume. The conflicts and disappointments of the homecoming sequence increase Allen's internal conflicts between his pre- and post-war goals and set the groundwork for the external conflicts that arise in the rest of the narrative.

The factory job grows intolerable, and Allen is preoccupied with the construction site, which keeps him from getting to work on time and doing his job satisfactorily. His family confronts Allen about his poor job performance, and again he tries to explain his desire to pursue a new plan for his future and the engineering work where he can accomplish things, where he can "build, construct, create." His mother realizes the level of Allen's dissatisfaction with the factory job and supports him in pursuing his dream.

Finally free from the factory routine, Allen travels from state to state taking temporary construction-engineering site jobs wherever he finds them. Broke but undeterred, he eventually attempts to pawn his medal but learns it has little or no monetary value when the store's owner shows him a box filled with hundreds of them. Traveling by train or walking the ties, broke, dirty, tired and hungry, he appears more satisfied with this life of uncertainty, 
one in which he is freely pursuing, though not yet accomplishing, his own goals, than the security of the factory job. After several months, he meets a man who forces him to participate in an armed robbery. Police shoot the armed man and arrest Allen. In court he is sentenced to serve ten years at hard labor. At this point in the film, Allen's veteran status changes to one of convict or fugitive. His admirable military record surfaces again only briefly when, later in the film, Clint testifies at a hearing.

As a convict, Allen is observant and a quick study of the routine but makes a critical mistake, protesting the warden's harsh treatment of a sick prisoner, soon after he arrives and receives a severe beating. One month into Allen's sentence, Barney, a fellow convict, is released; the same day the sick prisoner dies. Allen realizes that his only two legitimate options are, as another convict, Bomber, explains, to either "work out, or die out." A third option, "to take it on the limb" seems to Allen the best choice for him. With some help from fellow convicts, Allen escapes, and with outside help from Barney, who hides him overnight at his gambling hall/hotel, Allen flees to Chicago where he gets a walk-on job at an engineering company's work site and creates a new identity using an alias.

Thus, five years after his hero's return from war, James Allen becomes Allen James. Allen works hard, studies civil engineering and earns several promotions and the respect of the community. He rents a small apartment from a woman named Marie, who is drawn to his good looks, respectability and money. After a couple of years, she demands more from Allen, who is not interested in making a commitment to her. Following another promotion at work, he plans to move to a new place, but Marie surprises him with a letter from his brother that she has opened and read. It reveals Allen is a fugitive, and she uses this information to coerce him into marrying her with threats to turn him in to the authorities. 
Allen grows tired of their sham-marriage and frustrated with a life that is not his own. After he meets another woman named Helen, Allen demands a divorce, and Marie threatens again to turn him in to authorities. He calls her bluff, but soon after the argument, detectives come to his office to arrest him.

City officials support Allen and help fight his extradition. We infer that Marie has granted him a divorce after his respectability and income disappeared. With Marie out of the picture, Allen and Helen talk about their future together. Allen's goal to live his own life is the key motivation in his decision to clear up the issue of his unfinished prison sentence so he can, as he believes, "be free." Against the advice of his lawyer, he returns voluntarily to sState custody with a verbal promise of a pardon after ninety days.

Once Allen is back in custody, the State's promise begins to unravel. Allen is placed in a work camp that is more brutal than the one he escaped from and is back on the chain gang. Here he finds Bomber, his buddy from the previous prison camp who failed his own escape attempt. During the subsequent hearings, Clint presents Allen's war record and testifies to his integrity of character insisting that, after being forced at gunpoint into a single act of crime, Allen "showed his true character by rising from less than nothing to become a prominent and honored citizen." The State denies the pardon, but makes a new promise with new terms. Although Allen meets the terms, the State suspends its decision "indefinitely." A shot of Allen's clenched fists and agonized facial expression as he learns his fate suggests that he is at the edge of rationality. He decides to escape again.

The final scene of the film takes place a year after this second escape, with Allen still on the run. He finds Helen to say good-bye to her. The last image of Allen is of a visibly traumatized man. His eyes are widened in fear and anxiety, and his body is tense and seems 
small in its ragged and slouched appearance. As he backs away from both Helen and her pleas to help him, he moves as if drawn to the darkness, which envelops him. Only his face remains dimly lit, allowing us to see his suffering as he surrenders his only remaining desire and the last of his freedom. His complete disappearance into the darkness is accompanied by the sound of his footsteps as he runs away.

\section{Seeing James Allen as a Combat-affected Veteran}

The first minutes of I Am a Fugitive from a Chain Gang characterize James Allen as an accomplished World War I veteran with clear plans for his future. Allen's combat-affected persona is driven by "restlessness, the inability to settle down after having had a taste of another, more demanding life" (Early 222) and leads to his leaving a job "when any job was becoming prized" (225). As the Allen character is developed, PTSD symptom-like responses of avoidance/numbing, hyperarousal, reliving/reexperiencing are introduced and resurface at key moments throughout the film, thereby contributing to a portrait of social incompatibility. The returned soldier becomes the veteran who is "naïve and victimized" by both women and a sociocultural environment where he "hasn't the skills to cope" (Early 226). The PTSD symptom-like responses exhibited by Allen after arriving home are in contrast to the characteristics of competence and confidence that were established before his arrival. Allen's soldierly characteristics make possible myth-building in the form of a veteran myth of criminality: it is because he is a former soldier that he struggles to return to civilian life and the ill-fitting expectation that he will take up what society considers an appropriate role for him. The use of Allen's honorable service to construct a veteran myth indicates how readily combat heroism can be set aside for the film's narrative and implies a readiness to do so in the sociocultural context in which this film was made and released. 
Within a discursive unity of veteranness, ideas about receiving medals and being honored with parades and gestures of gratitude suggest that "veteran" functions as a symbol of society's collective pride and its effort to provide closure to its war by embedding the war in history. However, the ways Allen has changed during his military service are "out of step" with social expectations. His personal development or damage appear peripheral to these shared ideas circulating in veteranness. As Allen pushes back against this role and works to be free from constraints imposed upon him, he demonstrates anger, avoidance and flashbacks. These reactions, which resemble PTSD symptom-like behaviors and responses, push him further from society's acceptance.

\section{Avoidance/Numbing, Hyperarousal, and Reliving/Reexperiencing}

In the narrative, Allen exhibits symptom-like responses as soon as he returns home, responses that the film portrays through close-ups and reaction shots that visually highlight his emotions, helping the audience recognize and even share in his enthusiasm to return home, his helplessness and frustrations in prison and relationships, and finally his agony in the final scene. Avoidance/numbing is notable at the train station when Allen quickly suggests they leave to go home rather than explaining how his wartime experiences changed his career choice. Clint's and Mr. Parker's own behaviors indicate that they do not realize that Allen might have a plan of his own. In this instance avoidance postpones Allen's introduction of his career goal while preventing an immediate confrontation that Allen was not expecting.

Hyperarousal is also suggested in the train station scene when Allen is met with Alice's disappointment, Parker's job offer, and Clint's pressure to accept it as soon as he steps off the train. He quickly becomes ill at ease and jittery and has trouble figuring out how to deal 
with the homecoming conditions that immediately threaten his individual plans. He copes with his reaction through avoidance, in this case simply getting out of the situation.

Similarly, Allen's response to his brother's prompt to tell them "all about the war" is to joke his way past it. While Allen's reaction might be seen as putting the war behind him, it can also be seen as an avoidance response of not wanting to talk about his many war experiences in the detail necessary to clarify the differences between his and others' perspectives on his goals. Thus, when Clint's choice of wording effectively distances Allen from his personal war experiences by suggesting they are "all about the war" (rather than Allen's own experiences), Allen chooses to say nothing further, leaving an awkward silence. Instead, Allen approaches his mother, takes her hand and sits on the arm of her chair. His actions suggest an unwillingness to talk about his war experiences while allowing him, his family, and the audience, to set these experiences aside. His decision to keep his individual experiences from becoming known also tacitly implies that "all about the war" is an appropriate way to talk about his—or anyone's—-military service.

Responses suggesting reexperiencing or reliving a traumatic event are introduced as part of the Allen construct on his first day back at his old job. In this scene we see hyperarousal and reliving stemming from Allen's war experiences. A quiet, slumping Allen shows up at the factory. Parker is showing Allen to his office when we hear a nearby explosion. Allen exhibits a startle-response to the sound, flinching as though it were artillery exploding. Seeing that his boss takes the explosion in stride, Allen admits his reaction looked strange and he links it to his combat experiences and the instinct to look for "the nearest dugout." Parker brushes off Allen's physical reaction, protesting that surely a blast would not startle him, thus articulating a popular expectation that a veteran would be accustomed or 
desensitized to explosions. Allen's reexperiencing response, however, suggests he is more sensitized because of what happened to him in combat. Parker points out the explosion came from a construction site visible from Allen's office window. As this information sinks in, that the blast was not an effort to destroy human life, but to "build, construct, create" as was Allen's career plan, Allen's reaction changes. His posture straightens, his eyes widen, and he appears enlivened as he moves to the window to see the construction site. Parker leaves, and Allen continues to gaze at the construction site, the scene fading out as he mindlessly flips through piles of paperwork.

Later in the film, avoidance/numbing and reliving/reexperiencing occur together. Not long after Allen's prison sentence begins, he watches the warden threaten a sick prisoner with a thick leather whipping strap and growls "the skunk" loud enough to be heard. The remark earns Allen the beating that would have gone to the sick man and he endures the lashing silently, without screaming out in pain as another prisoner did before him. This violence imposed by the authority of the legal system and carried out by those subject to that authority, here the warden and convicts, parallels the hierarchical violence of the state in which those in power declare war and citizens go to the battlefield. Allen's ability to endure the beating can be interpreted as his refusing to submit to unjust authority or refusing to give up on his personal experiences, but it can also be interpreted as both avoidance/numbing and as reliving in the sense of doing his soldierly duty to defend others. Allen seems emotionally numb to the cruelty imposed on his body, as though he is reexperiencing life and death combat conditions. His outward manner reveals his strength and determination to survive and win the battle over who will define his individual character - the post-war Allen or the indifferent warden. The unresolved question is whether or not he gives up his 
personal dream and the very desire to be free. He bravely performs his duty to receive the beating in place of the other man, who is saved from this violence (the battle) even if not from the prison system (the war). In combat, Allen's actions lead to his being awarded a medal for heroism. In civilian life, they lead to Allen being the victim of more violence.

Avoidance/numbing also surfaces in Allen's relationships with four women who enter and exit his life. Although this film was made five decades before the diagnostic criteria for PTSD would define an avoidance/numbing group of symptoms, the filmmakers recognized, at some level, that relationship failures were a reasonable part of this veteran's story. All four relationships contribute to a veteran myth grounded in posttraumatic stress and resulting in criminality: the failure of one (Alice) is directly tied to his veteran status and his changed goals and the remaining three (Linda, Marie and Helen) fail due to his criminal status, in which his behaviors and responses to situations resemble PTSD symptoms.

The relationship with Alice begins as a traditional story of boy meets girl, boy goes to war, with a presumed ending that girl and boy reunite after the war and live happily ever after. However, when Allen arrives home, Alice is disappointed in his civilian appearance because what she expected was a decorated soldier in uniform. Alice was part of his pre-war life and because Allen defined different post-war goals than what was expected of him, his relationship with Alice is severed at the train station.

The second woman, Linda, is a prostitute with whom Allen has a one-night stand at Barney's club after his first escape. Although Allen resists letting Linda in on his story, he does not resist her sexual advances after he realizes she is not seeking to have a claim on him. She is an ally and tells him he is "among friends." As a prostitute, Linda is on the wrong side of the law, so Allen's belonging in her company is an essential component of the 
criminality myth. This redefinition of his peers from his fellow returning soldiers to the gamblers and prostitutes at Barney's reinforces his decline from hero to criminal.

The third relationship, with Marie, lasts for several years. After the fugitive Allen reinvents himself under the alias of Allen James, he builds a successful career and marries Marie, who is a sexual dalliance for him as he is a financial resource for her: "You know it wasn't love as well as I do," Allen tells her when she demands more attention from him. After he decides to find a new place to live, Marie finds the letter from Allen's brother and discovers he is on the run. Saying she would be less likely to turn him in if she were his wife, she uses the information to force him to marry her. After they marry, her presence is mostly off screen with the exception of their last argument about his insisting on a divorce and her promise to turn him in to authorities.

The fourth relationship begins as Allen has built a successful career and appears to be achieving his goals. Allen falls in love with Helen and wants to marry her, but the dialogue when he first meets her further suggests Allen's avoidance. Explaining why she is the only guest besides Allen not on the dance floor at a night club, Helen announces that she does not like dancing "in such a crowd," to which he responds, "I don't like crowds anywhere," an admission of the avoidance symptom-like response. While Allen enters a love-based relationship with Helen, he is unable to maintain it, and it ends after Allen's second escape as he cuts his last tie to society.

PTSD symptom-like behaviors and responses also motivate changes in Allen's employment story. A scene leading to Allen's departure from the factory job to pursue a new career shows the dramatic range in his state of arousal, from uneasy resignation of his goal and going through the motions of the factory job routine to a high degree of anger in 
response to his family's inability to understand his career dilemma. The scene includes two symptoms of hyperarousal: sudden anger or irritability and problems with concentration. As the scene begins, Allen's family is finishing supper without him. They are worried because Allen is often late for work, and, as his brother Clint points out, he has been 'loitering around that new bridge for no reason at all." Clint's phrasing indicates a stark difference in perspective between how Allen understands his attention to the bridge-building site and his family and employers understanding: while Allen sees it as a tangible link to his preferred career and of his freedom, others see it as evidence of a poor work ethic and lack of appreciation of society's generosity. When Allen finally arrives home he appears worn, tired, and generally disinterested in the daily routine but joins them at the table at the request of his brother. Clint points out Mr. Parker's disappointment in Allen and his work, thereby attempting to strengthen his own argument by leveraging society's perspective through an authority figure.

In hopes of explaining himself to his family, Allen argues, "I just can’t help it." Trying to understand his frustration, his mother expresses concern that Allen is "not well," but he assures her that "it isn't that, Mom, I'm all right" finally telling her, "I try my best when I get there but I just can't concentrate." Allen reminds them he had other plans for himself after the war and that the factory job is "not the kind of work I want to do, and I said so when I came home. It's too monotonous.” When Clint persists, remarking, “you don’t seem to realize...," Allen cuts his brother off and erupts out of his chair in anger. "That's it, realize," he exclaims, as he becomes visibly more agitated, speaking loudly but mostly to himself. His anger continues to grow as he sees this is how to explain to his family that his war experiences are incompatible with the factory routine. He counters Clint's words, insisting, 
"No one seems to realize that I've changed, that I'm different now." Pacing, he jams his hands into his pockets as he attempts to describe his transition from a soldier to a civilian. “I’ve been through hell!' he exclaims. "Folks here are concerned with my uniform, how I dance. I'm out of step with everybody. All the while I was hoping to come home and start a new life, to be free, and again I find myself under orders, a drab routine, cramped, mechanical, even worse than the army." Unfamiliar with this level of agitation, his family sits stunned by the outburst. But Allen is not finished, and this time he raises the stakes of his argument, bringing it to a peak in a summary of his civilian, post-war, struggle: "I've learned that life is more important than a medal on my chest or a stupid, insignificant job." Not comprehending Allen's rage or argument, Clint tries to interject, but their mother stops them both, commenting, "He's got to be happy. He has to find himself." This show of support effectively releases Allen from the constraints he has been trying live within. Significantly, this outburst changes the direction of Allen's story and he leaves the factory to find a construction job.

During an argument with Marie, another outburst dramatically changes the direction of Allen's life. His anger grows with the awareness that he is again trapped, this time in his marriage, and forced to set aside his own goals. He calls her bluff and she storms out of the room, promising to make him regret his anger with her and setting the stage for the next scene. It begins with the confident returning soldier evident in Allen James the engineer. It is this Allen who is meeting with city officials on a proposed bridge project when detectives barge in to arrest him. The confident relaxed composure of alias Allen James the engineer changes quickly to the anxious tension of James Allen the fugitive. 
After he is taken into custody, Allen demonstrates a heightened alertness to danger, or hyperarousal. In a jailhouse scene, he is being interviewed by a mob of reporters. Allen has built a good reputation with city officials and initially answers questions freely, suggesting he trusts that the reports are on his side in his fight to be free. With his hands jammed into his pockets, in a manner that recalls a confrontation with his family years earlier, he admits that he wants "this rotten chain gang system exposed." However, his demeanor and gaze notably change when he is asked a question suggesting he could return to the chain gang. A photographer snaps a picture at the moment. Allen visually scans the mob of reporters. His facial expression changes and he looks threatened by the mob, as though their enthusiasm were dangerous. He responds as though the question implies that he will in fact be returned.

Perhaps the most highly charged scene of hyperarousal, tainted with suggestions of reliving/reexperiencing, occurs after Allen is back in prison and appealing his case. Clint gives him the news that he has lost his appeal. Allen is enraged at the State, whose "crimes are worse than mine; worse than anybody here!" and he vows to his brother, "I'll get out of here! Even if they kill me for it!" Allen grasps the bars that separate him from his brother, his only tenuous link to his freedom. The desperateness of his situation is visible in his trapped body and tortured voice: tightly framed in a small window, all we see of him is his face and hands; the rest of his body is hidden behind prison doors and bars. His brother convinces Allen to sustain his commitment to be "honorably free" by serving out the year. Allen, by sheer force of his own will, contains his rage and surrenders to the new terms. He no longer sees his incarceration as paying for a crime through harsh punishment, but as revenge by the State for his having escaped the accepted rules and norms of punishment. 
Near the end of the film Allen exhibits another intense reexperiencing sequence after his second escape. The scene begins at a prisoner work site and concludes after Allen destroys a bridge. At the work site, Allen and fellow prisoner and friend Bomber attempt an escape by stealing a prison worksite dump truck. They speed away from the chain gang while guards shoot at them from several guard posts. A carload of guards chase after them. The elder Bomber uses dynamite to slow the guards by blasting a hillside that crumbles onto the narrow road. Bomber falls from the speeding truck after they cross a bridge over a deep ravine and Allen goes back for his fallen friend, but it is too late. Bomber is bloodied and lifeless on the side of the road. As he assesses Bomber's condition, Allen's facial expression is emotionless and distant. He stops fleeing and shifts into combat mode. Allen must disregard the loss of his friend and continue the fight. He retrieves some of the dynamite from the truck and destroys the bridge before the guards can cross. The next camera shot is a close-up of Allen's face. His eyes are wide and alert, and his posture shows he is poised and prepared for more fighting. Allen succeeds in his prison escape by reliving and reexperiencing combat both physically and psychologically.

\section{Veteran Myth from James Allen Representation}

A veteran myth begins to appear through the James Allen representation early in the film through the developing image of Allen as a returning soldier. Initially, James Allen is associated with qualities such as confidence, competence, likeability and heroism that are in turn linked to the nation's victory in the war. These qualities also resonate with the monumentality myth. Not only are these the qualities of the veteran, they are also the qualities of the nation. Additional behaviors and reactions that resemble the criteria and symptoms of PTSD replace these qualities, and it is through them that he moves to criminal 
then fugitive status. Ultimately, despite the film's sympathetic stance, a veteran myth of criminality of James Allen is evident in the image of the veteran as a fugitive from society's civilian norms. We see hyperarousal in Allen's quickness to become excessively angry when compelled to live a life that meets other's expectations him. We see avoidance and numbing in his refusal to talk about his war experiences and inability to develop and maintain close relationships. We see reliving and reexperiencing demonstrated by episodes of combat flashbacks. Ultimately, the effects of PTSD symptom-like responses leave Allen living in perpetual trauma: "no friends, no rest, no peace; that's all that's left for me," he says to Helen before backing away from her and the audience in the final scene. When Helen shouts to him asking how he will get by, he shouts to her from the darkness, “I'll steal!” Thus Allen's last words in the film confirm the image of him living not only in perpetual trauma but also as a perpetual criminal.

The audience's final glimpse of Allen in the final scene (Figure 2.4) is markedly different from the first (Figure 1, above). The final scene is introduced by a fade-in of a newspaper editorial. It indicates a year has passed since Allen's second escape. The headline reads, "What has become of James Allen-Is he, too, just another forgotten man?" Allen's future, so full of promise at the beginning of the film as a returning veteran, has dramatically changed to one that is both unknown and unseen at the end of the film. 


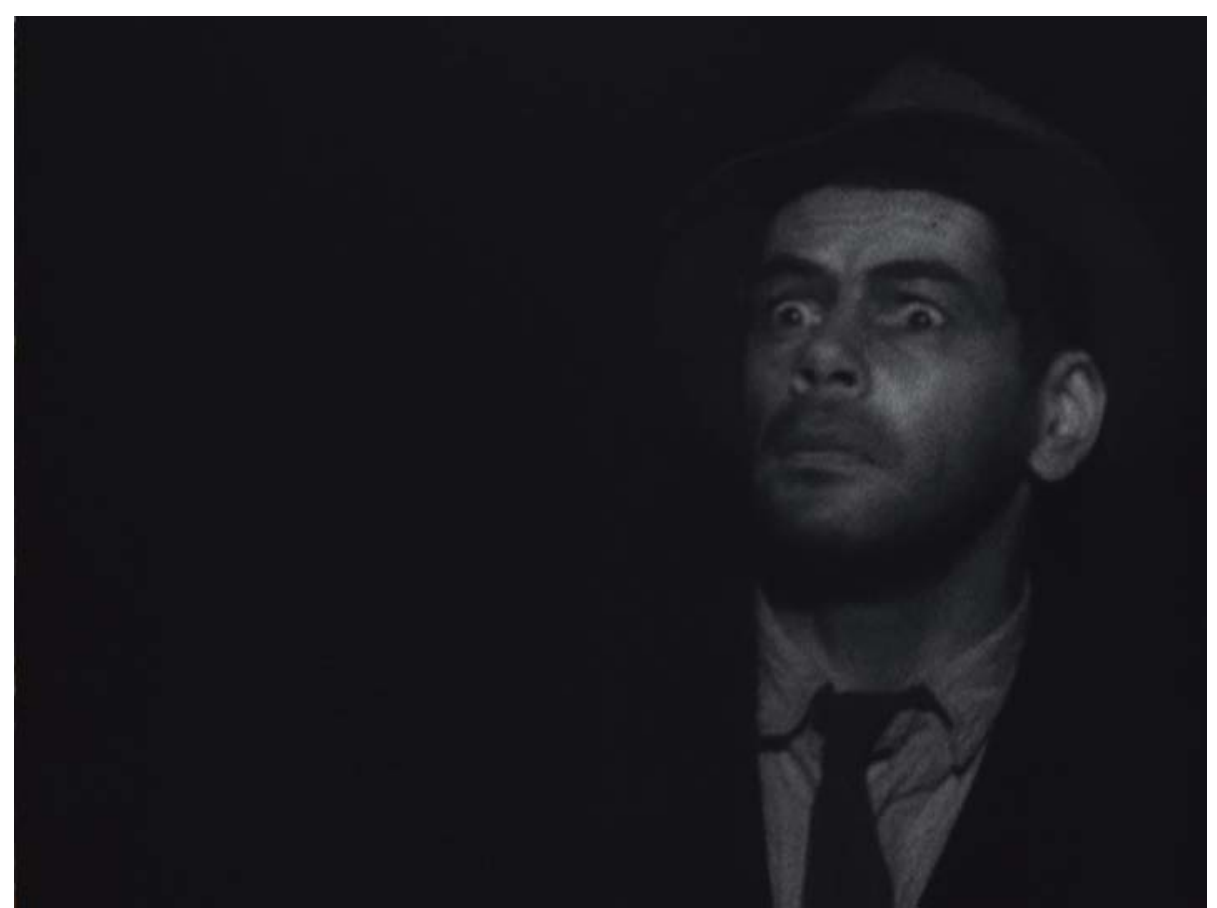

Figure 2.4: James Allen in the final scene of I Am a Fugitive from a Chain Gang (DVD screen capture, I am a Fugitive From a Chain Gang).

In multiple ways, I Am a Fugitive from a Chain Gang can be interpreted as typical of popular culture discourse about veterans in general, and as especially appropriate within the social norms during this period for the representation of a WWI veteran. This veteran falters to the point where he becomes completely marginalized; significantly, each step toward the margin is triggered by the behaviors and responses that are similar to symptoms of what will, six decades later, be called PTSD. The leadership Allen developed during his service goes unrecognized by his brother, who insists Allen return to his pre-war job and his pre-war social position. However, Allen becomes an accomplished engineer as a fugitive living under his alias, Allen James. The history of his veteran status is set aside in the film's narrative but is not erased from his story; it is critical to his downfall. Allen's inability to conform after the war to what was expected by others supplies the rationale to build unsociability into the heroic veteran character. The film expresses this by criminalizing him and sentencing him 
for armed robbery. Even though the audience sees Allen had been tricked into being party to the crime, he still becomes a prisoner. He becomes a fugitive only because he seeks his freedom. Without Allen fighting for freedom as a soldier, the fight for freedom from prison would have been less dramatic.

After WWI, terms such as combat exhaustion and battle fatigue were in circulation, so Clint's perspective that Allen is "tired" and that "a good night's sleep" will help him return to a normal, pre-war routine would not have been an unreasonable expectation. However, Clint's suggestion has a different effect on Allen, who becomes tense and aggravated as the resourcefulness and stability he demonstrated and were valued in the army have little influence at home. Allen's veteran status at the beginning of the film as someone competent is displaced by his incompetent performance at the factory job from an outsider's perspective (that of his family and his employer). Allen the competent veteran is not erased — it is essential to his attempt to build his engineering career while a fugitive- but the expectation that he would leave the war and all of his wartime experiences behind creates conflict that sets in motion the changes that provoke the armed robbery, prison sentence, and unsuccessful fight to be free.

In I am a Fugitive from a Chain Gang, Allen's goal of individual freedom is as worthless to his brother, boss and the judicial system as is the heroism medal. Equally without value is Clint's testimony of Allen's honorable service during his appeal hearing. Allen has a drive "to be free" that is justified in the film by his personal goals and contrasts with his lack of freedom on the chain gang, and it is this drive that becomes a reasonable catalyst for his escapes. Further, his work ethic as a fugitive displays the competence indicated by the returning soldier on his trip home, but this freedom is an illusion and easily wiped away 
when Marie calls the authorities. These aspects of the representation are only possible because of Allen's combat veteran status. A veteran myth of criminality, then, is built on Allen's characteristics as a combat veteran, and the subsequent obscuring of those characteristics, with the additional meanings of the convict and fugitive roles that redefine him for the remainder of the film and result in his complete marginalization from society. Further, the process relies on Allen's actions and responses to events in ways aligned with the symptoms of PTSD; these symptom-like actions and responses motivate the critical direction changes in the narrative as it builds a veteran myth of criminality. 


\section{World War II Veterans Al Stephenson and Fred Derry}

The introductory segment of The Best Years of Our Lives orients the audience to three post-war sociocultural situations that represent the particular challenges for society and the returning veterans that circulated in popular media after WWII. Each broadly shared idea of a veteran's return is addressed through one of three veteran's stories that make up the film. Each story identifies different veteran characteristics that ultimately construct one overriding veteran myth of psychosimplicity. Homer's story is centered on the psychological adjustments to permanent physical injuries and what veterans and their families needed to do to come to terms with the injuries, a challenge that is ultimately met through simple adaptation and acceptance. Al's story centers on his personal struggle to reconnect emotionally with loved ones and find his way through a socio-economic conflict between the value of individual character and the profit motive of banks that threatens his job, a dilemma that is resolved through simple assertiveness. Fred's story centers on personal perseverance: he struggles to find his wife, a job and a place for himself in his hometown and is successful because he simply matures.

Because the Homer representation entails a physical injury and so falls outside the selection criteria outlined in chapter one, my analysis examines only the Fred and $\mathrm{Al}$ representations. $\mathrm{Al}$ and Fred leave the war physically uninjured, but both carry lingering effects, a sort of residue from the war that needs to be cleared away before they can successfully adapt to life after the war. In The Best Years of Our Lives, a veteran's homecoming, saturated with and dependent on PTSD symptom-like responses, is a process of readjustment. The process takes time, and in the film is crafted to meet the Production Code 
by incorporating traditional Christian morality, marriage, a happily-ever-after ending and a veteran myth of psychosimplicity.

\section{Film Synopsis: The Best Years of Our Lives, 1946}

We meet Al, Fred and Homer after the end of the war as they are on the final leg of their journeys to their hometown. The first of these three we encounter is Fred. He is in uniform and carrying heavy duffle bags, and we presume he has just arrived from overseas as he enters an airport terminal (Figure 2.5). The busy airport has no available flight home so he tries ATC (Army Transport Command) across the airfield to catch a flight from there.

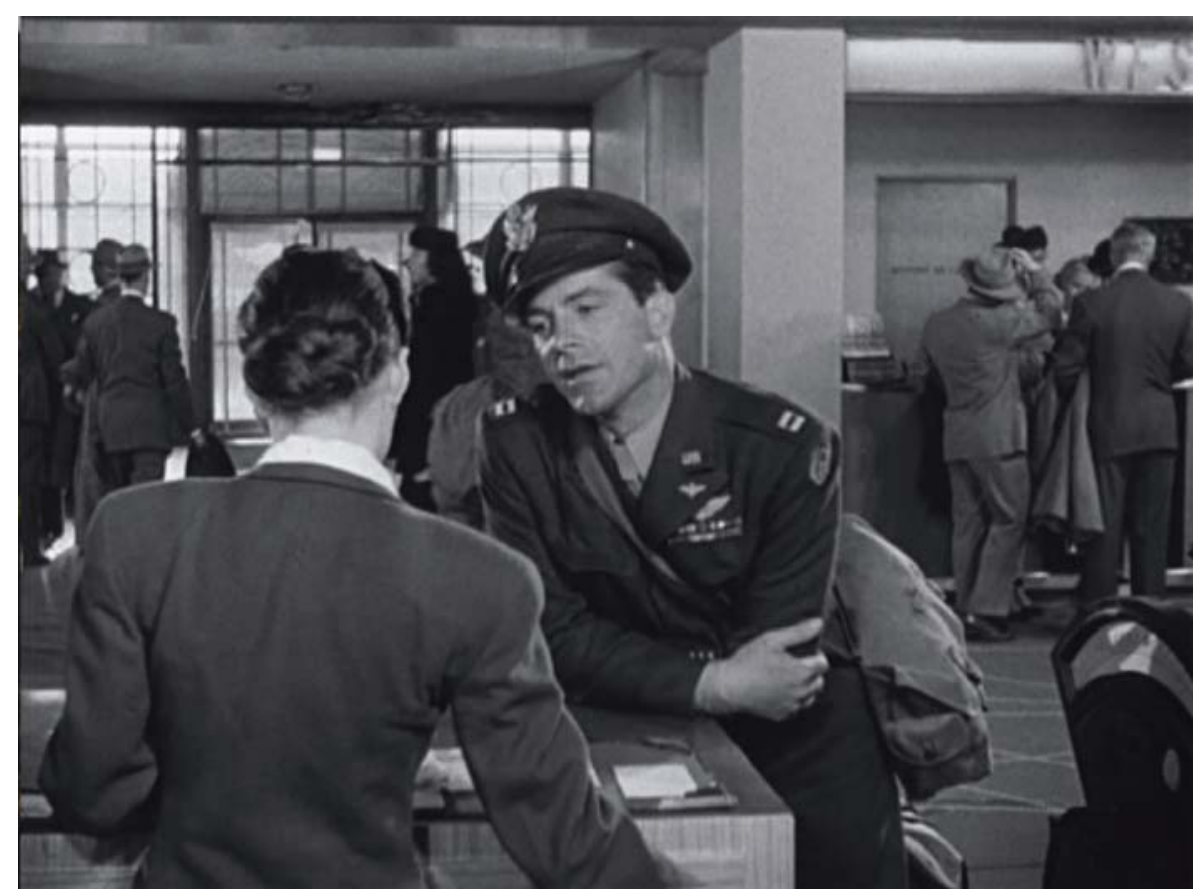

Figure 2.5: First image of Fred Derry at an airport after arriving in the United States (DVD screen capture, The Best Years of Our Lives).

As Fred waits on stand-by he finds a seat while several servicemen respond to a request to move some equipment. Homer, a returning sailor who has been sitting against a wall with his hands in his pockets and is waiting also, is briefly hassled by an airman. The sailor's demeanor is quiet and unmoving, yet we can see by the way he shifts in his chair and looks 
at the servicemen that he is aware of the harsh remark. Later, when a flight is announced, both Fred and Homer hurry to sign on. Fred signs the sheet first, saying excitedly, "Boy, it sure is great to be going home," and hands the pen to Homer, who removes a prosthetic hook from his pocket and takes the pen. "Sign on the dotted li..." says the clerk as he notices the device and then awkwardly offers to write Homer's name for him. He brushes off the offer, kidding, “What's the matter? Think I can't spell my own name?” This only makes the clerk more nervous saying "No, I, I just thought..." but Homer goes easy on him with a forgiving, "I know, Sarge." As Homer starts writing, he pulls out his other hand, also a prosthetic hook, to hold the paper still. The clerk and Fred glance uneasily at each other, seemingly unsure what to do or say. Fred's facial expression is one of shock at seeing the loss of Homer's hands, but this initial reaction fades when he recognizes Homer shows adept skill at using his prosthetics and an independent attitude. Fred, recognizing the independence Homer displays, behaves toward Homer as though he were any other returning soldier. As they toss their bags in the plane, the ruckus wakes $\mathrm{Al}$, who is already on board (Figure 2.6). The men introduce themselves and the interaction allows Al's character to be introduced. Fred once again is an observer. He watches the first interaction between Homer and $\mathrm{Al}$ when Homer reaches to shake Al's hand. Al quickly overcomes his surprise and shakes Homer's "hand" as he would any other man's. When Fred asks Al how long it's been since he has been home, Al lightens the mood, saying, "oh, a couple of centuries," and puts the men at ease with each other. The introduction sequence shows Fred as a leader with a higher military rank than the other two, $\mathrm{Al}$ as a hardworking man dedicated to his unit, and all three of them as resilient. These character traits become essential components of their individual homecoming stories and personal challenges. 


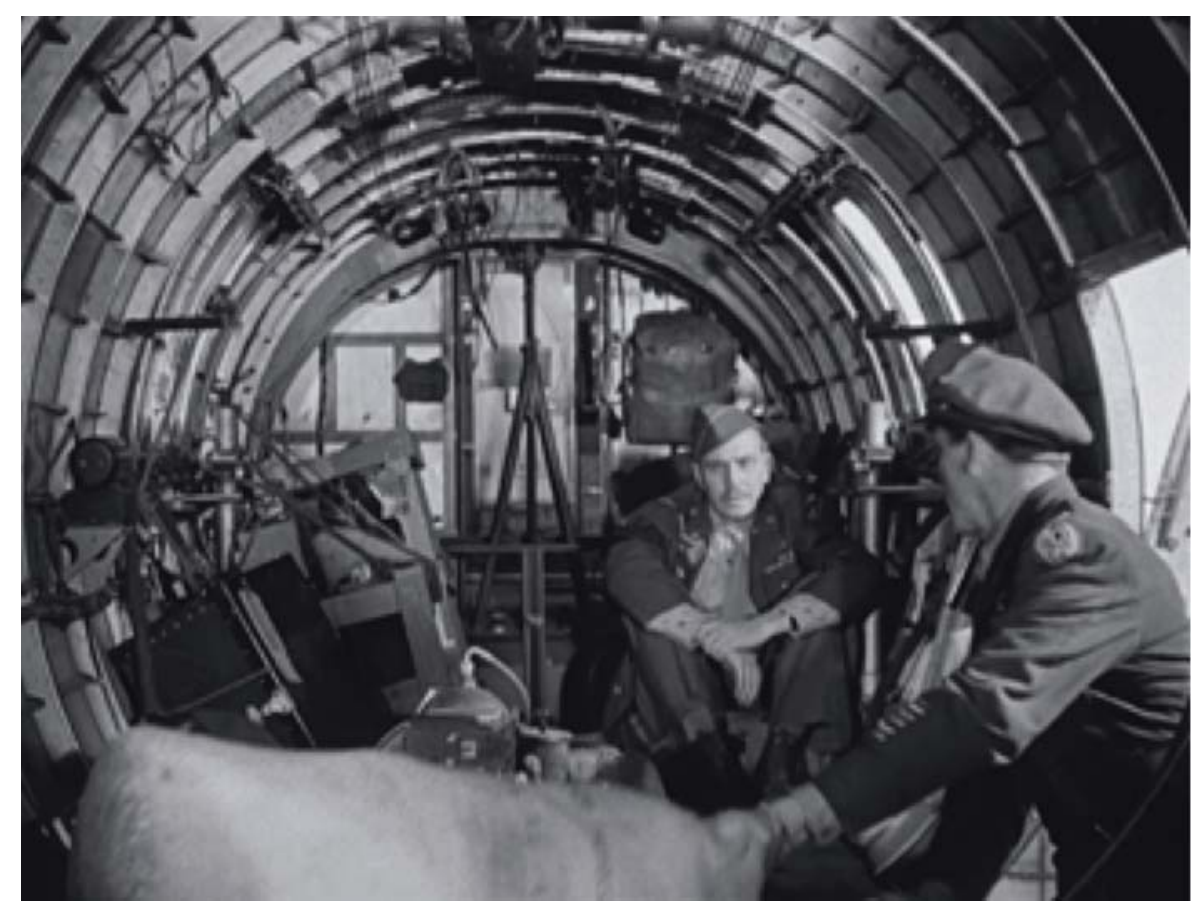

Figure 2.6: First image of Al Stephenson (facing the viewer) upon returning to U.S. (DVD screen capture, The Best Years of Our Lives).

The men settle into a former military plane and introduce themselves. Fred moves through the aircraft with ease and familiarity. He was a bombardier in the Air Force and suggests they ride up in the nose of the plane and look out from the place that, as he tells them, "used to be my office." On the long flight, they express both eagerness and anxiety about going home and in the process, give voice to the ideas about veterans that await them. Fred shrugs off his concerns of being "nervous out of the service, I guess," and Al shakes his head, worriedly pointing out that he expects "everybody's gonna try to rehabilitate me." As Homer dozes, the sleepless $\mathrm{Al}$ and Fred share mutual concern that Homer's return may be much more difficult than theirs.

The next day they fly over Boone City on approach to the airport. A tone of nostalgia creeps into their voices as they speak of how little the town has changed during their deployment. Fred unwittingly foretells the life that awaits him, saying the town looks "just as if nothing had ever happened." As the airplane turns to approach the airport, the three men 
notice an enormous aircraft graveyard filled, as far as they can see, with junked warplanes. They talk comfortably about the war for a moment, but then their tone changes back to nostalgia, this time for the war.

After landing, the three share a cab. Homer is driven home first. Anxious, he suggests they go back to Butch's Place, a pub owned by his uncle that they passed by on the way from the airport and a location they return to later in the film. After Homer exits the cab, Fred and $\mathrm{Al}$ are relieved to see Homer's young sister excitedly run from their family's house to the house next door where Homer's girlfriend Wilma lives to announce Homer's arrival. Their worries return after Homer's mother sobs at the sight of the hooks and they see him stand stiff and unresponsive to Wilma's embrace. In the cab, Al grows increasingly anxious the closer they get to his apartment building. His tension is clearly visible in his agitated body language as he sits at the edge of the seat, wringing his hands, jittery eyes darting from under his furrowed and darkened brow from the driver to Fred to the road ahead. He, too, attempts to delay his return home, but Fred refuses to change course, and drops off Al, who looks almost longingly after the cab as it drives away. Fred, the highest ranking of the three, returns to the poorest neighborhood. The small home is unkempt and deteriorating and freeway ramps darken already dreary surroundings. Fred learns his wife has moved out and taken a job, so he goes out to find her. Thus, by the end of this first sequence, each of the three soldiers has arrived home, the point of separation from the military, to begin their transition to civilian life as veterans.

After watching Fred ride off in the cab, Al goes up to his apartment. The apartment desk clerk does not recognize $\mathrm{Al}$ and tells him to wait so he can be announced to Mrs. Stephenson. You're Mr. Stephenson?" asks the clerk, emphasizing the "Mr." After seeing the 
clerk's surprised expression, Al quips, “What'd you expect, a four-star General?” as he heads for the elevator. $\mathrm{Al}$ is a sergeant, a military combat rank comparatively below his upper-class civilian rank. The harshness of his tone suggests he clearly understands both ranking systems and how visual cues are used to quickly assess social rank and a man's reputation and position within the social order. As an employee in the banking industry, Al realizes a man's reputation helps define his socioeconomic stature or personal trustworthiness, which translates to a personal value, a sort of collateral, used as a predictor of his ability to repay loans. The conflict between rank/class and reputation/value is central to Al's post-war employment dilemma.

$\mathrm{Al}$ also faces the challenges of returning to family life and his relationship with his wife, Milly. She shows much patience with Al's post-war behaviors, mainly his excess drinking, which leads to the main conflicts that play out though his story. His drunkenness helps him avoid intimacy with his wife, provides situations that lead to his daughter becoming romantically involved with Fred, and also affects his judgment as a banker, which puts his job at risk. Each conflict results from Al's PTSD symptom-like behaviors and each conflict is fully resolved by the end of the film.

Both $\mathrm{Al}$ and Fred face challenges on personal and public scales. While Al's play out in an upper-class social scene of the 1940s, Fred grapples with overcoming the harsh realities of having grown up in poverty and having committed indiscretions as a youth. As does Al, Fred has difficulty reconnecting with his wife Marie, literally and figuratively: first he is unable to physically locate her, and second remains emotionally disconnected from her because Marie wants him to remain the uniformed soldier that she married. Fred and Al struggle for different reasons in their personal lives and their employment. Al and Milly were married for 
twenty years, have two grown children, know each other very well, and need to find their way back to emotional intimacy after being apart for so long. Fred and Marie married very young while he was in training and barely had time to get to know each other before he went to war. Al's employer promotes him after his return, but $\mathrm{Al}$ struggles with how to incorporate what he learned about the integrity of men from his war experiences into his job as a loan officer at the bank. Fred's struggle is to find his way in society as a man after leaving as barely more than a boy. Before the war he had a teenager's job working as a soda jerk in a drug store and was still living at home, so when he went off to the war he left Marie behind to live with his parents. He has a great deal of trouble finding work because his only adult experience was as a bombardier. When he does find a job, he ends up getting fired. He and Marie fight constantly, and he falls in love with Peggy, Al's daughter, which causes tension between him and Al.

Eventually, $\mathrm{Al}$ manages to apply what he learned from his war experiences to his banking job. Fred, every dimension of his personal life and employment in disarray, decides to leave town but then has a change of heart at the airport as he waits for a flight. This change is precipitated by a sequence of events that take place in the warplane graveyard that he, $\mathrm{Al}$ and Homer talked about on their trip home. The events allow him to confront and purge his war memories and PTSD symptom-like responses that are causing him to fail. He decides not to leave after finding a job with a contractor who is recycling the planes into prefabricated homes.

Homer's story is one of triumph as well, as Wilma, sticks with him and demonstrates she has the courage to meet the challenges posed by the loss of his hands. The film's final 
sequence shows Homer and Wilma getting married, Al fully recovered from his drinking problem, and Fred and Peggy reuniting after his divorce from Marie.

\section{Seeing Al Stephenson and Fred Derry as Combat-affected Veterans}

The Best Years of Our Lives tells three veterans' stories as part of a larger portrait; they are “representative of some larger truth for returning veterans" (Early 15), of society's post-war concerns centered on reintegrating veterans back into civilian society through the combined efforts of the veteran, his family and friends, and the business sector. The PTSD symptomlike responses of Fred and Al, including avoidance/numbing, hyperarousal, and reliving/reexperiencing, are a significant part of their veteran constructs as they are transitioning from one social action (soldiering) to another (participating in civilian life). All three veterans "become 'nervous out of the service' in their own fashion" (Early 15). The ease with which each veteran's posttraumatic stress dilemmas are resolved reveals a veteran myth of psychosimplicity. I use this term because, although the myth constructed in this film does recognize that combat veterans face difficult and unique psychological challenges due to their war experiences, their challenges are resolved due to letting go of the war and the passage of time, which allows them to experience the hardships their post-war frames of mind cause so they can see that they are making choices that are detrimental to them. Once they chose to "get over it," in other words to let go of the traumatic effects of combat, they all move on with productive and happy lives. Before this optimistic conclusion, each man must first work through several conflicts that provoke PTSD symptom-like responses, which are not only residue from the war but also integral to their recovery of mental health and reintegration to successful lives. Al's drinking paves the way for his speaking his mind about bad banking policy. Fred's constant conflicts lead to the warplane graveyard where he purges 
his war memories. In this way, the film constructs a veteran myth of psychosimplicity, which entails the idea that veterans can control the symptoms of combat trauma. In summary, psychosimplicity suggests a decision-making process in which the veterans work through their post war difficulties by simply deciding to let go of the trauma of the war and refocusing their effort from dealing with post-war dilemmas to exercising socioeconomic productivity and leading moral and socioculturally acceptable personal and public lives.

\section{Avoidance/Numbing, Hyperarousal, and Reliving/Reexperiencing}

We can see avoidance/numbing responses in both Fred and Al. In the scene where Al arrives at his apartment, he hesitates before approaching the door and pauses again before ringing the bell. When his son opens the door, Al quickly quiets his son's excitement and does the same with his daughter Peggy, explaining that he is trying to surprise his wife. His arrival is early, days before what he had messaged to them, and so undermines any plans his family might have had for a welcome home party. By arriving ahead of schedule and suppressing his family's excitement, $\mathrm{Al}$ exhibits an avoidance/numbing response.

In the home environment Al's appears ill at ease, suggesting a hyperarousal response. Noticing his discomfort, Peggy attempts to put him more at ease, saying, "You'll get us back to normal" before she and her brother leave their parents alone. After her exit Al grumbles mostly to himself, but partly to Milly, "or maybe go nuts myself." His words and demeanor create a stark contrast with his daughter's enthusiastic optimism, as though the outcome of his battle to come home is as uncertain and chaotic for him as the battles he fought in the war.

The uneasiness quickly changes to a numbing response as $\mathrm{Al}$ and Milly both become aware they are alone. Al lights a cigarette, giving him something to do other than face the 
intimacy of being alone with his wife. Milly watches him warily and invites him to talk about the kids. Milly's effort backfires and triggers memories of the young soldiers Al served with, a reliving/reexperiencing response as he tells her that even the young soldiers "were all old men like me," and describing youth as "painful" and "frightening." Milly tries again, but triggers irritability rather than relaxation. She invites $\mathrm{Al}$ to sit down, but he snaps that he is “perfectly relaxed standing up.” He wonders aloud and with increasing aggravation in his voice, if there is "such a thing as a drink in this house?" Milly leaves the room to get him a drink and Al's facial expression shows both relief for the reprieve from the intimacy that confronted him and regret that his actions caused his wife to retreat from him. In one respect, both Peggy and Milly are trying to rehabilitate him, exactly what he expressed dread about on the flight home. Peggy tries to change how he feels about being at home, and Milly provides a direction for him to take.

Moments later, Al exhibits avoidance/numbing in dramatic fashion. As Peggy comforts her visibly shaken mother in the kitchen, $\mathrm{Al}$ suddenly bursts through the door, his aggravation replaced with exuberance. In a behavior that allows him to avoid feeling the turmoil of a homecoming that is to him similar to battlefield chaos, he also effects numbing by insisting that the three of them go "out on the town" to "celebrate the old man's homecoming." Not taking no for an answer, he ushers the three of them out of the apartment. In opting for a public display of celebration, the problem of personal and private intimacy is averted. Social norms, as seen here, support and nurture the numbing symptom. Al drinks heavily throughout the evening, ultimately bringing Milly and Peggy to Butch's Place and so confirming his continued need to extend his reprieve from the intimate home environment. The fact that $\mathrm{Al}$ is drawn to this place, which Homer pointed out on the cab 
ride home from the airport, suggests that he seeks the companionship of the soldier's shared anxiety about homecoming.

As it turns out, both Homer and Fred are already at Butch's Place when Al arrives. By the end of the evening they are both falling-down drunk, and Peggy and Milly can finally take them home. Fred's wife is still not at her apartment, so the women bring him home with them and Peggy helps Fred to bed in her room while she takes the sofa.

During the night, Fred has a reliving/reexperiencing symptom-like response in which a traumatic combat mission replays in vivid detail as he sleeps. Through Fred's nightmare we learn not only some of the details of his war trauma but also that the trauma stays with him after the war. The scene begins with us watching a sleeping Fred grow increasingly restless. Vague sounds of airplane engines fade in and out of the soundtrack. The camera closes in on Fred's growing unrest and he begins mumbling in his sleep. At first his words are inaudible but become clear as his dream intensifies, "[inaudible] ... on fire. She's on fire!” The camera cuts to the living room. Peggy wakens to Fred's utterances, which are growing louder. She goes to him and as she opens the door to enter the roar of airplane engines suddenly becomes a prominent part of the now very loud soundtrack. Peggy sees Fred is in the midst of a nightmare and shakes him, yelling for him to wake up. He sits up when she tries to rouse him, but is still sleeping and shouting. His eyes are wide, his face is covered with sweat, and his hands grip the bed covers as the intensity of his nightmare continues to increase. Fred yells, "Gadorsky! She’s burning up! Get out! Get Out!," and then with an agonized tone, "She’s gonna hit! Look out!" Peggy covers Fred's eyes and we infer that the plan crashes with Gadorsky on board. Fred sobs as the episode of reliving the bombing run and reexperiencing the death of his friend comes to an end. Peggy tries to comfort him and 
although Fred turns away from her efforts, the reassurances appear to alleviate some of his distress. He resumes a more peaceful sleep, having never fully wakened to his present, civilian surroundings. In the morning, the anxiety and helplessness that overtook Fred in his sleep are gone, and he has little recollection of the drunken night's events. In a fully awake state, Fred appears unaffected by the trauma.

Fred's reexperiencing/reliving this same battle occurs at a different level later in his story after he finally meets up with Marie. Similar to Al, Fred has little success reuniting emotionally with his wife, but the film's narrative attributes the difficulties for Fred and Marie in part to the brevity of their relationship, since they married only a few weeks before he went overseas. Another part of their difficulty stems from Fred's perceptions of how he and his hometown have and have not changed during the war. In the scene of Fred and Marie reuniting, there are suggestions of avoidance, reliving and numbing responses. Initially, Marie is excited that Fred is home, and he appears happy to be back with her, but a disconnect between them is soon notable when he unpacks several photographs. Marie asks about black shapes among the planes, but Fred, instead of explaining to her that they are anti-aircraft artillery explosions, says in a detached, almost nostalgic voice, that they are "little black flowers that grow in the sky." His reflective intonation suggests this is the way he and his buddies referred to them and that he is experiencing a less traumatic flashback. At the same time his detached tone of voice and use of the flower metaphor suggest numbing through his inability to share the truth of war with Marie.

Fred exhibits several symptom-like responses in rapid succession in a subsequent sequence that situates him between pre- and post-war ideals. In these scenes Fred downplays or numbs his conscious reactions to Gadorsky's death; responds angrily toward Marie when 
they argue about their financial situation stemming from his unemployment, which for him is an unexpected outcome of his wartime performance; and reexperiences the nightmare of the loss of his friend. The sequence is reminiscent of the death spiral that claimed Gadorsky's life: Fred's own life is out of control and he is unable to escape a fiery crash, managing to retain only a small bit of hope. The sequence begins as Fred comes home with groceries, prepared to make dinner for him and Marie. They have run out of money because of his inability to find suitable employment. Marie takes this opportunity to press Fred about whether he is trying hard enough to find a job. She asks if he is "really all right" and then clarifies, "in your mind." Referring to the nightmare, she asks, "What was Gadosky?" Aside from correcting her pronunciation of his dead friend's name and telling her that Gadorsky was "a friend of mine ... he got it over Berlin," Fred appears to take the conversation in stride. Marie continues, "Can't you get those things out of your system?" and then suggests, “Maybe that's what holding you back, you know, the war is over, you'll never get anywhere unless you stop thinking about it." Fred appears emotionally unmoved by Marie's assessment of his efforts, but he becomes visibly irritated when she tells him to "come on, snap out of it," a provocation indicating Marie's indifference concerning Fred's war experiences instead of the patience and compassion that are exhibited by Milly and Peggy. He glares at her and seethes, "Okay Honey, I'll do that." Marie grows irritated too. She wants a life with more fun than Fred is providing, and their argument escalates. She threatens to go out by herself and he physically restrains her. In a sudden outburst, he reveals how the post-war challenges he faces have become for him a new nightmare, saying that he needs to 'Wake up and realize I'm not an officer and a gentleman any more, I'm just another soda jerk out of a job.” 
Fred's life continues to unravel. Reluctantly, Fred takes the only job he can find, returning to the drugstore and the soda jerk job. He falls in love with Peggy and she with him. After $\mathrm{Al}$ convinces Fred that he will do all he can to keep his daughter from being caught up in an affair, Fred ends the relationship. Not long after, Fred is at work and becomes angry when a customer tells Homer he lost his hands "for nothing." Fred punches the customer and loses his job. He arrives at home unexpectedly early, and finds that Marie has a man, also an ex-serviceman, at the apartment. Fred wearily asks him if he has had trouble "readjusting" too. As the man leaves, he tells Fred, "It's easier if you just take everything in your stride." Unconcerned with his wife's infidelity and wanting to socialize, he is unmoved when she tells him she is going to get a divorce and he immediately starts packing to leave Boone City.

While Fred's life continues to fall apart, $\mathrm{Al}$ finds rehabilitation. $\mathrm{Al}$ is welcomed back to the bank where he worked before the war and is offered a promotion to be Vice President in charge of small loans. His boss explains that Al's war experience makes him "invaluable" to the bank because of the GI Bill of Rights and the bank "needs a man who understands the soldier's problems" and the "fundamentals of sound banking." Al soon realizes the two invaluable traits are in conflict with each other. He is frustrated that bank policy requires him to turn down a loan to a veteran who has no collateral with which to secure the loan. $\mathrm{He}$ decides to approve the loan and argues that the man's character, tested in battle, was enough for him and should be enough for the bank because they promoted him due to his war experience. Fellow bankers protest Al's decision and he is nervous about losing his job. His anger that "sound banking" will override the character of the men who fought in the war 
and proved themselves as reliable and worthy of the bank's investment fuels his excess drinking.

Alcoholism is a coping mechanism, a numbing agent and a character trait used to indicate Al's battle with combat related posttraumatic stress throughout his transitional period. It is also the facilitator of his transition from military life to normal civilian life because getting drunk helps him to speak his mind at a crucial moment. We see this transition at the banquet when he is asked to give a speech. Al is intoxicated, and Milly's worry is clearly visible in her facial expressions and in the way she watches him and scratches marks into the fabric of the tablecloth to keep track of how many drinks he has been consuming. As he stumbles to the podium, Milly is wondering, as we the audience are, what will come of Al's speech given that he's just downed his fifth drink. He begins impolitely and it seems likely he will vent his frustrations over lending policies and end up getting fired. But then his language changes as he talks about the strength of character of the combat veteran who applies for a loan, but who is of meager monetary means. Being intoxicated helps him to speak openly to his banking colleagues about policies that tend to overlook the collateral that does not translate directly to dollars. Using an analogy from his war experience, he hypothesizes about soldiers refusing to fight a necessary battle "that involves considerable risk" for which "we haven't sufficient collateral." Al explains they would end up losing the battle and then losing the war. He eloquently argues that the future of the bank depends on investing in the hard work of men whose collateral is earned through their deeds rather than only their pocketbooks.

Al's hyperarousal, triggered by numbing and drinking to intoxication in response to tensions caused by bank policy, highlight that he is functioning in the workplace with PTSD 
symptom-like responses and behaviors. However, his symptoms also facilitate his eventual reintegration into society by creating the conditions in which he manages to incorporate what he learned about men under fire and argues the bank will thrive if they also value these men. Essentially, Al's symptom-like behaviors result in his speech, which essentially outlines an ultimatum for banking practices: that bankers decide whether or not to value the nonmonetary capital of veterans. Changes to lending policies to value the hard-learned dedication, devotion and integrity of the nation's returning veterans would be key to the success of the industry. This idea, not easily realized or voiced by Al, was introduced in the film's narrative when he was offered his post-war job. Until he chose to speak his mind, his PTSD symptom-like behaviors were hindering his productivity leaving him drunken and alienated. Once $\mathrm{Al}$ has this breakthrough, both he and his banking colleagues are of the same mind and can now work together to see to it that the nation, thanks to her veterans being financially empowered, realize socioeconomic growth and success. Drinking to excess cleared the way for him to fight long-settled bank practices to defend his fellow veteran's financial futures. It also provides a vehicle for showing how a wife's patience and trustexemplified in the banquet scene by not limiting how much $\mathrm{Al}$ was drinking-will bring out the best in her husband. At the end of the film, after he completes his transition to a productive life, he has given up alcohol and is at ease with Milly as they joke about her keeping tabs on his drinking at Homer's wedding reception.

Fred's symptom-like behaviors also help to cure his subconscious, "nervous out of the service" condition exhibited by his failure to succeed at personal relationships and employment. He loses Marie, Peggy and Al. His refusal to be satisfied with simply returning to a pre-war life amplifies the intensity and difficulty of his post-war readjustment, and again 
we find Fred waiting at an airport for the first available flight, not caring where he goes. While waiting, he wanders around the airport and walks through the plane graveyard that he, $\mathrm{Al}$ and Homer saw at the beginning of the film. The engines and interior controls have all been stripped from the planes. He comes across one with its nickname, "Round Trip?," painted on the nose and makes his way into the nose of the dusty, dilapidated B-17 bomber, his old “office." In a dramatic sequence of images, we see Fred from outside the plane as though we stand on the ground in full view of him, a possible mission target. The next image is a point of view shot triggered by Fred's glance to one side to where the engines had been. As the camera pans, loud, angry music punctuates the space of the four missing engines, intensifying the dramatic effect of the sequence. We then see a shot of the full width of the engineless plane as the sound of droning engines mixes with the music. The next shot pans in toward the plane as engines roar, giving the sense the plane is flying. The sequence moves to a close-up of Fred looking daze as he leans forward, looks down, sweat running down his face. He is, again, reliving and reexperiencing war traumas as he is absorbed into a flashback. The camera moves behind him, showing a nearly silhouetted image of Fred with the cloudy and filthy glass lit by the sun, impossible to see through. He is isolated and alone, nearly as invisible to outsiders as outsiders are to him. The sound of roaring engines and loud music are a dramatic indicator of the chaos Fred feels. Then, a barely audible voice calls out to him. The voice shouts "Hey you!" "What are you doing in that airplane?" breaking through. Fred snaps out of his flashback and sees the image of a man framed in the gun site. "I used to work in one of those," Fred explains after climbing out. The man is a contractor who is reclaiming the warplane materials to make prefabricated houses. Fred, more clear-headed after leaving the plane, asks for a job. The man begins talking about the war, but Fred cuts 
him off, brushing past both men's war experiences. The man gives him a job. Thus, Fred's posttraumatic stress symptom-like responses lead him to the plane graveyard where he buries his war past and starts a new life by making a choice to "get over it" and move forward with his life. Fred's ability to make this choice indicates how acceptable it was to characterize the ease with which soldiers could, or should, brush off their war experiences.

The final scenes of the film are of Homer and Wilma's wedding. Fred is the best man with Al, Milly and Peggy attending as guests. The event suggests that all three veterans have "made it" back home. $\mathrm{Al}$ is no longer drinking, a promise he made to Milly.

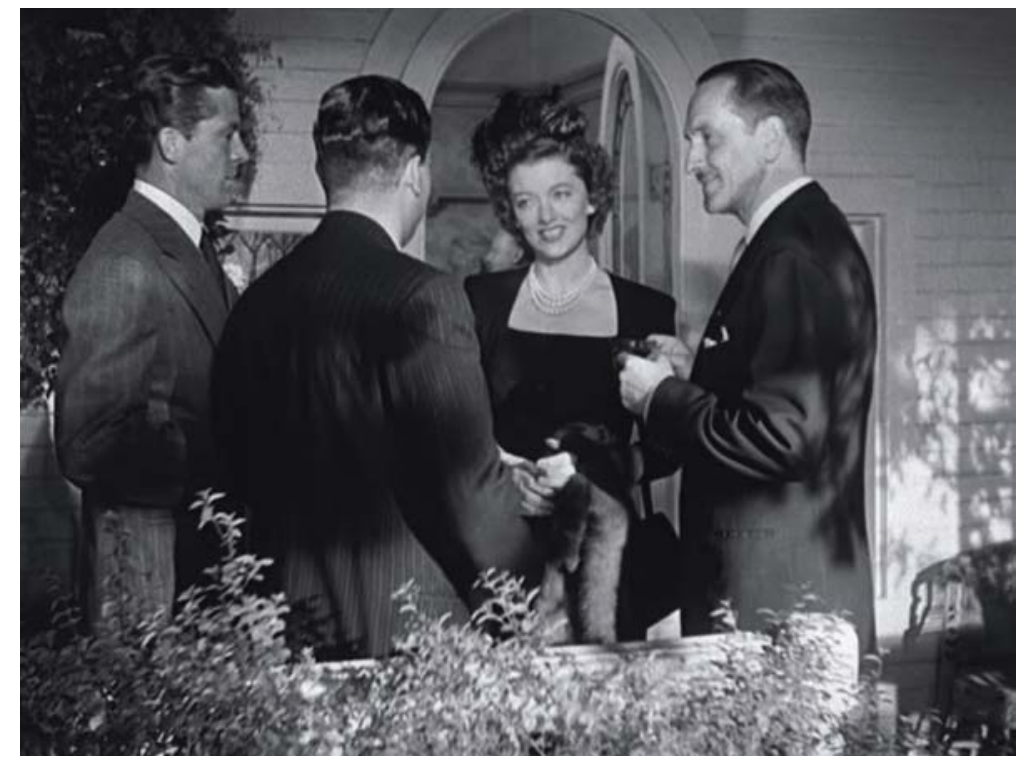

Figure 2.7: Al Stephenson in his final speaking scene (far right) at Homer's wedding (DVD screen capture, The Best Years of Our Lives).

He is back to the "normal" that Peggy predicted he would bring to the family. Al and Milly are again happily married and their closeness has comfortably returned (Figure 2.7). Fred, single and employed, and Peggy, still in love with him, reunite after the ceremony and promise to work at a life together (Figure 2.8). 


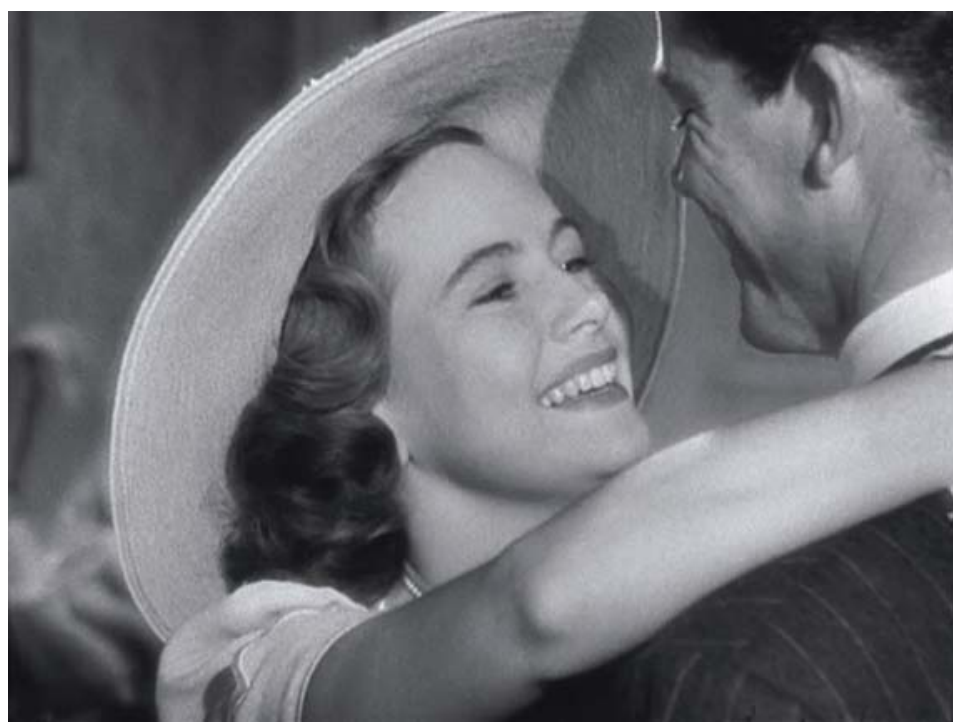

Figure 2.8: Fred and Peggy as they reunite in Fred's final scene after Homer's wedding ceremony (DVD screen capture, The Best Years of Our Lives).

\section{Veteran Myth from Al and Fred Representations}

The veteran representations analyzed in this chapter from the films I am a Fugitive From a Chain Gang and The Best Years of Our Lives do not use actual flashbacks of battle or wartime in the reliving/reexperiencing scenes. Both films stay in their present-day timelines. Both use a style of linear storytelling and dramatic techniques to indicate the reexperiencing/reliving symptom-like responses. These techniques emphasize not only the personal but also the invisible aspects of the war experiences that combat veterans live with as combat-related posttraumatic stress.

Veteranness, the dominant veteran discourse, influenced films during this period to tell particular kinds of stories. These films deal with PTSD by eliminating the character from society or by demonstrating the "rehabilitation" $\mathrm{Al}$ feared and commented on as the men were traveling home. Allen, in a veteran myth of criminality, is completely disappeared from society when the film ends. $\mathrm{Al}$ and Fred, in a veteran myth of psychosimplicity, simply choose to move past the psychological trauma of their wartime experiences. In doing so, $\mathrm{Al}$ 
returns to a happy home and productive employment where the trauma of his combat experiences is translated into valuable knowledge to be used by the banking industry and in this way extends Al's personal success to a broad sociocultural gain. Fred transforms from his pre-war, soda-jerk youth to a grown man's maturity once he purges the trauma of his wartime experiences. His divorce from a woman who engaged in partying and frivolous pursuits separates him from his youth, indicating he finally accepts life's challenging lessons. Choosing appropriate, mature solutions according to middle-class norms of the time, he acquires a grown man's career and a stable relationship with Peggy.

All three veteran representations analyzed in this chapter reach their negative or positive outcomes because of the PTSD symptom-like behaviors and responses that dramatically modify their post-war lives. Allen's, Fred's and Al's PTSD symptom-like response(s) and behavior(s), popularly marketed, as true-to-life film representations of veterans, are indicative of the dominant veteran discourse spanning the 1930s and leading up to the 1950s. The narrative of I an a Fugitive from a Chain Gang dramatizes the injustice of Allen's fate by emphasizing his heroic veteran status and helping the audience see his suffering. The narrative of The Best Years of Our Lives suggests that a post-war homecoming will be accompanied by psychological challenges for the veteran, but these challenges can be overcome by simply choosing to "get over it" and becoming productive and contributing members of society will naturally flow from these choices. Because PTSD symptom-like responses and behaviors constitute the primary personality characteristics of the main characters and motivate the action of the film's narrative, they are indicative of shared sociocultural meaning_-discursive unities — that represent combat veteran's "problems" that need solving. For $\mathrm{Al}$ and Fred, the combat-affected behaviors they exhibit are precursors to 
what will later be called "invisible injuries" that need time ${ }^{16}$ (to settle back into a civilian routine) and rehabilitation (support and encouragement to reestablish a socially acceptable lifestyle) in order to heal. Transitioning from soldier to civilian required both $\mathrm{Al}$ and Fred to ultimately accomplish rehabilitation through the PTSD symptom-like behaviors that initially threatened to destroy them. Veteranness in The Best Years of Our Lives is a temporary struggle that is won, essentially, by expunging the trauma of combat experiences through the earned reward of doing the work to create the necessary closure, rehabilitation and healing that allow veterans to "snap out of it" and get on with their post-war lives. The simplicity of the curative power of fighting posttraumatic stress, as $\mathrm{Al}$ does at the banquet and as Fred does in the airplane graveyard, is indicative of a dominant discourse that incorporates ideas from clinical fields into popular media. Being "nervous out of the service" is a choice.

As part of the dominant discourse of veteranness, the veteran myths of criminality and psychosimplicity operate cooperatively to generate a sympathetic perspective: empathy and sadness; gladness and satisfaction. A sympathetic perspective allows the audience to either feel the tragedy of the veteran's loss, as through the James Allen representation, or feel the joy of rehabilitated veteran's success, as in the $\mathrm{Al}$ and Fred representations. In this way, these myths remain consistent with the monumentality myth and together circulate within an overarching concept of veteranness that reinforces both the veteran's sacrifice and ability to succeed due to determination and hard work.

16 The length of time between the beginning and end of the narrative is unclear. Based on events that occur in the individual stories of Fred and $\mathrm{Al}$, my estimate is a time span of at least a year or a little longer. During this time, Al's employment and alcoholism dilemmas are revealed and resolved and Fred's marriage and employment dilemmas are revealed and resolved. 
CHAPTER 3

\section{Representations of Vietnam War Veterans}

We went to Vietnam,

And some of us came back.

That's all there is ...

Except for the details.

—Jim Gray 


\section{Introduction: Representations of Vietnam War Veterans}

The cultural and political turmoil during the 1960s and 70s dramatically altered the sociocultural contexts in which representations of veterans of the war in Vietnam appeared in visual media. The Vietnam War was the first to be broadcast regularly on television. News reporters, wearing combat fatigues, delivered their reports near combat action and showed snippets of war and soldiers. Same-day video news footage supplemented still photographs in newspapers and magazines and differed from movie-theater newsreels of earlier wars in its immediacy and realism, also contributing to a sense of the brutality of war for viewers back home. After their service deployments, soldiers returned from jungle and river delta warfare to a volatile political and social environment saturated with infighting between supporters and protesters of the war.

Social turmoil also prompted a dramatic shift in film representations related to war in Vietnam and in the way major film studios approached the conflict. Film critic, scholar and industry executive Jeremy Devine explains:

When America went off to fight communism in the jungles of Vietnam, twenty years of glorious World War II imagery from films accompanied the troops and policymakers. ... Only one film was made about the Vietnam War during the conflict itself. Most appropriately that was the very personalized work of a man who exemplified gung-ho Americana, John Wayne. His instantly dated and reviled film The Green Berets was released in 1968 (Devine xiii).

The Green Berets bore little resemblance to the war in Vietnam as recognizable by filmgoers and critics through the daily, televised news coverage of the time. The film depicts the jungle war with seemingly standard ground-war scenes that replicate earlier war-film footage of 
tanks and bases, appearing to swap out the setting of the action to make it appear appropriate for the Vietnam landscape. The plot relies on a spy-breaking narrative to motivate the missions leading to battle scenes with gory deaths to Americans by way of primitively constructed, gruesome death traps. The squad of military-men meets informers in gambling halls dropped into jungle settings. Significantly, the film was problematic not only as a formulaic film construct of American intelligence gathering and battle scenes emblematic of Hollywood's classic film era. It also exemplified the powerful censoring influence of the Production Code and helped explain the Hollywood film industry's reputation as a propaganda machine. The film, "Although ridiculed from various points of view at the time of its release," with its unrealistic story arcs and combat action scenes with no resemblance to that seen in photojournalism, when "considered some twenty years later, [the film] strikes a viewer most forcefully with its unintended surrealism" (Anderegg 24). Indeed, The Green Berets is the film that ushered the war film out of major studio production until after the war ended:

Hollywood reacted [to the film's failure] as any for-profit business would; it retreated from the unpalatable. No longer could it serve its traditional propaganda-boosting role or entertain in a conventional sense. Therefore it was not until two years after the fall of Saigon in 1975 that the now-familiar Vietnam War films such as The Deer Hunter and Coming Home were released (Devine xiii).

The film industry's response to the criticism of The Green Berets amidst the cultural turmoil of the Vietnam War period can be seen as a plot twist in a broader sociocultural narrative of veterans. In this narrative, the film industry needed to find a way to include Vietnam War 
veterans in films that would bring audiences to the theater. The alternative was to continue avoiding the Vietnam War and ignore the veterans of the war as well.

Although PTSD had not yet been added to the DSM or entered popular discourse during the war, when major studios did begin producing dramatic films with Vietnam War veterans as main characters, the veteran's personal, internal struggles were central to their stories. It is these veteran representations I examine in this chapter. The three-hour narrative of The Deer Hunter (1978) is "basically about friendship and courage and what happens to these qualities under stress" (Cimino, DVD production notes). The central character, Michael, is the deer hunter whose hunting philosophy provides a metaphor for his philosophy of "everything." I focus my analysis on the post-war segment of the film where a veteran myth of unrecoverability is exposed: that is, the myth of the veteran's inability to recover from his war experiences, which are presented as embedded in his reflexes, as well as society's inability to recover or return the veteran to a conventional civilian life. The second veteran representation is Private Eriksson in 1989's Casualties of War. The film is based on a true story of the kidnap, rape and murder of a Vietnamese girl by U.S. soldiers and the consequences of their actions. The present-day part of the film takes place as Eriksson rides a city bus and relives the mission that is central to his posttraumatic stress responses and behaviors. Most of the film takes place as memories or dreams, "rooted in the realm of recollection as if the unfolding flashback is a collective nightmare" (Devine 299). The few minutes of Eriksson's present-day scene suggest a veteran myth reminiscent of the psychosimplicity seen through the Fred and $\mathrm{Al}$ representations in The Best Years of Our Lives forty-three years earlier (see Chapter 2). However, Eriksson's recovery is grounded more 
firmly in his personal experience rather than in the broader social conditions into which Fred and $\mathrm{Al}$ are received.

\section{Veteran Discourse in the 1960s through the 1990s}

As a diagnosis, Posttraumatic Stress Disorder first appeared in the third edition of the Diagnostic and Statistical Manual (DSM) in 1980 after a controversial political battle between supporters and opponents of the formation of a formal diagnosis. Wilbur J. Scott traces the process of how PTSD came to be included in the official diagnostic manual used by psychiatric and psychology professionals. The first edition of the DSM-I, published in 1952, contained an entry for a condition named "gross stress reaction," described as a "temporary condition produced by extreme environmental stress" (Scott 295). While relevant research "revealed that symptoms could persist for months or even years," the clinical consensus, at that time, was that the condition "should disappear after the individual was removed from the stressful situation" (Scott 295). By 1968, DSM-II dropped gross stress reaction as a recognized condition. Treatment plans close to the front were implemented from the start of the Vietnam War in order to return soldiers to active duty as quickly as possible. The approach seemed to be working ${ }^{17}$ and suggested to military leaders and psychiatrists that they had "licked the problem" (Scott 297).

17 Raymond Monsour Scurfield, in A Vietnam Trilogy_Veterans and Post Traumatic Stress: 1968, 1989, 2000 describes "The Profound Psychiatric Paradox" military psychiatrists and psychologists were confronted with. It was their job to decide "whether someone was too crazy to be sent back to killing, or was crazy enough to be evacuated out of the war zone-or was in 'danger' of 'premature evacuation.' ... It was our responsibility as psychiatric gate-keepers to keep that gateway from blowing open. ... The military instituted a simple but exquisitely designed rule to help keep people from getting an early ticket home. If anyone committed a crime in Vietnam and was incarcerated ... the amount of time spent in jail was added to the Vietnam tour of duty. Otherwise, the brig would have been full of soldiers keeping safely out of harm's way. The incarceration facilities in 
The DSM-II contained no classification for combat-related disorders, which surprised psychiatrists who were documenting persistent symptoms in veterans from WWII and the Korean War. By the time of the publication of DSM-III, "the struggle for recognition of PTSD by its champions was profoundly political" (Scott 295). Symptoms were similar in soldiers who had not been subjected to artillery barrages and many military leaders and physicians considered the symptoms evidence of cowardice or malingering and signs of weakness (Scott 296). Mental health professionals relied on "diagnostic nomenclature that contained no specific entries for war-related trauma" and it was typical for VA physicians not to collect the military histories of "disturbed" Vietnam War veterans for their diagnostic work. In spite of its removal from the manual, many psychiatrists considered gross stress reaction to be a valid and useful diagnostic tool (Scott 298).

The debate about lasting effects combat-trauma overflowed into popular media. Scott describes how in 1971 psychoanalyst Chaim Shatan, in an Op-Ed piece for The New York Times, identified what he called a "post-Vietnam syndrome" that, according to his observations, “... occurred nine to thirty months after return from Vietnam” and included

Vietnam were purposely rendered unlivable, besides, to further discourage this kind of 'malingering.' ... And there was yet another deterrent to medically evacuating soldiers out of Vietnam. There was the possibility that they would be sent right back! A number of soldiers who were medically evacuated to Japan ended up being re-evaluated there and were sent back, not to the psychiatric unit but directly to their original unit. As described by my former VA colleague, friend and Nam vet social worker, Shad Medshad: 'It was worse than if he'd ever left. I learned quickly to think twice before sending anyone off to Japan. It was a real Catch 22 . The problem was that people were not crazy. They were in a crazy, maddening situation. After three weeks in Da Nang in a relatively stressless environment, with medication, their symptoms disappeared. They'd get on that plane for Japan, figure they were on Easy Street headed for home. They would hit Japan acting just fine. 'You can withstand active duty. We're flying you back,' they'd be told. That served as another trauma in itself. They'd be sent back. Only to flip out again." (Scurfield 43-44). Soldiers were also caught in conflicting situations: "On the one hand, you have to serve with your buddies and not let them (or your country) down in a war. On the other hand, you believe that you are going off the deep end and that your very sanity and physical survival depend on escaping by any means possible from the craziness of war" (43). 
symptom themes of "guilt, rage, the feeling of being scapegoated, psychic numbing, and alienation" (Scott 301). In 1972 Shatan produced a longer scholarly article about the syndrome, which caught the attention of mental health associations and "things started mushrooming" (Scott quoting Shatan 301). By June 1974, the APA was developing DSM-III. Other successful challenges to diagnostic descriptions ${ }^{18}$ energized a movement to redo the way the APA considered war-related reactions. The Vietnam Veterans Working Group was formed to publicize the debate about what it termed Post-Combat Disorder" (Scott 305) and a Committee on Reactive Disorders that included representative from the DSM-III task force began "the political hardball that lay ahead" (Scott 306). On March 5, 1978, after years of proposals by supporters and opponents of changes that included work to clarify causes, diagnostic criteria and labeling, an agreement was reached and Posttraumatic Stress Disorder was included in the DSM-III to be released in 1980 (Scott 307). Scott points out that, "PTSD is in DSM-III because a core of psychiatrists and veterans worked consciously and deliberately to put it there" and that they "ultimately succeeded because they were better organized, more politically active, and enjoyed more lucky breaks than their opposition" (308). Specific terminology now existed and clinical communities had particular language to use and diagnostic standards to apply.

While the professional communities now had resources for identifying and discussing PTSD in clinical discourse and evaluation, popular discourse contended with a legacy of terms and meanings for referring to posttraumatic stress that had existed for centuries. In

18 An example of a successful challenge to existing entries in the DSM occurred in the description of homosexuality as a mental disorder. At the time, the term was substituted with sexual orientation disturbance in which "homosexuality would qualify as a mental disorder only if the individual experienced distress or dissatisfaction with being gay" (Scott 304). 
1991, the editors of Veteran, the official news magazine for the Vietnam Veteran's of America (VVA), published Steve Bently’s essay “A Short History of PTSD: From Thermopylae to Hue, Soldiers Have Always Had a Disturbing Reaction to War.” Bently found that, as far back as 1678, Swiss military physicians identified and named a set of behaviors of an acute combat reaction that they named nostalgia. The short essay covers much historical terrain and, significantly, points out the difficult-to-distinguish characteristics of posttraumatic stress that resist diagnostic standards. Bently points to a different perspective, more sociocultural rather than clinical, and suggests that posttraumatic stress characteristics are not subtle or illusive, but that they might be too big to be seen up close by examining the veteran. He suggests that the impact of the disorder, measured on a veteran's level of social functioning (see criteria $\mathrm{F}$ in Chapter 1), could be indicative of cultural disorder rather than an individual psychological or psychiatric disorder and that PTSD might actually be a sign of sanity amidst the insanity and incivility of war (Bently 1991).

As clinical and popular discourse advanced ideas of posttraumatic stress as a diagnosable condition catching up to the historical evidence about combat-affected veterans, visual media was in the midst of an expansion of veteran discourse driven by veterans themselves. Sandra Varco, executive director of the National Vietnam Veterans Art Museum, writes about the museum's inception in the foreword of the book Vietnam: Reflexes and Reflections (Sinaiko 10). In Chicago in 1981, a group of Vietnam War veteran artists calling themselves the Vietnam Veterans Arts Group wanted to show their work in a gallery show and it was one of these artists, Ned Broderick, who titled the show Vietnam: Reflexes and Reflections. Various organizers became interested in helping make the exhibit happen and sought out additional veteran artists; the exhibit opened in October 1981 and succeeded beyond their 
expectations. A public sharing of Vietnam veteran's war experiences and their responses to the many traumatic dimensions of combat began in earnest. The art show went on the road to over thirty sites between 1983 and 1992, all the while growing in size. In 1995, the city of Chicago gave an abandoned warehouse and grant money to renovate the space into a permanent gallery, and the National Vietnam Veterans Art Museum ${ }^{19}$ opened.

In 1998, the National Vietnam Veterans Art Museum published a "remarkable and unconventional" ((Sinaiko front flap) book titled after the exhibit that featured both the art and the artists from its collection. Referring to the harsh reality of the war and its lasting effects as represented in the exhibit, Varco writes in the book's introduction, "The works of art in this museum, and this book, do not allow the viewer to be neutral; they demand a response" ((Sinaiko 13), and goes on to explain that many veterans have "said they do not want to forget, as to do so would lessen the sacrifices made by so many" ((Sinaiko 13). Similar to television news coverage from the Vietnam battleground, the book helped reveal the effects of combat on veterans, effects that were persistent and powerful and, like the veterans, outlasted the war. The book demanded that viewers confront the fact that the end of war does not equate to the end of the experiences or effects of war on the returned soldier, and it did this primarily through the visual media of art. "Wars," Varco continues, "usually unite societies, and certainly generations, but this one did not" ((Sinaiko 13).

The painting reproduced on the front of the book's dustcover seems to exemplify that separation. The title of the painting is Hi Mom ... I'm Home (Figure 3.1); the artist is Ned

19 The Vietnam Veteran's Art Museum also has an Internet home at www.nvam.org and participates in social media. 
Broderick, who served with a Marine battalion in the DMZ for more than a year and half during 1966-67. Broderick's reflects on his wartime experiences in 1996:

We arrived in Vietnam with 1,250 guys and in six months were down to 430. In those days we went directly from operation to operation ... we wore our uniforms until they rotted off our backs ... we were never in a building; never saw an electric light. ... We saw people die in every conceivable way; all that was war was with us and with our enemy as well... (33).

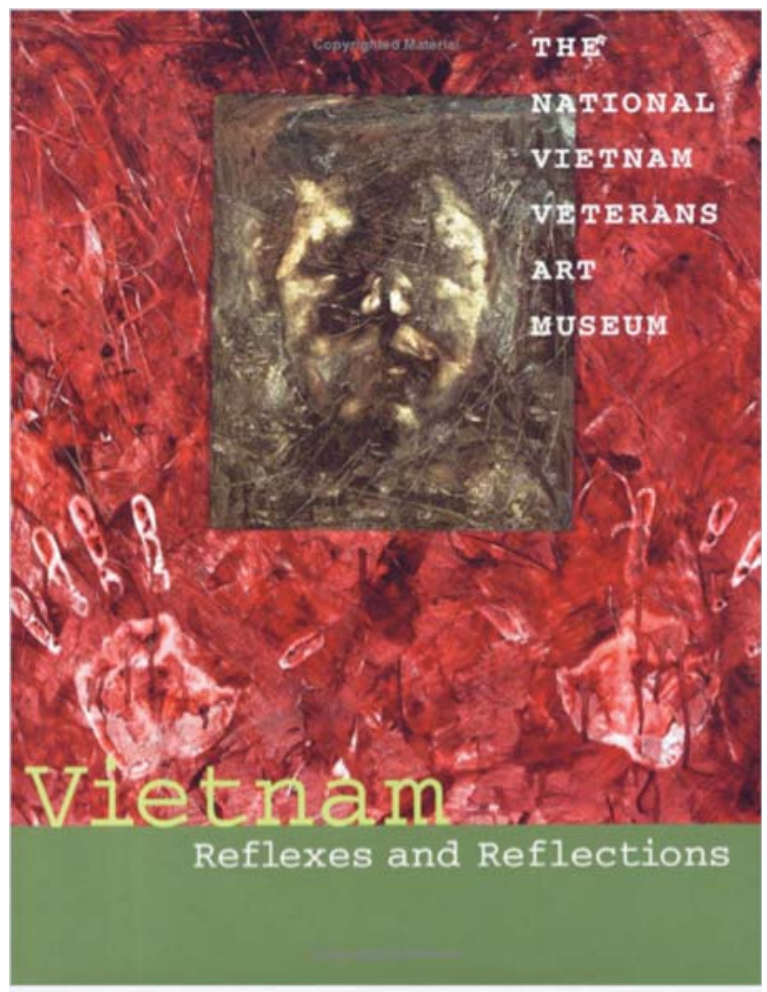

Figure 3.1: Ned Broderick's Hi Mom ... I'm Home on the cover of the National Vietnam Veterans Art Museum's Vietnam: Reflexes and Reflections (Internet screen capture, amazon.com).

Reproduced on the cover of the book, the image is out of its "natural" context, the painting displayed in the art museum.

The painting incorporates several distinctive images and artistic techniques that may carry connotations for the viewer. A man's face is half-hidden in camouflage-green colors; 
the face, reminiscent of a death mask, is set off by straight lines that define the edge of the green rectangular shape, making it uncertain whether the face is in front of, even with, or behind the field of red. The reds that surround the face/mask are a variety of shades from bright, bloody reds to dark nearly black reds. White imprints of hands, palms toward the viewer, appear as though they had been briefly pressed against an invisible barrier between the man in the painting and the viewer; again, however, there is ambiguity about whose handprints these are and if the man in the painting made them or if the viewer is made to feel as through they themselves touched the plane without realizing it. The man is trapped in the green, surrounded by blood and chaos.

The painting was completed in 1994 when information about PTSD would have circulated among clinical, veteran and popular segments of society, and the visual elements and techniques used in this work of art are suggestive of PTSD symptom-like behaviors and responses. The facial features are toned down in both color and emotion and give an impression of numbness and distance. The identity of this particular man and the painting's status as a self-portrait or representation of a subject is unclear. In either case, the painting creates a sense of detachment, as if the subject were unwilling to be fully seen or unable to feel recognized as the man he is or was. Hyperarousal is also suggested in the field of red and the textures that appear smeared, etched and slashed across the surface. The disorderliness suggests a chaotic state of mind and inability to concentrate. The contrast between the red and green creates a dynamic visual vibrancy that destabilizes the facial and hands planes so either one can be foreground or background. The textures and visual movement imply as much internal as external chaos, a state of mind that could be hypervigilance. The scrapes and gouges may be seen as wounds detached from the body, suggestive of trauma to the 
man's state of mind. Yet, the nearly square shape of the painting gives it a visual weight that stabilizes the composition and holds it together so it stays in its tortured place, containing the chaos to the canvas and to the man in the painting.

At the same time, the handprints invite a personal, human connection to the man, who onlookers can only barely see and cannot touch. He reaches out, but either stops or is stopped at the surface of the canvas. The face either cannot or will not express emotion. Numb and emotionally flat, the man's expression is in stark contrast to the chaos that surrounds him and the effort that the hands must make to pass through the barrier between him and the viewers. Broderick's painting may thus be interpreted as the representation of a veteran who is telling us that he, or veterans like him, is trapped between "out there," where the viewer is, and "in here," where the veteran is, and that the distance between the two, while not physically large, is nonetheless impenetrable. The painting further suggests that the impenetrable distance between "veteran's perception of in here" and "civilian's perception of in there" with here/there is due, at least in part, to the residue of the veteran's combat experiences and, significantly, the way outsiders look at the veteran.

When used as a design element on the front cover of the book, this meaning is retained, but another idea is added; the naturalizing of the concept of impenetrable distance between Vietnam War veterans and everyone else, conveyed through the visual techniques that suggest PTSD. The cover of the book is powerful and unsettling, as art often seeks to be, yet at the same time, myth threatens to distort the powerful meaning of the painting by naturalizing a signification of veterans as anguished, reactive, internally wounded and unreachable: what I term a veteran myth of unrecoverability in which the veteran's inability to recover from the trauma of combat is met with the inability of civilians to recover a 
normal relationship with or to the veteran. We see the veteran but cannot be fully with him, as if it he exists only as an image of his war trauma on a physical surface. Thus Broderick's painting becomes an essential component of the collection's signification. Because of its role as the image on the cover of the book, the contents of the book are informed by this one piece. The PTSD symptoms, the numbing and hypervigilance, paired with and more prominent than the title of the book, Vietnam: Reflexes and Reflections, overlays the meaning of the painting onto all of the artists and artworks presented in the book. The contents of the book are introduced to the reader of the book with an added meaning, suggesting that they be seen from an impenetrable point of view and putting these veteran experiences are on display in the same way as art in a museum.

Another, perhaps more widely recognized work of art that relies on various meanings of the word "reflection" and that potentially sustains a veteran myth of unrecoverability is Lee Teter's 1988 painting Reflections (Figure 3.2).

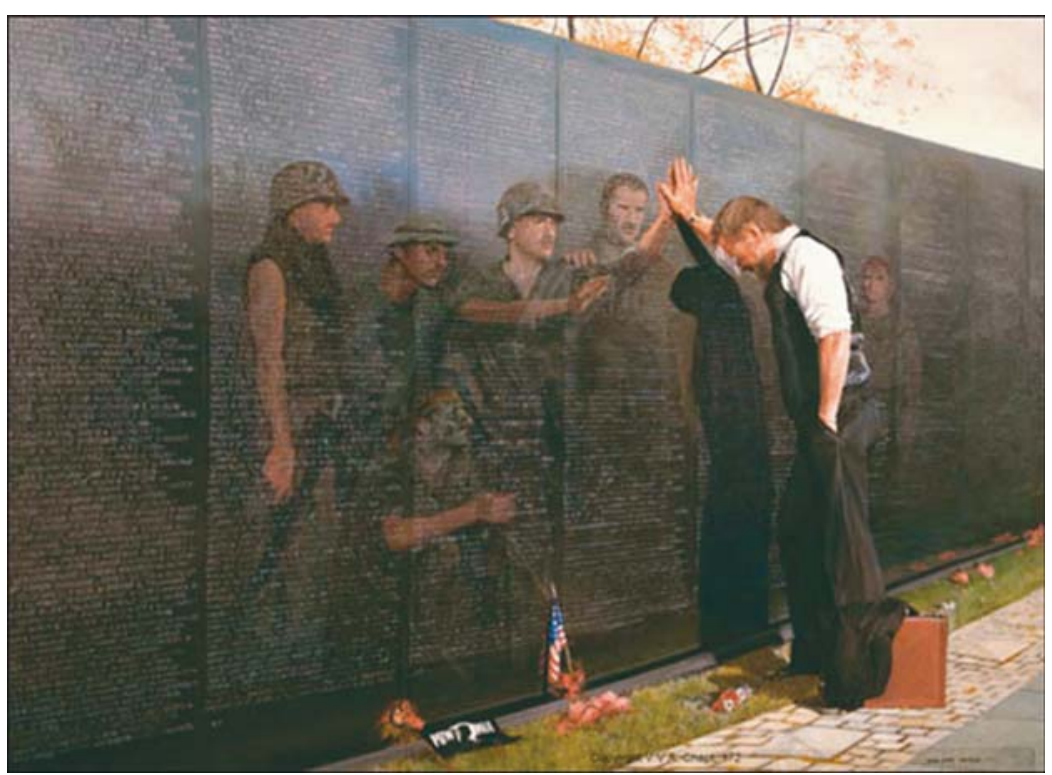

Figure 3.2: Reflections by Lee Teter, 1988 (Internet screen capture, leeteter.com). Teter licensed the rights to the painting to Chapter 172 of the Vietnam Veterans of America who sell prints to raise funds for the organization (Belsaw). 
The painting shows a middle-aged man in a business suit, his suit coat draped on the briefcase at his feet. The man leans on his hand on the polished surface of the Vietnam Veterans Memorial, "The Wall," as he appears to grieve his fallen friends. His hand aligns with the hand of a soldier's reflection, one of five soldiers visible on the black granite surface. Presumably, these images are a reflection of the experiences the man relives, and this reexperiencing/reliving of his war experiences is suggestive of PTSD symptom-like responses. Another image on the wall is of a nurse who is separate from the soldiers but whose presence reinforces the idea these soldiers died in the war. The ideas of soldier and veteran are as inextricably bound together as the man is to his reflection, which is in turn bound to his war experiences.

Writing in May of 2010, over twenty years after he had created the painting, Teter recognized that it has come to have different meanings over time and in different contexts. While not a veteran himself, Teter struggled with his personal perspective and the way he saw it contrasting with broader social perspectives about veterans in late 1980s popular discourse:

I was very concerned when the picture you see in Reflections came to me. I was afraid the concept would be spat on the way veterans had been spat on by people who did not understand them. You must remember that in 1987 veterans were still stereotyped, by Hollywood and ignorant radicals, as babykillers, disturbed and unable to cope with their past (Teter, Artist statement).

Key to his decision to paint Reflections was his awareness of his friends being "forever changed by their experiences" and his recognition of a critical need to bring the private turmoil, experience, and isolation of the combat veteran into a visible social and cultural conversation (Teter, Artist statement). Teter's painting reinforces an idea of the veteran's 
isolated personal experience and of the enduring quality of their traumatic memories. At the same time, PTSD symptom-like responses are deeply embedded in a message of veterans unrecovered from the war, both those who died as soldiers and those who returned to isolated reexperiencing. Because the painting incorporates the Vietnam Veterans Memorial Wall, meanings associated with a monumentality myth also contribute ideas of sacrifice and loss, but because those ideas are integrated into the painting they also color the image of the veteran. "The Wall" runs out of frame on both sides of the painting symbolizing for us that his experiences are out of sight as well. We see only small present in a long, dark continuity of past and future experiences. His name may not be on the wall, but his memories and reexperiencing are part of the memorial.

While the experience of posttraumatic stress is visible outright in Teter's Reflections, it is also recognizable in other representations in less conspicuous ways. Benjamin Suarez served in the Army in Vietnam during 1971-72. He "was assigned to look for signs of American POWs" (Vietnam: Reflexes and Reflections, 183). His painting, Self-Portrait: The Vietnam Vet (Figure 3.3), was painted over the course of twelve years and completed in 1985. The image, a face, barely fits on the 30 by 24 inch canvas. It looks traumatized, dark and in turmoil. What is unseen is as powerful as what is seen:

This painting has been worked and reworked for more than twenty years and at times destroyed, though the original portrait was always resurrected. That's the whole Vietnam connection: sometimes the memories are very sharp, sometimes buried or covered over in paint. Sometimes the memories and the painting sat in a closet of sorts, only to resurface again. It is an attempt to accept and face the reality of Vietnam, to document on canvas one image that might bring closure ((Sinaiko 183). 
The time span indicates the persistence of the dark, distorted, tumultuous ideas of "self" out of which Suarez' self-portrait eventually materialized. "For years I dreamed of that strange man at the window; was he giving me some sort of signal? Who is looking out and who is looking in?” (183).

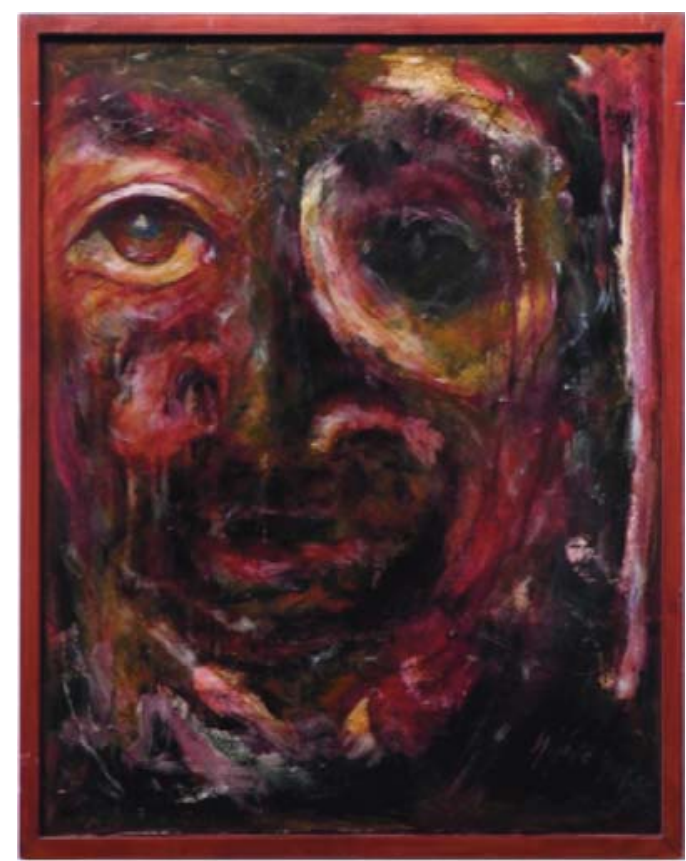

Figure 3.3: Self-Portrait: The Vietnam Vet by

Benjamin Suarez, 1973-1985. (Internet screen capture, National Veterans Art Museum Online).

The personal responses of veterans to their experiences of being in combat is exemplified in the work of Broderick, Teter (from an outsider perspective), Suarez, and the artistic work published in Vietnam: Reflexes and Reflections. That the personal perspectives of combat veterans entered the public sphere successfully was a significant development for public discourse during the period of the Vietnam War. By contrast, during the period of the World Wars and early visual media, veteran's dilemmas were enveloped into general societal practices such as Al's employment dilemmas and his drinking to excess, Fred's strained marriage, affair and eventual divorce, Allen's criminal conviction, and the monumentality of the Civil War veteran pictorial. Yet, although the period of the Vietnam War ushered in the 
individual, internal struggles of veterans in a much more pronounced and personal manner, a veteran myth of unrecoverability nonetheless circulates in the dominant discourse of the period. The film representations I examine below are no exception. In them, the veterans' post-war social behaviors are explicitly defined by the war and made visible in their PTSD symptom-like responses. Unlike the World War films where the veteran's recoveries were enmeshed with society's recovery, the narratives of the Vietnam War films highlight the veteran's personal struggle to figure out their post-war lives. I start my analysis with Michael from the 1978 film The Deer Hunter ${ }^{20}$ and then examine Eriksson from Casualties of $W a r^{21}$, which was released in 1989.

\section{Vietnam War Veteran Michael}

The 1978 film The Deer Hunter was released three years after the war in Vietnam ended and two years before PTSD appeared in the DSM. It is the first major motion picture to deal with a veteran's combat-related posttraumatic stress directly as the dominant theme of the film. Michael, Nick and Steven are the three main characters with Michael being the central character around whom the film's narrative is structured.

The film consists of three main segments: before, during, and after Michael and his friends enlist in the army. The first segment introduces the audience to Michael, his character and values, his circle of friends, and the different relationships among them. The second

20 The Deer Hunter won five Academy Awards including Best Picture, Best Director, and Best Supporting Actor. Robert DeNiro was nominated for Best Actor in a Leading Role and Christopher Walken won for Best Actor in a Supporting Role (imdb.com)

${ }^{21}$ Casualties of $W$ ar placed 3rd in the National Society of Film Critics Awards (USA) in 1990 for Best Film, 2nd in the New York Film Critics Circle Awards in 1989 for Best Director, and won the Political Film Society (USA) Award in 1990. Michael J. Fox and Sean Penn starred in the film (imdb.com) 
segment takes place during the war and shows the intense combat Michael, Nick and Steven are involved in, the terror they experience as captives in a remote prison camp, their harrowing escape from captivity, and the effects of these traumas on their relationships. The third segment shows Michael's return to the U.S., the problems he faces at home, the truths he must keep from his friends, and his attempts to restore a sense of normalcy. In my analysis I argue that, despite the fact that he manages to bring everyone back together physically, a veteranness of unrecoverability is maintained through the Michael representation.

The three-hour film's story takes place over a period of a few years and concludes in the spring of 1975 shortly after the evacuation of the American embassy in Saigon and the formal end of the war. The rhetorical choice to use actual news footage of the last helicopters leaving the roof of the embassy during the fall of Saigon suggests the film was designed to be received by audiences as a realist interpretation of Vietnam War veterans in general.

\section{Film Synopsis: The Deer Hunter, 1978}

The first segment introduces us to Michael and a group of his close friends that include Nick, Steven, Stan, Axel, John, and Linda, Nick's girlfriend. In the opening scene Michael, Nick and Steven finish their shift at the steel mill and relax together at John's bar as preparations are underway for Steve and Angela's wedding. The wedding takes place the weekend before Michael, Nick and Steven leave for basic training. As the night winds down, Michael and Nick, his closest friend, talk about going to war, and Nick asks for and receives Michael's promise not to leave him there if, as he says, "you know, if something happens." 
The morning after the wedding, Michael and Nick go deer hunting with two other friends, Stan and Axel. Michael explains his philosophy of hunting to Nick, saying "one shot is what it's all about," thereby identifying himself as someone who is dedicated, prepared, determined, and certain about what he does. This is how he hunts and how he lives: he is fully committed. Michael is disappointed when others are not prepared, because their laziness means they need another "shot" to get their part right. An example of Michael's frustration is shown during their hunting trip when Stan admits that he forgot to bring his hunting boots and wants to borrow Michael's spare pair. Stan sees himself as a tough-guy and a ladies-man, but Michael sees him as trivial, shallow, living in the moment without considering the consequences of his shortsightedness, and refuses to lend Stan the boots. While Michael remains calm and determined, Stan gets angry. Nick steps in and smoothes over the conflict.

The second segment shows the trauma the three friends experience during the war as combat soldiers. Michael is with a unit fighting a gruesome battle in a remote village. Nick and Steven, with a different platoon, discover Michael is one of few survivors of the battle and all three are taken hostage with roughly a dozen other soldiers as the North Vietnamese Army closes in. Kept in bamboo prisons, half-submerged in a rat-infested river, they are forced by their captors to play Russian roulette. Presumably all the prisoners, some already shot in the head but still alive, will be rotated through the game until all are dead. Michael finalizes an escape plan that requires that, when they are made to play each other, he and Nick insist on having additional bullets loaded into the game's weapon until there are enough bullets to fight back against the captors. It works, and Michael, Nick and Steven escape that camp leaving only the dead or nearly dead behind. (Initially, Michael plans to 
leave Steven because he had been wounded in one of his rotations in the game, but Nick convinces Michael they cannot leave him to die.) The escape is dangerous, and they become separated. Nick is picked up by American helicopters that spot them in the river, but only manage to rescue Nick due to the dangers of the terrain and the fact that they are in enemycontrolled territory. Michael finds a way out of the river and manages to pull out the severely injured Steven and carry him to relative safety. He eventually meets up with a column of fleeing refugees and persuades a squad of South Vietnamese guards to take the now unconscious Steven with them in their jeep. At the end of the segment, the three men do not know each others' fate. The audience knows Nick had been under psychiatric evaluation in a hospital and that Michael learns Nick has been drawn into an underworld of a Russianroulette gambling-ring. Chasing after Nick, Michael calls to him but loses him in the chaos of the street.

The third segment begins with Michael returning home in a cab. The cab driver comments on the banners that stretch over the street to welcome Michael home, and he tells the cab driver to continue on past his house. He instead goes to a hotel. The next morning, Michael returns but waits on a hill across the street, out of sight, until he is sure everyone has left except Linda, Nick's girlfriend, who has been living in the house while he and Nick were in Vietnam.

In a sequence of short scenes, Michael's post-war relationships with his friends and community are revealed. Welcomed warmly by Linda, they talk briefly about Nick, who was reported AWOL, but Michael volunteers no additional information. Linda urges Michael to accompany her to the grocery store, and as they walk he receives enthusiastic greetings from several people in the neighborhood. After leaving Linda at the store, Michael waits outside 
the steel plant for Axel and Stan, who are at the end of their shift at the steel plant. They invite Michael to join them at John's bar where the group of friends usher Michael to the back, through hand shakes and cheers at his return, to celebrate in privacy.

The friends share a toast to Nick and Steve, and Michael does not tell them what he knows about Nick's dangerous actions. The conversation reveals that Steve is back from Vietnam, although no one knows where he is. Michael hurries out of the bar to talk to Angela, who is the only one who does know. Presumably in shock over what happened to Steven, she is unable to speak to Michael. She manages to write a phone number on a piece of paper and gives it to Michael. Using a payphone to call Steven, Michael hangs up the receiver before getting through to him.

Michael returns to the house and hurries to gather his gear. Linda is home and wants to be with him. When she proposes they go to bed, asking "Can't we just comfort each other?," Michael is too restless and tense and cannot agree to it.

This homecoming sequence establishes the group of friend's post-war normal in which everyone is accounted for except Nick. The sequence also reveals one of Michael's personal challenges, how to deal with his knowledge of Nick's going AWOL. This situation is complicated by Michael's strong attraction to Linda, revealed on the night of Steven's wedding when, slightly intoxicated, Michael comes close to admitting his feelings to her. Because she loves Nick and because Nick is his best friend, Michael keeps that secret to himself. However, after Michael's return, their mutual attraction leads to a moral crisis for Michael. Both the viewer and Michael are aware that Nick could still be alive and could come home some day; that Michael promised to bring Nick home if anything happened to him; that Michael had been willing, in the traumatic conditions of prison torture, to sacrifice 
the physically injured Steven so he and Nick would have a better chance to escape certain death in the prison camp; and also that Nick, who went missing from the psychiatric hospital after his rescue from the river, has been psychologically injured by his war experiences.

The next day, Michael, still dressed in his uniform, accompanies his friends to a bowling alley as they play in a local league. He stands back and observes as his friends play, but mostly watches Linda. As he does this, Stan approaches Michael and their brief interaction concerning Stan's womanizing serves to remind the audience that they are very different personalities. At the end of the evening, Axel, Stan, John and Michael plan to go hunting in the mountains.

The hunting camp sequence includes two significant scenes that highlight Michael's primary dilemma: how to reconcile his pre-war philosophy of life with his post-war internal struggles. The first incident contradicts his "one shot" metaphor for hunting and living by showing him choose not to shoot the deer he hunts down, and the second shows him exploding in rage in response to Stan's pretense of toughness. Together these scenes are a catalyst for Michael to confront his post-war inability to follow through on his promises-he goes hunting but does not take his shot, and he has left Nick in Vietnam as he promised not to.

Michael returns from the hunting trip with a renewed commitment to get things right. He finds Linda at work, where she has been crying. He waits for the end of her shift and takes her home and to bed. The next day, he leaves to find Steven and bring him home from the VA (Veterans Administration) hospital. He then goes back to Vietnam to fulfill his promise to bring Nick home. Michael finds Nick in the gambling halls risking his life in high-stakes Russian roulette games. Again, Michael forms a dangerous plan to rescue Nick, 
but Nick dies in front of Michael, who takes him home in a casket. The film ends with a scene of the group of friends at dinner after the funeral. The last time we see Michael in the film (Figure 3.4), he seems more in control and as ease with himself than the others who are grieving the death of Nick. His facial expression suggests that he has overcome internal conflicts, at least the need to bring his friends home, and found a peace that will allow him to move forward with his life. However, his inability to grieve Nick's death, his withholding of information about Nick's last days, and the fact that he is always in uniform (aside from the last hunting scene) suggests Michael carries vivid and traumatic war experiences with him as he moves forward with the same soldierly determination that helped him stay alive in the war.

\section{Seeing Michael as a Combat-affected Veteran}

Several scenes in The Deer Hunter show behaviors and responses of Michael's that resemble symptoms of PTSD. Before enlisting in the army, Michael was friendly and outgoing, calm and confident, but after he returns from the war, "nothing will ever be just like old times" (Early 215). When he arrives back home, he initially avoids his friends, risks shooting one of them, is uneasy with the attention from others in the community, and unable to enjoy deer hunting like he did before the war. The appearance of an unrecoverability veteran myth through the Michael representation relies on PTSD symptomlike behaviors of avoidance/numbing, hyperarousal and reliving/reexperiencing. Most of the pre- and post-war portions of the film are shot with low-key lighting, a visual technique that also darkens the mood. Other techniques suggest a distance between Michael and his friends. He makes little eye contact, often looking away or down, or watches others with a wary, nervous demeanor. His restrained and subdued post-war physical postures and 
movements, except when he is with Steven or Nick, show his inability to feel comfortable after his return.

\section{Avoidance/Numbing, Hyperarousal, and Reliving/Reexperiencing}

Avoidance is clearly shown during Michael's cab ride home (Figure 3.4). When Michael sees the banners stretched over his street, he tells the driver, 'Just keep goin'. Just keep goin'," and slouches down to avoid being seen by his waiting friends. The scene takes place at night with low key lighting, giving an added sense of isolation to the scene. Instead of going home, knowing his friends are eager to see him, he checks into a motel.

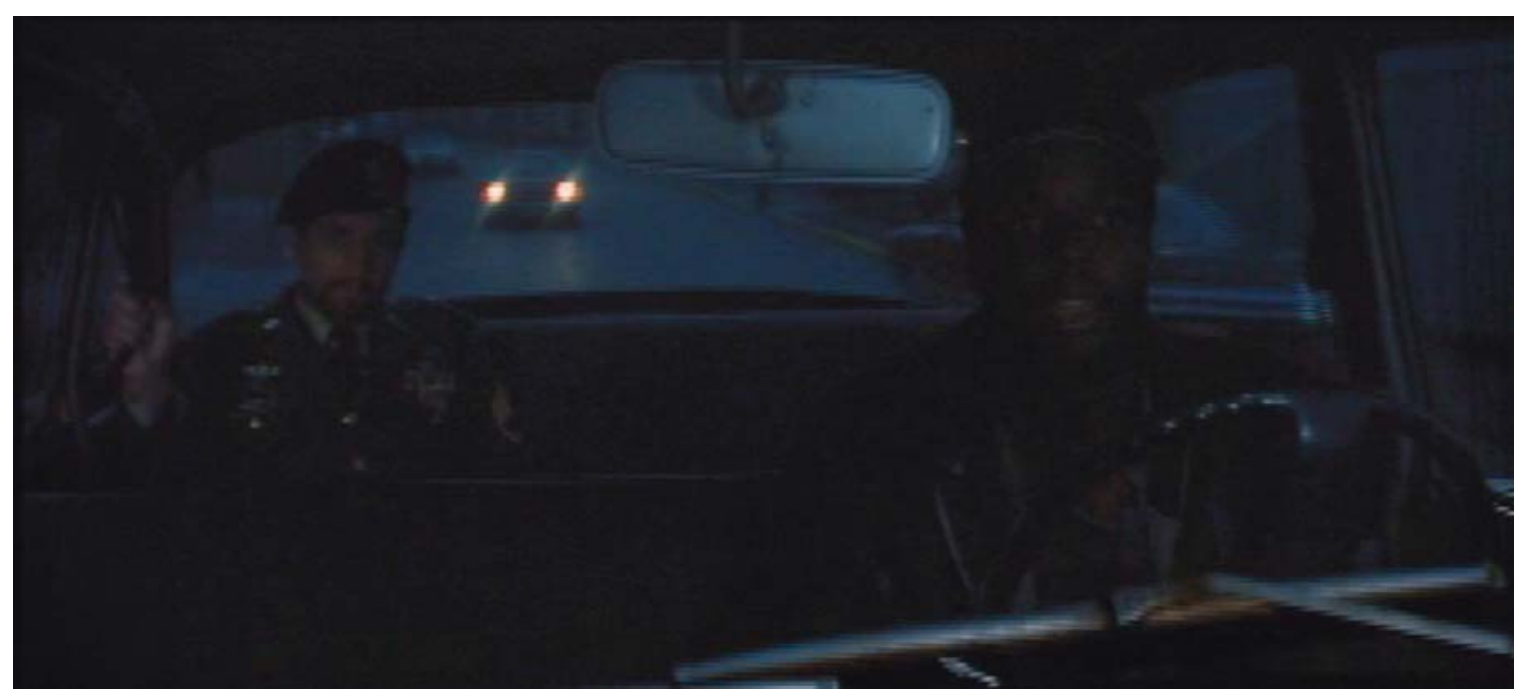

Figure 3.4: Michael, nearly unnoticeable, in the cab as he returns from Vietnam in The Deer Hunter (DVD screen capture, The Deer Hunter).

Upon entering his motel room, his body language tells us he is keyed-up, jittery and restless. He paces, removes his coat, tie and cap as he presses the heel of his hand to his forehead as though trying to ease an intense pain there. At this point music begins on the soundtrack that intensifies an already melancholy, lonely and tense mood. He paces in the small room, but there is not much space; he starts toward a short, lighted hallway, but turns back to the dimly lit room. He appears too jittery to sit, and instead of using the room's 
furniture, he crouches with his back against the wall in his small space, and takes a position with his arms held toward the floor and between his legs, as though his ankles were bound to his feet. While we did not see him bound in this way while in the prison camp, his body position appears constrained and tortured. His clothing strains against the tension in his body as he crouches. The darkness emphasizes our sense of his isolation. He hears a whistle blow at the nearby steel mill, and he looks up. He takes out his wallet and pulls out a picture of Linda. Michael stares at the picture with a worried expression, perhaps over what he will tell her about Nick or over what form their relationship will take now that Nick is not likely to return. Michael knows the dark underworld that Nick disappeared into in Vietnam. As viewers, we see that Michael's experiences burden him with secrets he will be unable to share with his friends.

The next morning, Michael returns to his house, but he remains out of sight, careful to be sure everyone has left the house before he approaches. When he is sure Linda is alone, he finally approaches. At first he moves toward the front door, but decides to go around to the back entrance. Linda is very happy to see him and hugs him. Michael does not return her embrace but allows her to hug him as he moves them both through the doorway and into the house. Avoidance is visible through his behavior of waiting for everyone but Linda to leave, his preference for using the off-street entrance (which decreases the chances he will be seen), and his quick entrance into the trailer in order not to be seen. Once inside, Michael behaves much like a guest in his house: even though Linda sits and moves around with ease, he stands for the duration of the visit. He dismisses the significance of his own war experiences and an injury she asks him about, deflecting attention from himself with "It was nothin'. Just the usual complications, that's all." She tries again, but he deflects with, "Lots 
of guys go through it." They talk about Nick and he comforts her after she begins to cry. Michael keeps what he knows about Nick's being AWOL to himself when talking to Linda, He avoids eye-contact, and even through Linda seems to wait briefly for Michael to offer additional information, he reveals nothing.

He offers to walk her to work and as they walk, Michael talks about Nick, but in the past tense. Earlier in the film, it was Michael's emotional control that helped them all stay alive, and he speaks in a matter-of-fact tone as he tells her, "I just want to say how sorry I am about Nick," and "I know how much you loved him and I ... I know that it'll never be the same." As Michael talks Linda remains silent and appears to sadden, unsure if Michael is telling her more than the official word that he was AWOL. He adds, "I don't know, maybe you don't want to talk about it," and these words end the conversation.

Linda suggests he come into the store, "Just to say hello." Michael is reluctant and attempts to walk away, again avoiding others, but Linda is insistent and pulls him in "just for a second." Michael resigns himself to her wishes and follows her into the store. He is visibly uncomfortable, but tolerant of the hugs and kisses from the store employees who greet him. Linda opens his coat so they can see his medals and his reaction is reserved as he endures the attention and being handled by them. Michael and Linda plan to meet back at home when she gets off of work, and he leaves the store.

Michael goes next to the steel mill where Stan and Axel still work and waits, again out of sight, until they walk by him. As they do, Michael calls out their names and runs up to them, jumping onto them from behind. It appears he is attempting to replicate a roughhousing style of companionship they shared years earlier. In using this wait-in-ambush approach to engage his friends, Michael displays a hypervigilant approach to controlling the interaction 
and the mood and tone of the reunion by shaping the social reengagement as a pre-war buddies-just-goofing-around moment rather than dealing with the memories of the war he just left. Michael has already displayed, in earlier scenes, his wish to deflect attention from himself. After the initial roughhousing and Stan and Axel's teasing of Michael for not being at the party, Michael only admits "I got delayed" and then changes the subject to Stan and his new moustache. But when Stan asks, "How does it feel to be shot?," the question is too personal for Michael, in part because it was part of the trauma of his war experiences and in part because, as established earlier in the film during the hunting trip in the first segment of the film, he and Stan have not developed a close, sharing relationship. Michael's deflection skills are well-honed and allow him to quickly respond, 'It don't. It don't' hurt. If that's what you wanna know." His response provides an answer yet limits the disclosure to information about his physical body rather than his emotional or psychological experiences. After this brief statement, Michael again quickly shifts attention back to Stan and Axel, avoiding further talk about the war.

Michael demonstrates hypervigilance/hyperarousal in the form of anger and frustration on the second hunting trip with Axel, Stan and John (the bar owner). On this trip, Michael is confronted with his promise to Nick on the first hunting trip not to leave him behind in Vietnam if anything happened to him. After spending the day hunting, Michael sites a deer, but it moves and he follows it to get his shot right. After several opportunities, the deer stands still, but Michael cannot shoot. The scene symbolizes Michael's inability to fulfill his commitment to doing right after letting Nick down and leaving him behind to die. He yells into the mountains, "Okay!" in a loud, drawn out admission of his failure to live to his own standard as well as a declaration that he will fulfill his responsibility to Nick and Steven. 
That evening, Michael returns to the hunting cabin to find Stan playing the tough-guy role that Michael is tired of. Stan is aiming what he thinks is an unloaded revolver at Axel, who is kidding Stan about his womanizing. As the scene unfolds, Michael becomes angry, takes Stan's handgun away from him, sees that it is loaded, and fires a round. At this point Michael loses the control he so diligently demanded of himself since he returned. In a rage he empties the bullets from the gun and loads a single round, replaying the sadistic game of Russian roulette that his Vietnamese captors played with him, Nick, Steven and the other prisoners. "You want to play games?” He holds the gun to Stan's forehead, yelling, "How do you feel now! Huh? Huh? Big shot!” and pulls the trigger. Stan is fortunate that the chamber is empty. The scene shows that Michael's ability to relive the most traumatic and agonizing elements of his wartime experiences is a very close to the surface.

His and Linda's mutual attraction allow avoidance/numbing to be shown and also offers the turning point before his choice to bring his friends home. After learning of Steven's whereabouts, an emotionally stressed yet calm and controlled Michael explains to Linda, "I gotta get out of here, I'm sorry, I just gotta get out" his jittery, anxious body movements contradicting the appearance of psychological calm. When it becomes obvious that Linda is hurt, he continues, explaining, "I feel a lot of distance ... I feel far away," and walks out. Linda soon goes after him, and in the next scene we see that they are in his hotel room. As she leaves the bathroom to join him in bed, she finds him asleep, fully dressed in his uniform.

Later in the film, after the volatile scene in the hunting cabin, Michael waits for Linda to get off of work. The PTSD symptom-like responses and behaviors of hyperarousal, avoidance/numbing and reliving seen in the Michael representation are essential to his 
realization that he must make a choice. He reaches a turning point where he must decide whether to live up to his personal philosophy or not. After returning from the hunting trip he finds Linda and they are able to be sexually intimate. At this moment, he has reached the point furthest from where he wants to be. The next day, Michael brings Steven home from the VA hospital and learns Nick may still be alive. He then goes back to Vietnam to find and bring Nick home. His PTSD symptom-like behaviors and responses thus create the hardships that lead to his crisis point where he goes on a mission to bring his friends back together.

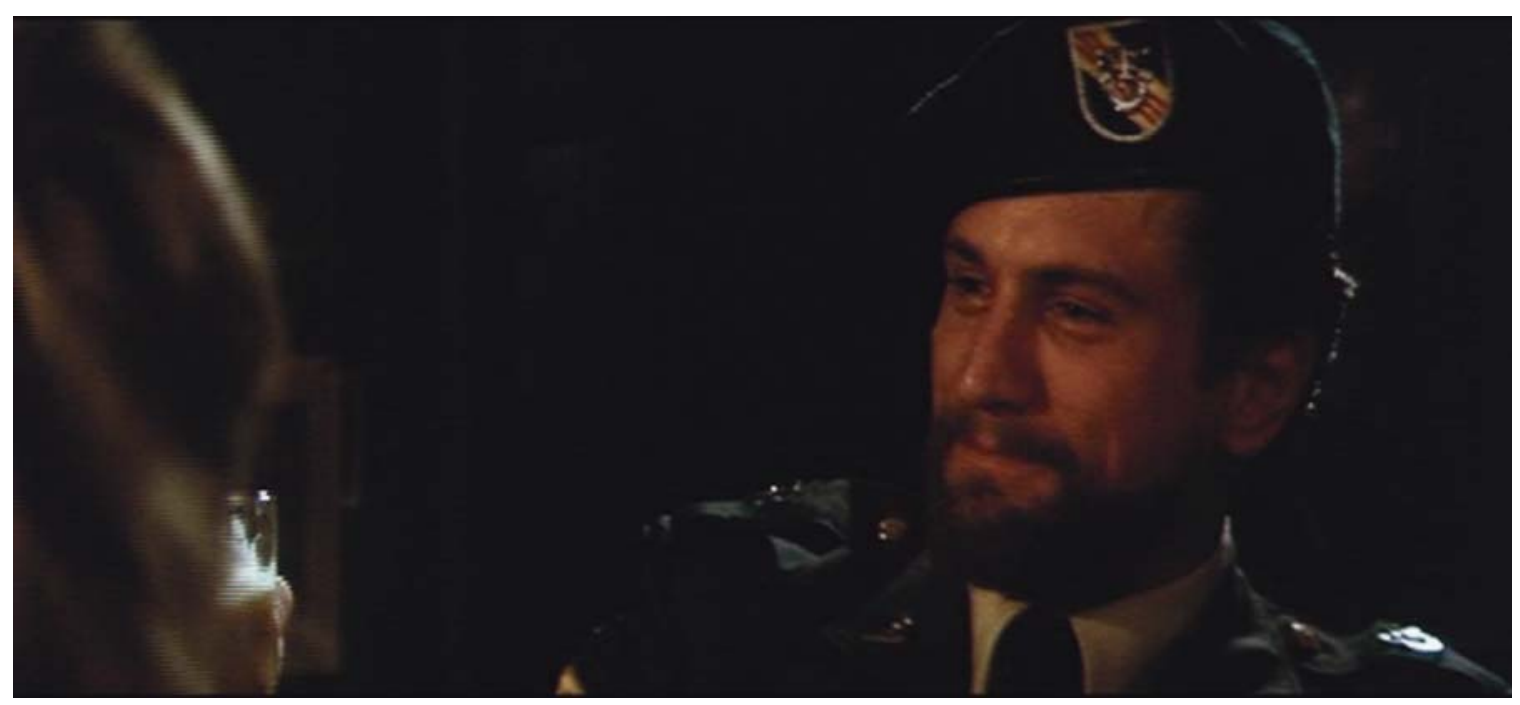

Figure 3.5: Michael after Nick's funeral in The Deer Hunter (DVD screen capture, The Deer Hunter).

What Michael accomplishes by fulfilling his mission happens through his prisoner of war survival techniques and has the status of a pseudo-recovery in the sense that he becomes the perpetual soldier fighting to survive. Indeed, the final post-war segment of the film reinforces a myth of unrecoverability by casting a dark, post-war sociocultural mood over Michael, the experiences others cannot see, and a society that also struggles with its own war trauma. 


\section{Veteran Myth from Michael Representation}

Among the symptom-like responses in the post-war Michael, we see avoidance/numbing, hyperarousal and reexperiencing. Avoidance is used to reveal Michael's post-war problems and hyperarousal triggers a crisis, allowing Michael to not only relive the dangerous game with Stan but to relive being the problem-solver and rescuer of his friends. Michael discovers the answer to his troubles through reexperiencing his soldier-persona. Reexperiencing is his personal evolution and his new, post-war normal. The development of these symptoms throughout the narrative of the film suggests to me that The Deer Hunter, though the Michael representation, maintains a veteran myth of unrecoverability, an idea that he is perpetually reliving his prisoner of war survival experiences. This myth is reinforced by Steven's permanent injuries and the death of Nick. It is also reinforced by the fact that Michael continues to wear his army uniform throughout the entire returned-home segment, with the exception of the love scene with Linda and the hunting scenes. Further, it is the trauma of war that first made it difficult for him to be back home, but it is the trauma of reexperiencing part of his captivity outside of the context of the war, and nearly shooting Stan, that shocks him enough to finish his mission to bring Steven and Nick home. The veteranness of Michael is a signification that a veteran can cure the damage of trauma through engaging in a new fight to win the battle against war's toll on the individual, but it hides the idea that the veteran is no longer in combat so his perpetual soldier persona seems reasonable as "recovery" but is actually hidden from view.

Similar to the psychosimplicity myth of The Best Years of Our Lives, where Fred and Al essentially cured their posttraumatic stress by getting "over it," The Deer Hunter "represents a simplified spectrum of ... mental effects of the war upon the veterans" (Walker 120). 
However, The Deer Hunter ends its narrative with Michael permanently changed by his war experiences, a more determined man than before the war because of, and thanks to, his PTSD symptom-like behaviors, but representative of a "continuing controversy and pain the war generated" (Devine 169) for veterans and the society they returned to. The audience's last image of Michael is of him, again, fully in uniform and surviving civilian life with his PTSD symptom-like behaviors. His war experiences made him more intense, more determined than he was before the war when his "one shot" philosophy was just an idea. At the end of the film, he lives knowing that one shot can end it all and that "one shot" can be just luck. As he and his group of friends mourn Nick after the funeral, they seem uncomfortable with each other as they sit down to dinner. Michael is calm, determined and controlled. He observes each person's grief and offers a toast to Nick. In so doing and in having brought Nick home he continues his own survival and moves the others with him. I consider this representation as exemplary of a veteran myth of unrecoverability because Michael internalizes and suppresses his symptoms of posttraumatic stress behind a soldier's resolve; he does not recover, he survives. The myth of unrecoverability is seen in Michael's needing to go into survival mode to live his post-war life.

\section{Vietnam War Veteran Private Eriksson}

The film Casualties of $W$ ar was released in 1989, fourteen years after the war in Vietnam ended. The present-day segment of the film is set in August of 1974 (Figure 3.5). Only a minute and a half at the beginning and three minutes at the end of the film are set in the film's present-day. The remainder of the narrative takes the form of an extended flashback sequence. The flashback story provides the viewing audience with the combat history behind Eriksson's present-day combat-affected responses and behaviors. My analysis focuses on the 
present-day segments where a veteran myth, similar to the psychosimplicity myth that developed from The Best Years of Our Lives, concludes the film. There are some notable differences in the sociocultural context from 1946 to 1989, one of them being the existence of PTSD in clinical discourse for almost a decade at the time Casualties of $W$ ar was released. The simplicity of Eriksson's "cure" at the end of the film is an indication of how PTSD was still being interpreted by media creators and translated for popular audiences.

\section{Film Synopsis: Casualties of War, 1989}

A written prologue that emphasizes the realist aspect of the Eriksson representation appears on the screen at the beginning of Casualties of $W$ ar: "This film is based on an actual incident that occurred during the Vietnam War. It was first reported by Daniel Lang in The New Yorker magazine in 1969." The text, in stark white lettering on black background, remains on screen for a full twelve seconds. The soundtrack rumbles with an ambiguous droning sound that slowly grows louder into more distinctive sounds of the bumps and thumps of public transport. A sudden, loud bang followed by the screeching of brakes jolts the viewer, arousing their emotional attention as the opening scene appears on screen (Figure 3.6). The soundtrack helps set up a contrast with the quiet calmness of the cable car scene. A passenger reads a newspaper, holding it so the viewers can read the bold headline, "Nixon resigning" which places the present-day of the film in early August of 1974. 


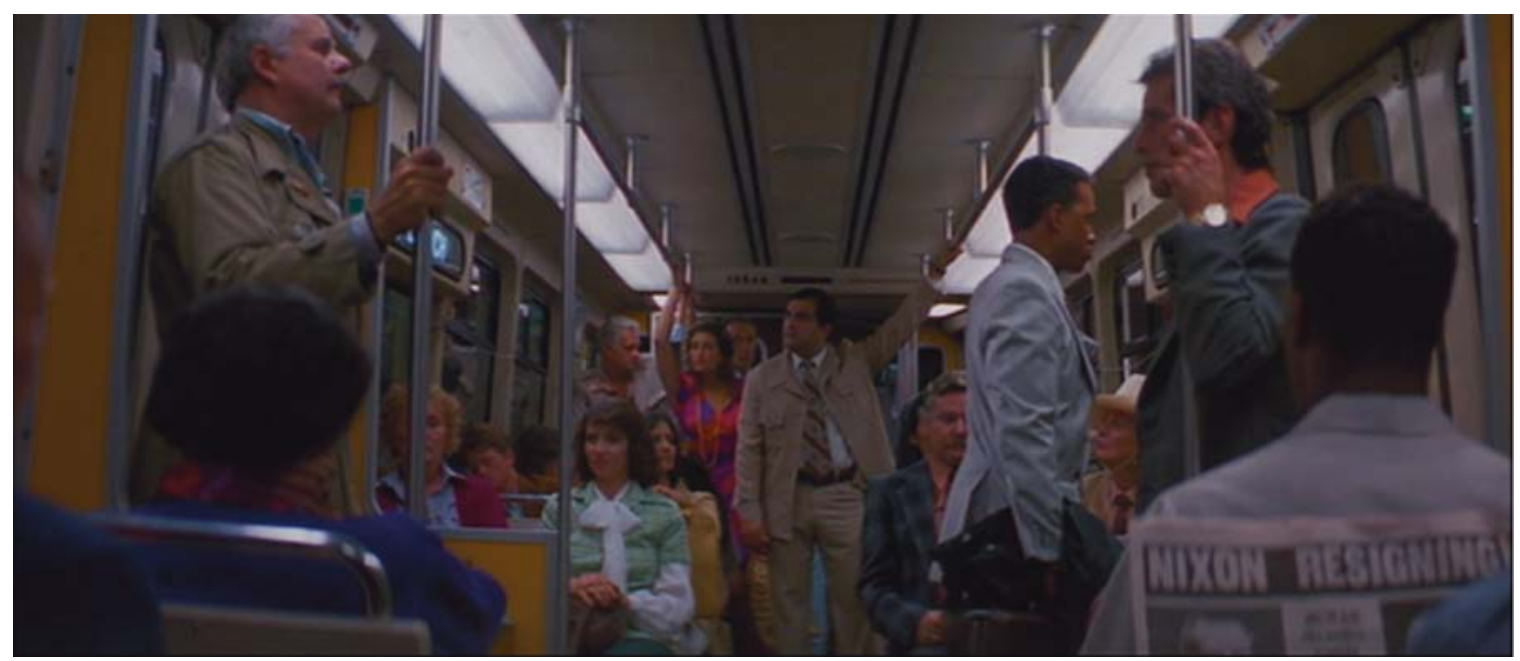

Figure 3.6: Eriksson, nearly unnoticeable as he rides a cable car in the opening scene of Casualties of War. His head rests against the window on the left behind the woman in the green blouse (DVD screen capture, Casualties of War).

Eriksson is dozing as the car stops. Predictably, some passengers get off and others get on. Eriksson wakes when the bus begins moving. One of the new passengers is a young woman. As he stares at her they briefly make eye contact, but she looks away. Eriksson's facial expression looks sleepy at first, but then confused. The viewer infers that she reminds him of someone. His head rolls back to the window and as he falls back asleep, the presentday of Eriksson in the cable car fades out while the next scene of Eriksson in combat in the jungles of Vietnam fades in.

For the next hour and forty minutes, the film shows Eriksson's war experiences as a newly-arrived soldier. Three weeks after he arrives he barely survives a nighttime firefight, but the experienced Sgt. Meserve saves Eriksson from being separated from the platoon and certain death. A small squad lead by Meserve gets a brief break from combat at a base camp, but they are soon assigned another mission, this one a "long range recon." Meserve, a hardened fighter and hot-head whose close buddy was killed a day earlier, becomes irate when he and his squad are not allowed off base. Because their passes are cancelled they are unable to "get laid" in the village next to the base. After Meserve gets orders for their recon 
mission he decides the squad will kidnap a Vietnamese girl to accompany them, "for a little portable R\&R." The guys in the squad do not think Meserve is serious, but at the start of the mission Meserve leads them to the village and takes a girl, which stuns Eriksson more than the other men.

The duration of the mission is two days. After many hours of hiking though the jungle on day one, the squad comes across an abandoned, primitively built hut where they make camp for the night. It is in this hut where Meserve and the other three soldiers rape the abused, exhausted, and frightened girl. Eriksson is afraid of Meserve, but does not succumb to his threats and intimidation. Eriksson's opposition to Meserve's actions only leaves him pitted against the rest of the squad because of Meserve's violent and intimidating leadership antics.

In the morning, they find they are near a ridge that overlooks a small Viet Cong fishing village. Eriksson is left to watch the girl as the others go "waste some gooks" under Meserve's rogue orders. She is sick and feverish, badly beaten, and terrified. He wants to help her, to free her. He attempts to leave with her to get her to safety, but the others return before he can work out a way to get her to safety. Meserve continues their mission when the activity on the river below the ridge shapes up to be a hostile, armed fighters rather than fishing boats.

The girl's persistent cough risks giving away the squad's location and when American helicopters and river boats appear on the scene, Meserve orders Eriksson to kill her quietly, using his knife, but he refuses. The others try to kill her but she survives and is able to get up, stumbling into full view. When Meserve orders the other three to shoot her, Eriksson tries to protect her but Meserve beats him down. A firefight ensues and his squad runs for 
cover and leaves Eriksson to fend for himself. As the firefight rages, Eriksson sees the girl dead at the bottom of a ravine and loses consciousness.

Eriksson wakes up in a field hospital and reports the mission to superiors. Frustrated that no adequate disciplinary action is taken, he brings formal charges. Eventually, he does get an investigation and the men are charged, convicted, discharged and sentenced to prison and hard labor. As the men file out of the courtroom, they walk past Eriksson, and as we watch each of them leave, a voiceover, repeated from an earlier scene, reminds Eriksson that when these men are released they could be "looking for a little payback!"

At the word "payback!" Eriksson flinches and jerks awake. He is breathing heavily and sweating as he looks out the window and tries to calm himself down. The cable car stops and the woman departs while he looks away. The look in his eyes suggests he is remembering and reexperiencing the trauma of the mission. He turns and, noticing she is gone, he rises to follow her. When he sees that she dropped her scarf, he picks it up and goes after her. She thanks him and turns to walk away. He calls after her again, "Chao koh!" She pauses, turns, and asks if she reminds him of someone. He struggles to say "Yeah," his body language suggesting a great deal of anxiety and tension. She looks at him, pauses, and asks, “You had a bad dream, didn’t you?” He utters, "Yeah," tension still evident in his body language. She watches his uneasy fidgeting and, after a moment, sighs and says to him, 'It's over now, I think.” After a brief pause, she turns to walk away. As he considers her words, his facial expression begins to change (Figure 3.7). 


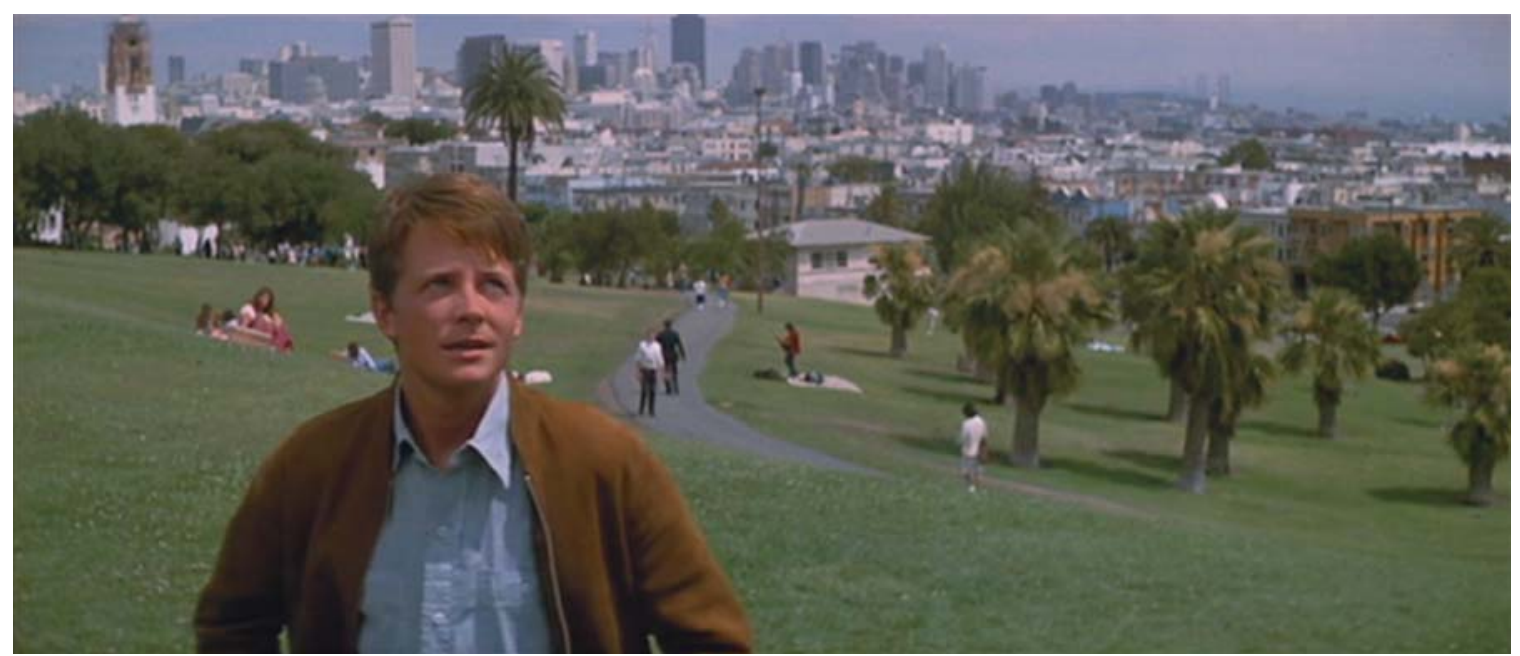

Figure 3.7: Eriksson in his last scene of Casualties of War immediately before he walks out of frame, toward the viewer (DVD screen capture, Casualties of War).

Eriksson looks as though he has been freed from both the "bad dream" she mentioned and from the guilt of having failed to stop the barbaric actions of his squad. His entire demeanor changes- - his shoulders relax and lower, his face softens, the pace of his movements slow_as relief appears to sweep over him. He looks calm in both mind and body, more at ease in his surroundings, as her words sink into his consciousness. Now fully awake, he walks toward the viewer and disappears out of the scene. The camera moves to a high angle shot, lifting the viewer's perspective to a point above where Eriksson walked toward us. The film credits begin to roll as we are left watching the young woman walking away through a calm, green, sunny park.

\section{Seeing Eriksson as a Combat-affected Veteran}

PTSD symptom-like responses of hyperarousal and reexperiencing can be recognized in the Eriksson representation during the four and half minutes of screen time that represent the post-war period. 


\section{Avoidance/Numbing, Hyperarousal, and Reliving/Reexperiencing}

Reexperiencing/reliving is indicated by the lengthy middle segment of the film and reinforced by Eriksson's physical responses to his memories: profuse sweating, rapid breathing, nervous tension and startling awake. Not only does the war story provide the viewer with Eriksson's wartime history, it also helps the viewer make sense of his behaviors related to the woman, who is the trigger for the telling of the story. The war story segment is very long and detailed, not what we would expect in a standard flashback like, for example, Fred Derry's flashback/reliving in the airplane graveyard in The Best Years of Our Lives. However, from the fade out/fade in transition from Eriksson dozing to Eriksson in a combat zone, the story can be interpreted as a vivid and disturbing collection of intrusive memories that Eriksson relives and reexperiences in great detail and in a manner out of his control. The time frame of the film, 1969 to 1974 , indicates that the reexperiencing of his combat experiences is persistent and recurring; five years later, the thoughts are as vivid as they were when he was in combat. The woman on the bus, bearing only a fleeting resemblance to the Vietnamese girl, is enough of a look-alike to trigger the vivid reliving of his war experiences.

Hyperarousal is also indicated during the few minutes of Eriksson's screen time in the present-day. His jittery body movements, rapid breathing, and excessive sweating are suggestive of the hyperarousal symptom of PTSD. Because he appears unalarmed by these symptoms, we can presume he is familiar with these physical responses, which suggests they are regular occurrences for him. The relief Eriksson exhibits in the final scene, a normal level of calm awareness of the present-day world rather than the persistent reliving of the war of years earlier, creates a feeling of meeting up with a long lost friend. The ease with which 
Eriksson recovers his old self, that long lost friend, is a variation of the psychosimplicity myth that preceded the unrecoverability myth.

\section{Veteran Myth from Private Eriksson Representation}

From the few minutes of present-day story at the beginning and end of Casualties of $W$ ar develops a veteran myth nearly identical to the psychosimplistic veteranness introduced in Chapter 2 above. The Fred and $\mathrm{Al}$ representations from WWII essentially "get over" the posttraumatic stress symptoms they exhibit after returning home simply by making the decision to put the war behind them. In so doing, Fred and $\mathrm{Al}$ immediately overcome the difficulties they encountered when readjusting to civilian life and society. The benefits of this improvement in their private lives extend to broad socioeconomic benefits for society overall. Eriksson's PTSD symptoms appear to be cured when the woman who triggers them simply tells him she thought his bad dream was over. I argue that this psychosimplicity is a variation of the Fred and $\mathrm{Al}$ myth because his nightmare of war is purely personal. There is no indication in the film that he has any other challenges such as self-medicating with alcohol or trouble holding a job that would affect his functioning in society; instead, we see only his internal struggle with his traumatic past, one that seems to be easily resolved.

Eriksson as a signification of healing one's personal trauma through confronting is thus greatly oversimplified. Once "cured" of his posttraumatic stress, he easily integrates back into society by walking toward the audience, thereby metaphorically rejoining society, but significantly, as he does this, he disappears. Once easily cured, or supposedly so, he then becomes unseen. The narrative of the film makes his traumatic combat experiences and his posttraumatic stress visible in order to fix it, and then the veteran literally goes missing. This veteran myth suggests an intertwining of two oversimplified ideas: the belief that a veteran 
should simply face his psychological challenges to eliminate them, and the belief that doing so will allow him to return to a happy civilian life. In this variation of the psychosimplicity myth, the veteran needs to choose to face his traumatic memories in order to neutralize them. Fred and $\mathrm{Al}$ needed to consciously decide to get over their war trauma and become contributing members to society's economic recovery after the war, but Eriksson needs only to decide to face his traumatic memories to cure them so he is no longer a troubled man and reminder of the war. The audience presumes Eriksson goes on to continued post-war success, thereby freeing society from its memories of the trauma of the Vietnam War. 
CHAPTER 4

\section{Post 9/11 Veteran Representations}

"I don't know, J.T. Do you know why I am the way I am?"

- Sergeant James, in The Hurt Locker 


\section{Introduction: Post 9/11 Veteran Representations}

After the World Trade Center attack on 9/11/2001, the sociocultural landscape changed in terms of how safe the public felt from large-scale violence carried out within the U.S. homeland. Legislation authorized unprecedented levels of vigilance to prevent additional attacks ${ }^{22}$. A nation's collective anger and calls for retaliation fueled an equally inspired US Congress and President to pass, on September 18, a resolution for the "Authorization for Use of Military Force," which meant another generation of soldiers would be sent to war.

Thirty-five years had passed since the end of the ten-year war in Vietnam and ten years had passed since the six-month Gulf War that ousted invading Iraqi forces from Kuwait. Veteran myths constructed and shared through popular visual media helped to reinforce ideas that veterans negatively affected by their war experiences could, if they wanted, either easily heal or hide their invisible wounds. The domestic turmoil of the Vietnam War had subsided enough that citizens and soldiers were ready to go into battle once again, and the War on Terror's ground war began in October of 2001 in Afghanistan and expanded into Iraq in March of 2003.

Throughout the post 9/11 period, the overall landscape of visual media continued to evolve. Access to visual media, for example, expanded and changed in significant ways from the Vietnam War period as technologies for producing visual media (photographs and video)

22 In response to the events on 9/11 the first Director of the Office of Homeland Security was appointed on September 22, 2001. In November of 2002, an act of Congress created the Department of Homeland Security (DHS) as a Cabinet-level department (www.dhs.gov). In addition, the "USA Patriot Act" (Uniting and Strengthening America by Providing Appropriate Tools Required to Intercept and Obstruct Terrorism) was signed by the President on October 26, 2001 to "take an essential step in defeating terrorism, while protecting the constitutional rights of all Americans” (www.pbs.org/newshour/updates/terrorism-july-dec01-bush_terrorismbill). The law quickly came under scrutiny and raised controversy over both of these objectives. 
became much more widely available and sharing content via social media outlets (e.g.

Facebook, Youtube, Flickr, etc.) became commonplace. The censorship imposed by The Production Code from the 1930s, 40s and 50s classical Hollywood era became a relic of the past for contemporary filmmakers and audiences. Movie theaters, once the only timely venue for major motion pictures, now compete with visual media accessed through cable, satellite, and Internet providers for viewing in the home and on mobile devices. News journalists embedded in military units report live from the frontlines of conflicts as everyday news fare. Representations that appear genuine and realistic to audiences in today's visual media rich society differ from veteran representations examined in the two previous chapters.

In this chapter, I analyze two war veteran representations: Sergeant James from the major motion picture The Hurt Locker (2008), and a selection of veterans from HBO's documentary $W$ artorn: 1861-2010 that attempt to bring PTSD into clear view. The veteran representations analyzed in this chapter are personal stories embedded in broader social wartime narratives in the social context of their personal lives and individual PTSD symptom-like responses and behaviors. As we entered the post 9/11 period, a legacy of veteran myths such as the criminality, psychosimplicity, unrecoverability, and monumentality myths circulated in sociocultural contexts. The veteran representations from The Hurt Locker and Wartorn: 1861-2012 contribute veteran myths to this legacy; one I leave partly undefined and one I term psychostasis.

\section{Veteran Discourse after $9 / 11$}

Veteran discourse was significantly affected by the events of $9 / 11$. The four, simultaneously hijacked passenger planes that were flown into the World Trade Center, the Pentagon, and a Pennsylvania field, respectively brought the U.S. to a renewed sense of a 
potential for global, political calamity. The sociopolitical conditions following $9 / 11$ cleared a pathway to war and provide a distinct demarcation from the previous period after the end of the Cold War when large-scale U.S. war involvement seemed highly unlikely. Similar to the domino-theory argument for the Vietnam War, the war-on-our-homeland argument helped unite the political powers within the U.S. in a manner that prompted two new, large-scale foreign wars: the first in Afghanistan (2001-present) and the other, an expansion of the first, in Iraq (2003-2012).

By 9/11, vet was acceptable as a term to refer to the veteran, combat veteran, or war specific veteran. The shortened word not only simplified the discursive practice of referring to a war veteran regardless of when or in what capacity they served, but also helped define the person through their war experiences while detaching them from a specific war. Veterans of WWI, WWII, the Korean War, the Vietnam War, Gulf War, other smaller conflicts, and during peacetime were part of the population and readily described as vets.

Audiences of popular films had watched depictions of the intensity of military training, combat, and the aftermath of military service. In addition to The Deer Hunter and Casualties of War (see Chapter 3), films such as Coming Home (1978), Apocalypse Now (1979), Platoon (1986), Full Metal Jacket (1987), and Born on the Fourth of July (1989) interpreted for audiences the chaos, horror, brutality and insanity of a soldier's combat experiences through fictional or fictionalized film characters. By the post $9 / 11$ period, the terms posttraumatic stress and PTSD achieved a type of normalcy due to a thirty year history in the DSM and increased usage in both clinical and popular discourse. The disorder could stem from experiencing any kind of traumatic event including horrific automobile accidents, rape, child abuse, violent crime and domestic violence in addition to events in war and combat. Psychologists and psychiatrists 
have developed and implemented treatment approaches to restore social functioning for sufferers. Outreach to undiagnosed sufferers also increased from the previous periods. The National Center for PTSD now provides a wide array of information about PTSD on its web site, reaching out to veterans and other trauma sufferers to help them better understand the disorder and the variety of options for treatment available to them. The site includes descriptions of Cognitive Processing Therapy (CP'T), which "appears to be the most effective type of counseling for PTSD," Prolonged Exposure (PE) therapy, Eye Movement Desensitization and Reprocessing (EDMR), as well as other group and family therapies (National Center, "Treatment"). In contrast to the previous periods, anyone who thinks they might be suffering from posttraumatic stress can begin learning about it from a reliable source.

News media also inform popular veteran discourse through ongoing coverage of the wars in Afghanistan and Iraq and through reports such as the Mount Rainier and Fort Hood shootings, which identify PTSD, or the mere possibility of it, as a causal factor in the violence. News coverage of soldiers returning from war and alarming reports of increasing incidences of soldier suicide also create more sociocultural awareness of military service, combat stress and undesirable outcomes. PTSD is also inferred through images (see Figures 1.1, 1.4, 1.5 in Chapter 1) that circulate throughout popular discourse.

In addition to clinical and mass media, contemporary veteran discourse also circulates through amateur media. Home computer, camera, video and mobile technologies allow almost anyone to create visual media and distribute it online using commercial sites and social networks. These media artifacts do not acquire the same level of distribution as studio films and other big-budget media, but their availability is a significant change from the two 
previous eras examined above and allows individuals to share their own experiences of PTSD.

An element of contemporary veteran discourse evident in visual media is the entanglement of the ideas of soldier and veteran. The marketing images for the Wartorn documentary's web site and DVD cover (Figures 4.1 and 4.2) are an example.

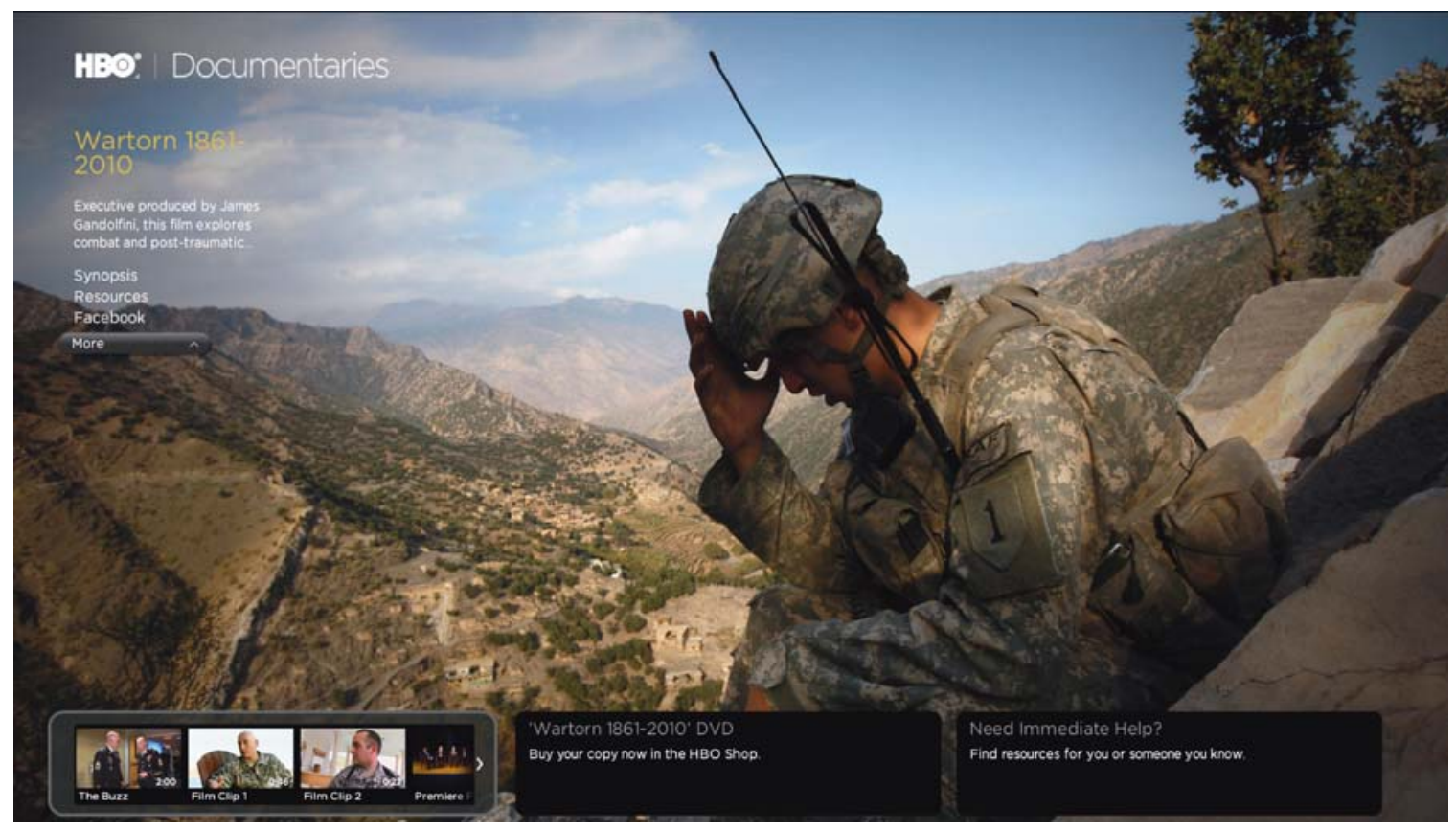

Figure 4.1: Web site home page for HBO's documentary film Wartorn: 1861-2010 (Screen capture, accessed February 21, 2011).

The photograph in Figure 4.1 is of a soldier at his post. The DVD cover uses the same image but with the U.S. flag as the soldier's backdrop. The flag appears faded, its colors nearly as drab as the military colors of the soldier's fatigues. 


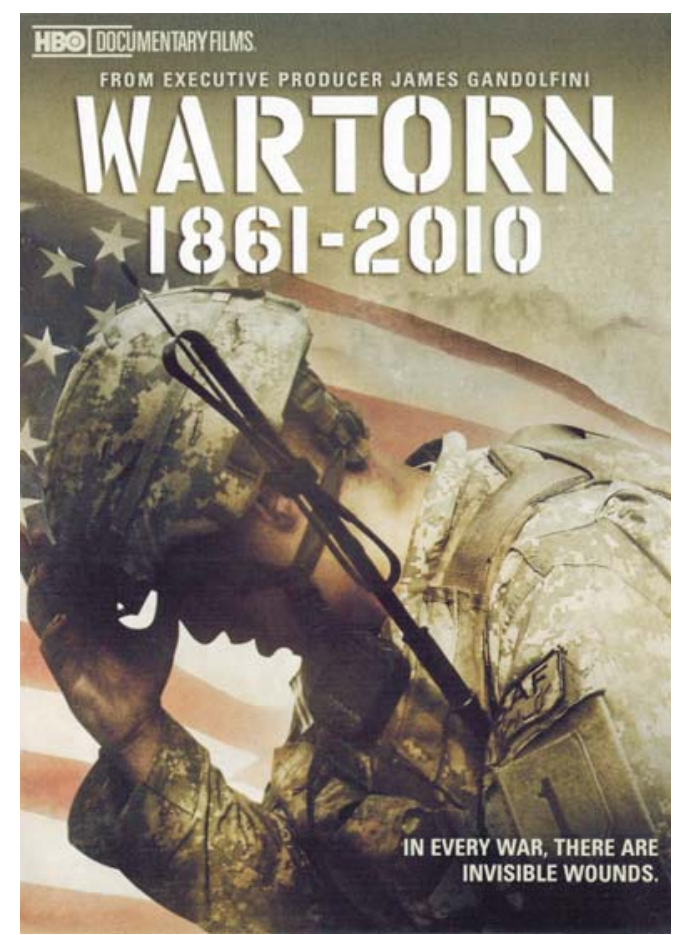

Figure 4.2: DVD front cover image for HBO's documentary, Wartorn: 1861-2010. (Scanned from DVD cover.)

The visual components of the images used on the web site (Figure 4.1) and the DVD cover (Figure 4.2) keep the ideas of active soldier and combat-affected veteran closely bound; essentially they are merged into one image of an invisibly-wounded soldier. I do not claim that active duty soldiers are immune from PTSD (the image does suggest the first diagnostic criteria, exposure and response to a stressor). Instead I argue that blurring the idea of the active soldier and the returned veteran helps support the idea of the temporariness rather than the persistence of posttraumatic stress. In contrast to the cover image of the soldier, most of the veterans whose stories are presented or are interviewed in the film have returned home.

The image offers popular audiences an invitation to see the stress of the soldier by situating the viewer close to him and at his side as he tries to cope with the immediacy of war stress and the inevitability of more to come. The title, $W$ artorn: 1861-2010, places this 
soldier in a tradition that goes back to the Civil War, into a history of invisibly wounded soldiers. The images appear to hide nothing: the close-up image of the soldier, the combat stress of fighting a war, and the U.S. flag are all clearly visible, but the connotative meanings suggested by the text "invisible wounds," accompanied by visual cues, obscures the "post" in Posttraumatic Stress Disorder. This turn, in effect, renders the combat veteran less visible, obscured by the concept of the soldier.

Popular visual discourse in this period also includes a series of Iraq and Afghanistan Veterans of America (IAVA) and The Ad Council's (AC) public service announcements (PSA) in video format for distribution as television and Internet commercials. The ads speak directly to returning soldiers' feelings of solitude. The ads are part of an outreach program to let veterans know they are "not alone." The feeling of solitude portrayed in one of the ads echoes the solitude of man in the $W$ artorn image. As we see in the following series of six screen captures from a 65 second video (Figures 4.3-4.8) titled "Alone," a soldier is returning from deployment. Wearing fatigues and his backpack, he has arrived at an empty airport where he is the only person departing the plane (Figure 4.3) and in the airport (Figure 4.4). As he continues his journey home, he is alone on a train and the streets (Figure 4.5). Finally, a man appears and walks toward him (Figure 4.6). The man, dressed in civilian clothes, including a Marines t-shirt, is presumed to be a veteran. He welcomes the soldier home and reaches out to shake his hand. As their hands meet, other people and city activity suddenly appear (Figure (4.7); in other words, not until the solitary returning soldier makes physical contact with an already returned veteran who reaches out to him does civilian society appear. Presumably, the returning soldier feels as invisible to society as society 
appears to him until he makes contact with another veteran. At that moment, the soldier's facial expression changes from wary to a more relaxed smile.

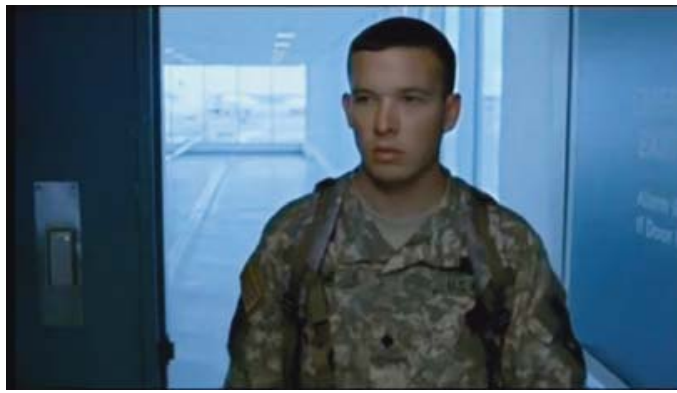

Figure 4.3 Returning soldier's airport arrival.

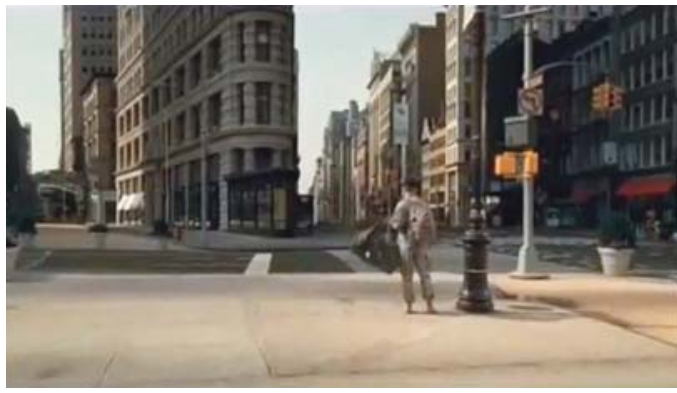

Figure 4.5 Returning soldier at bus stop.

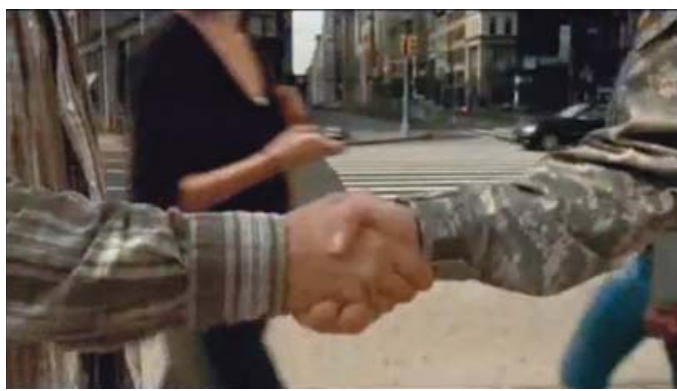

Figure 4.7 Handshake, surrounding activity.

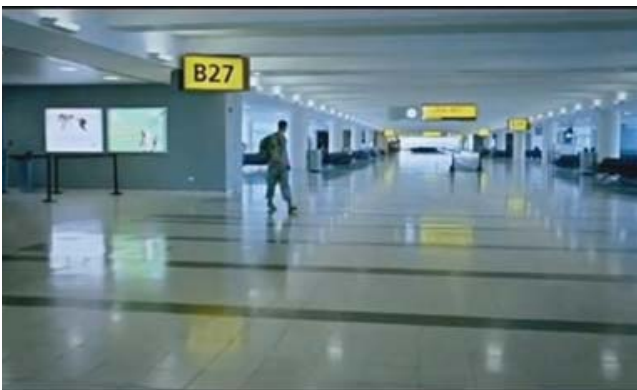

Figure 4.4 Walking through the airport.

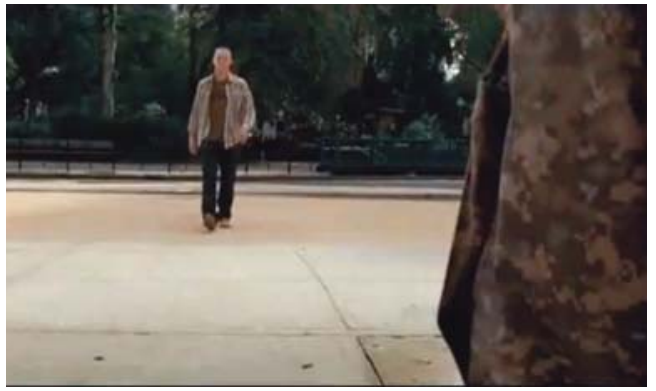

Figure 4.6 Man appears, walks toward soldier.

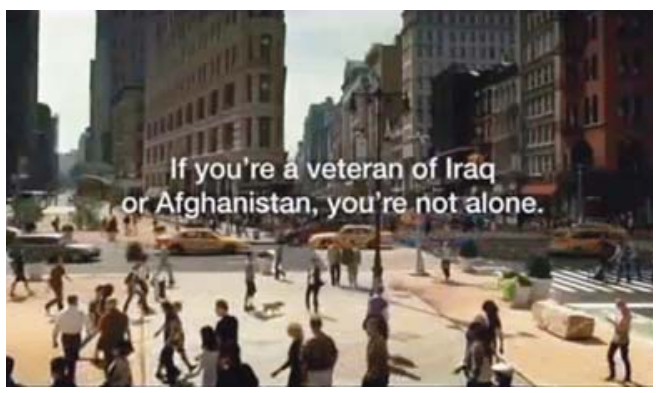

Figure 4.8 Text displayed at end of ad.

(Figures 4.3 - 4.8 captured from Internet video, “Alone,” IAVAVids, accessed July 22, 2013).

Messages in other of the IAVA/AC ads repeat the sentiments of overcoming the feeling of solitude, of feeling alone, and suggest that other veterans are here to help. In addition to the 'you're not alone' message, the ads state that, 'veterans are all around you' and 'we've got your back,' suggesting that the support system the soldier had in the service is still there, but also that it is exclusive of non-military persons who, in the ad, go on about their business without noticing or reacting/responding to the veterans (Figure 4.8). The IAVA ad speaks 
directly to returning soldiers while providing an opportunity for civilians to understand a soldier's perspective on the strange experience of returning home, an example of the veteran's feeling of being "precariously situated at the edge of normalcy" (Hale pg 17 above) The recognition that the returning soldier is caught up in an uncertain process of re-entering civilian life is reminiscent of Al's trepidation in The Best Years of Our Lives. Al's statement that “everybody's gonna try to rehabilitate me” suggests the attention was unwelcome. However, a psychosimplicity veteran myth appears from the period and a dominant discourse where a combat-affected veteran could simply put his war experience behind him by making the choice to do so. Unlike the earlier representation, this ad shows the already returned veteran reaching out to the newly returning soldier, who feels isolated rather than adverse to others trying to help him. However, both go unnoticed by the civilian activity that surrounds them and suggests a veteran myth of invisibility. Similar to the unrecoverability myth from the Michael representation (Chapter 3), the returning soldier in the "Alone" ad returns physically and feels isolated. Unlike the Michael representation, another veteran warmly greets the returning soldier to help him overcome his sense of isolation.

The remainder of this chapter presents my analysis of veteran representations from two films from the post 9/11 period. The first is Sgt. James from the 2008 film The Hurt Locker, released six years after the start of the war in Afghanistan and three years after the war expanded to Iraq. The second is a collection of veterans from the HBO documentary Wartorn: 1961-2010, released in 2011. Both leave us with complex and unresolved questions.

\section{Iraq War Veteran Sergeant James}

Sergeant Will James in the 2008 film The Hurt Locker is a fictional character who is portrayed as serving in Iraq after having previously deployed to Afghanistan. Most of the 
film tells a story of his war experiences as a bomb technician who disarms bombs and IEDs, the improvised explosive devices that U.S. popular audiences learned about after the war on terrorism began in Afghanistan. The Hurt Locker advertises itself as "powerfully realistic, action-packed, unrelenting and intense" and is cited by Time magazine as "one of the great war movies" (DVD back cover) ${ }^{23}$. A short segment at the end of the film shows James as a combat-affected veteran. While no clear or distinct myth can be seen as emerging from this contemporary veteran representation, it carries characteristics, ideas and concepts that suggest potential for myth-building. These ideas are suggested, in part, through James'

decision to return to the war after multiple traumatic deployments - the one that constitutes the majority of this film and at least one prior deployment where James acquired the frag scars pointed out by another character, Eldridge_-and also by James' PTSD symptom-like behaviors and responses exhibited during the brief civilian sequence of scenes at end of the film. Indeed, James ultimately identifies more with his soldier's role than his civilian role, which turns out to be intolerable for him. However, the film concludes with Sgt. James still dealing with combat-effects, leaving his PTSD-reminiscent state of mind to a volatile, unresolved and ambiguous future.

\section{Film Synopsis: The Hurt Locker, 2008}

The film begins with a mission that kills a bomb technician, one of three men in a tight unit, whom James replaces. He joins the unit with only 39 days remaining on its deployment. James' rowdy, reckless personality clashes with the friendly, efficient familiarity the three

23 The Hurt Locker won six Academy Awards including Best Motion Picture of the Year, Best Achievement in Directing, Best Writing for Original Screenplay and also Best Sound Editing, Sound Mixing and Film Editing (imdb.com). 
men of the unit had developed. However, James is very good at his job. The first missions of this newly formed unit--including Sanborn, who is intelligent, steady and mature; Eldridge, who is younger and more impressionable; and the newly arrived Jame--reveal James' seemingly careless attitude, risk-taking style and undeniable skill.

The unit's first mission with James is to investigate a reported IED buried in street rubble in a residential area. James tells the guys to "break out the suit," the protective gear he wears when disarming bombs. James overrides his unit's preference to send in the remotely controlled robot equipped with a camera to check out the situation first. As James walks toward the suspected site, he drops a smoke bomb that hides him from view of his support unit, who scramble to assess the situation so they can protect him. Following this display of James' recklessness is a display of his competence. After the smoke clears, a cab driver, a possible car-bomber, passes through a military barricade. The driver's intentions are unclear. James pulls out his sidearm and confronts the cab driver, who has stopped the car. James manages to get the driver to retreat and soldiers from another squad immediately apprehend him. Continuing on his mission, James locates the IED. He quickly disarms a large, single shell, but then notices another detonation cord. It leads him to a secondary device consisting of multiple shells and James gets to work disarming them. While James works on the device, a man who closely watches James from a window several floors above him is revealed to the audience. When James finds the main part of the bomb, and starts defusing them, the man starts quickly down the steps. When the man reaches street level, he exits the building and he and James are suddenly face-to-face. James, having disarmed the bombs, had been following the cord and found where it attached to the wall of the building to be detonated manually. Presumably, if James did not explode the bomb while disarming it, the man from the 
building would have detonated it manually, a situation that they acknowledge by looking eyeto-eye. James holds up a detonator and smiles at the man, who drops a small battery from his hand as he runs off. This mission is over. This sequence introduces James as a complex character who is both similar to and different from Sanborn and Eldridge. Like them, James is very skilled and competent, but he also appears to be reckless and willing to accept more risk. A difference is introduced when Sanborn and James first meet. James removes the plywood covering the window in his room in the camp even though Sanborn points out it is there to "cut down on the lateral frag," but James dismisses the risk, noting, "it won't stop one form coming through the roof."

The complexity of the James character continues when the unit is on base. James is carefree and playful when he meets a young Iraqi boy, Beckham, who sells pirated DVDs to soldiers on base and plays pick-up soccer games in the dusty streets. James jokes around with him, haggles and buys a DVD. The Sanborn and Eldridge characters also grow in complexity. Sanborn has been a soldier for nearly a decade. He respects the procedures that keep soldiers alive. He is more careful, safer, than James, but also very skilled. Eldridge regularly meets with a camp psychologist and grapples with questions of life and death how he relates to both in the ambiguity of combat. In his downtime, he plays video games in a virtual world of bloody violence. Eldridge also grapples with the differences between Sanborn and James as role models.

As the film progresses, the intensity and brutality of combat escalates and helps the viewer acquire a sense of how focused and ready-for-anything these soldiers must be to carry out their duties. Each mission introduces additional levels of danger and violence to the body and mind of the soldiers and draws clearer distinctions between James and his unit. 
Their next mission reinforces how much risk James is willing to put him and his unit in. They arrive on the scene and prepare James to approach a suspicious vehicle parked next to the UN building. A sniper attempts to detonate the car bomb as James approaches it but instead of exploding the car catches on fire. James puts out the fire and removes his protective gear. "There's enough bang in there to send us all to Jesus. If I'm gonna die, I'm gonna die comfortable," he tells Eldridge, who is covering James from nearby as Sanborn covers from the roof of the building. As James works on the bomb, the rest of the unit continues to assess a changing situation, which presents a growing risk to the entire squad the longer they remain on the scene. Eldridge notices a man filming them and Sanborn realizes that onlookers are exchanging hand signals with the man filming. Sanborn informs James of the increasing risk, saying, "We got a lot of eyes on us, James, we need to get out of here," growing more insistent once the building has been evacuated. Working diligently, James, apparently distracted by Sanborn's communications, removes his headset. The intensity increases for the audience as the conflict between James, who is determined to disarm the device, and the rest of his unit, who have a high degree of certainty they will all be killed, also increases. Finally, James locates the detonator and disarms the device only seconds before detonation. He crawls out of the vehicle, informing his unit, "We're done!" When James returns to their humvee, he lights up a cigarette. Sanborn walks up to James and punches him in the head, telling him, "Never turn your headset off again." Eldridge smiles, seemingly satisfied with Sanborn's actions. James takes it in stride and simply retrieves his fallen cigarette. This tension between the men contrasts sharply with external perspectives when the commander of another unit approaches James to tell him, with 
Eldridge listening, that he is impressed with James" "wild man" style and the 873 bombs he has disarmed.

As the film continues, each mission adds another level of trauma to the unit. We next see Sanborn, Eldridge and James tasked with exploding bomb materials. After their first remote detonation, James stops the job because he has forgotten his gloves at the detonation site. While he drives to the site to retrieve them, Sanborn and Eldridge watch. Sanborn considers killing James, commenting to Eldridge that, "accident's happen.” They do not kill him, but their resentment of James' behavior is clear.

In the following scene, the unit is returning to base when they come across a squad of contractors, bounty hunters who have captured known and wanted terrorists. The contractors are in need of mechanical assistance. Snipers begin shooting at them and they all take cover in a gully. After several of the contractors are shot and killed, Sanborn and James team up on a large caliber, long-range barrett rifle. James locates the targets and directs Sanborn, who fires the weapon. Working together, they kill three enemy fighters and Eldridge kills a fourth. In addition to the intensity of combat, this scene shows the extremely hot and dry conditions in Iraq. But unlike the previous sequence that made James out to be somewhat of a renegade, the ambush scene reveals James' commitment to his unit's survival by emphasizing his dedication to his men and his leadership, exemplified by his taking command during the ambush. We see this dedication when James tells Eldridge to hand a juice up to him and Sanborn, poking the straw into the package and holding it for him first, and also when James calms a nervous, panicky Eldridge so he can perform more effectively during the fight. 
This sequence of scenes reveals a dynamic and complex bond between the three men. Sanborn remains uncertain of James' reckless tendencies, but Eldridge perceives a competence he admires. During a scene of roughhousing among the three men, Eldridge sees "frag scars" scattered across James' body from an earlier deployment. James downplays their significance or perhaps does not recognize their effect on the young soldier. The scene suggests that Eldridge is developing a growing appreciation for James' leadership.

The unit's next two missions define some of James' inner conflicts. The first takes them to the dead body of a boy whom James confuses for Beckham, which is in the process of being booby-trapped as a bomb. James' self-discipline begins to unravel. He starts to prepare to explode the half-made bomb on site, but changes his mind and removes the explosives to retrieve the boy's body. That night he goes on a rogue, one-man mission into a nearby town to find who is responsible for Beckham's death, but his mission falls apart and he makes his way back to base. The second mission begins shortly after he returns to base. James joins Sanborn and Eldridge in the humvee and keeps his earlier whereabouts to himself. They have been assigned to assist at the site of an explosion within the "green zone," a highly guarded and relatively secure area within Baghdad for running U.S. operations and government functions. James, fresh from his failure to find those responsible for Beckham and feeling as though the bombers are nearby "watching ... laughing ..." initiates a private mission for the three of them to hunt down those who set off this explosion. Eldridge, who has been increasingly aligning with James in combat situations, is ready to go with him; Sanborn reminds them both it is not their job "to go haji hunting," but James, who outranks Sanborn, orders him to go along, reminding him, 'You don't say 'no' to me, I say 'no' to you." As they look for the bombers, shots are fired and Eldridge is wounded and nearly 
dragged off by two Iraq fighters. James and Sanborn chase them down, kill them and recover Eldridge. After they return to base, James is near the breaking point. Still wearing his gear, he goes to the showers and stands under the water, letting dust and blood wash from him. He sinks to the floor, exhibiting emotional distress and frustration, fiercely rubbing his face and head before banging his hands on the shower walls. Thus both of James' selfdefined missions are failures. The next day James sees Beckham alive, is surprised, and ignores the boy and his invitation to play soccer.

As Eldridge is being loaded onto a helicopter to be evacuated to a hospital, James and Sanborn see him off and Eldridge verbally lashes out at James, who apologizes to him for having gotten him shot. Eldridge, yelling so James can hear him over the sound of the engine and rotors, responds, “thanks for saving my life, but we didn't have to go out looking for trouble to get your fucking adrenaline fix, you fuck!” James backs off. Eldridge's rage seems unexpected; he had wanted to go with James, yet James' facial expression suggests that Eldridge's point hits home. Sanborn, observing the interaction, does not interfere. He says good-bye to Eldridge, telling him, "Take care of yourself ... see you on the other side, man."

In their next mission, James' every effort to disarm the bomb is defeated. When they arrive at the site, an Iraqi man has explosives padlocked to his body within an iron vest-like device. It is unclear whether he could be luring U.S. soldiers in to be killed, whether he is a victim of terrorists, or if he simply changed his mind about being a suicide bomber. Nearby, a translator tells James the man is “not a bad man, he’s just asking for help.” James approaches a soldier from another unit already on the scene to get his radio. The soldier asks James, "Can we just shoot him?" indicating the man would pose less of a risk if he were 
dead, but James answers with certainty, saying "No" as he takes control of the situation. Sanborn approaches James, telling him, “this is suicide, man” but James replies, "that's why they call it a suicide bomb, right," purposefully twisting the meaning. "Let's do this," says James as he takes on the challenge.

The construction of the bomb makes it impossible for James to save the man. A timer indicates only a few minutes remaining before detonation. James displays behaviors suggesting it is important to him that the man survives. As he is figuring out how to free the man, he is talking as a translator is heard on James' handset. "Please, I have a family," the man says. James attempts to calm him, telling him, "I know, I know.” With less than two minutes remaining, James is still trying to figure out a solution. With forty-five seconds remaining, James is using all of his strength to cut one of many bolts. Ordering Sanborn and the other soldiers to take cover, he is finally able to cut off one of the padlocks, but there are many more. Ultimately, time runs out and James must leave the man to his death. Before leaving, James tells him, “There's too many locks. There’s too many. I can't do it, I can't get it off." The man begins to understand and fear floods over his face. "I'm sorry, okay. Do you understand? I'm sorry," yells James, looking the man in the eyes. James stays with the man as long as he dares, but must leave him and seek cover. Running in the heavy suit, James turns back as the bomb goes off, obliterating the man and catching James in the blast. As in the opening scene, where the man in "the suit" was killed by a blast, James falls to the ground, but after a tense pause he moves. He survives the mission with minor wounds.

The next scene takes place in the humvee with James and Sanborn driving back to base. In response to Sanborn's question, “How do you do it, you know, take the risk?” James replies, "I guess I don't think about it." Sanborn continues, "Every time we go out; it's life 
or death. You roll the dice. You recognize that don't you?’ James acknowledges that he recognizes the risk, but pauses in the conversation before continuing, "I don't know, J. T. Do you know why I am the way I am?” Sanborn answers, looking at James, "No. I don't." James returns the look.

In the next scene, James has returned from the war. We can tell that some time has passed because James' hair is longer. We first see him grocery shopping with his ex-wife and young son (Figure 4.9).

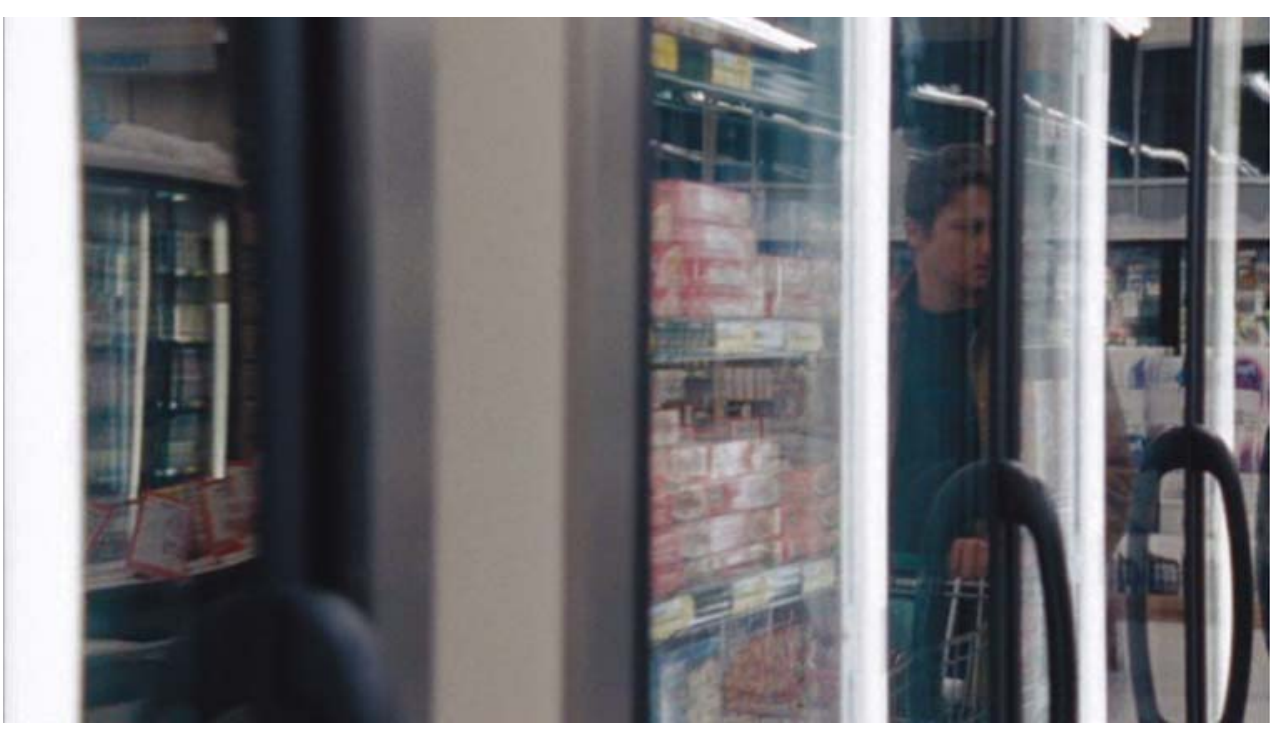

Figure 4. 9: The first image of Sergeant James in The Hurt Locker after he is out of the service is his reflection (DVD screen capture, The Hurt Locker).

The ordinariness of the setting is strikingly bland compared to the last war scene and the rapid cut helps the audience feel the contrast. The setting of being back in civilian life seems contrived or artificial compared to the dynamic and evolving settings of the missions and the base. The film cuts abruptly again to an outdoor scene and James cleaning the gutters of the house, then to a short close-up, profile shot of him apparently unable to sleep, with a fuzzy television screen in the background. Another rapid transition shows James telling his ex-wife a war story of a suicide bomber detonating in a market. She seems either uninterested or 
uncertain of how to respond. At the end of this short scene he says, "You know they need more bomb techs." The final civilian scene is of James talking to his young son, or rather to himself, because his son is too young to understand. James is figuring out who he is or what he is, and eventually explains that being a bomb tech may be the only thing he loves (Figure 4.10). As he considers this, the sound of helicopters can be heard and grows louder for the transition to the end of the film.

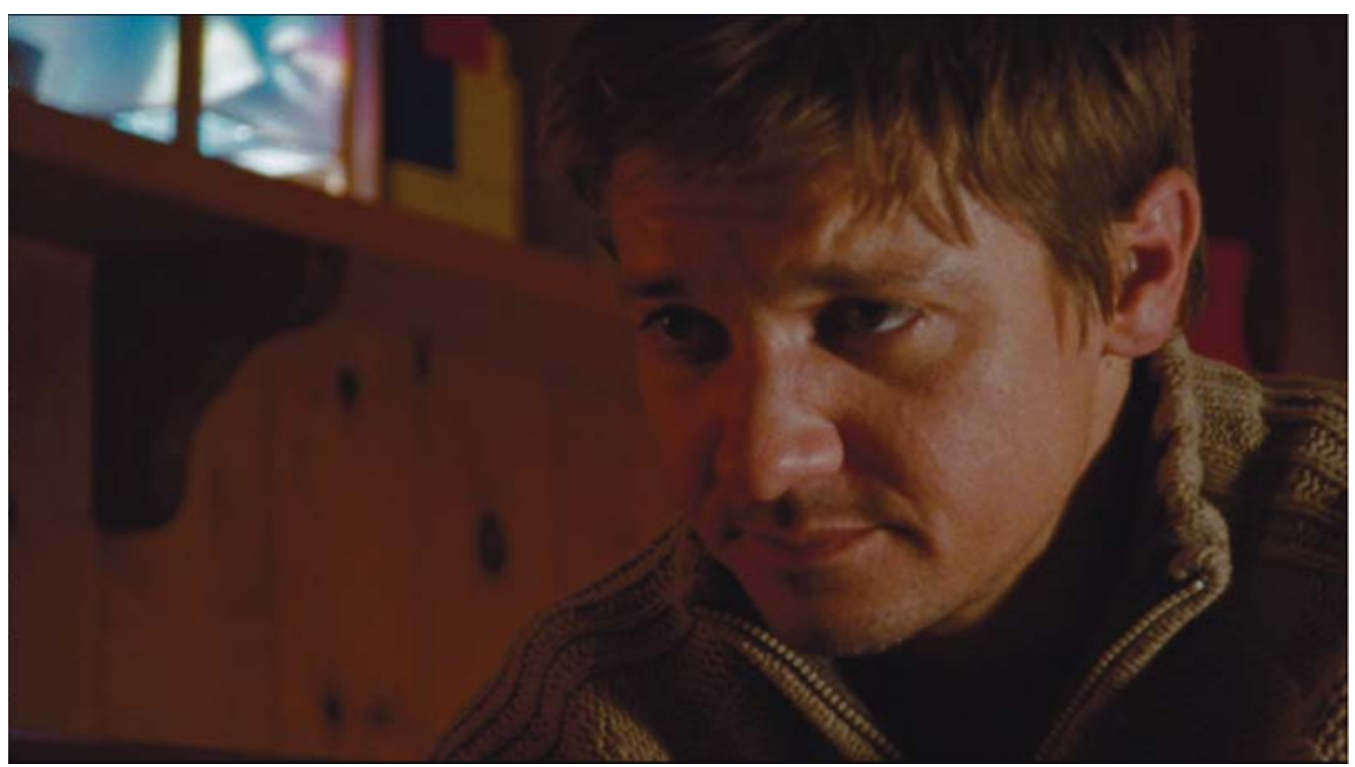

Figure 4.10: Sgt. James in The Hurt Locker, before he redeploys (DVD screen capture, The Hurt Locker).

In the final scene military helicopters are landing and unloading newly deploying troops. James is among them and is greeted by a soldier welcoming him to a new unit. The image is in slow motion, slowing the pace as James walks across the tarmac, the camera focusing on his boots. Via an almost invisible cut his light-duty uniform changes to field gear as the audience watches him step comfortably back into a mission. The camera pans up to show James' facial expression. He wears an easy smile, letting us know he is in his comfort zone. The final image of James resumes real-time pace and shows him in his bomb tech suit 
walking away from the audience and his new unit toward another bomb device (Figure 4.11). He appears confident and isolated on the desolate street.

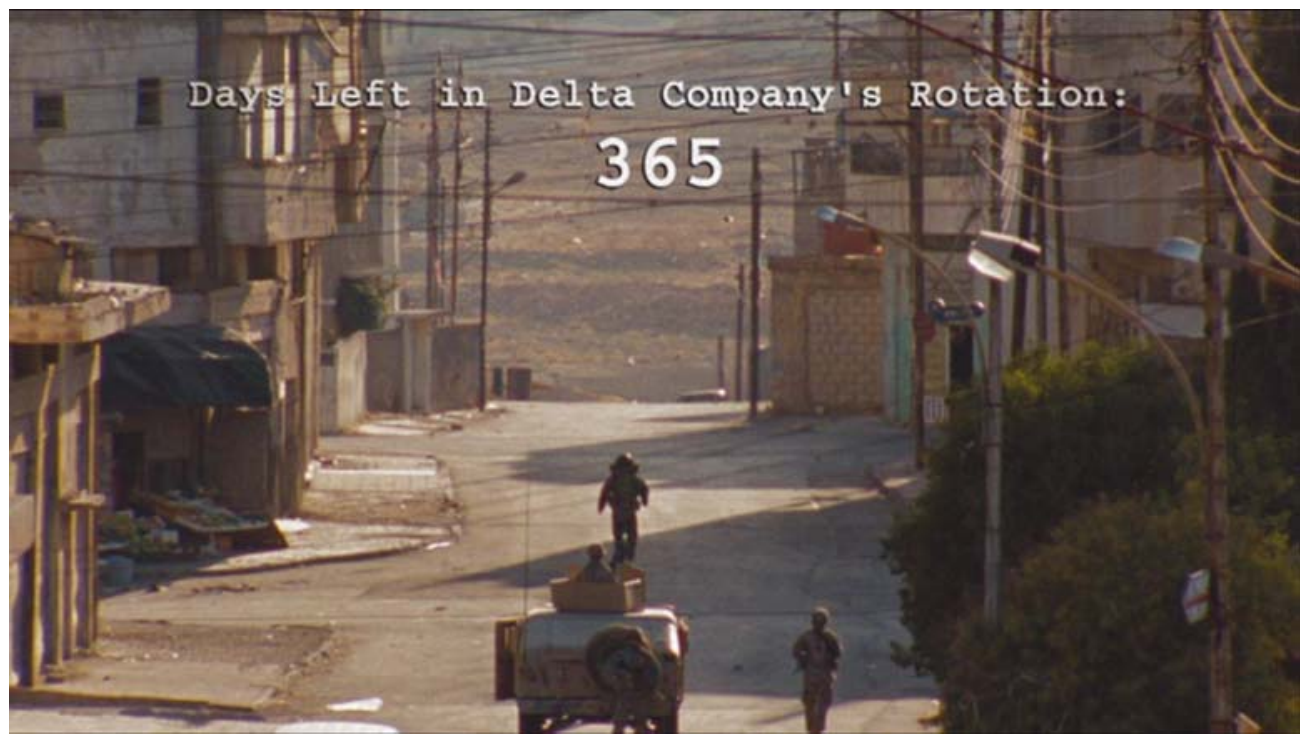

Figure 4.11: Sgt. James in the final scene of The Hurt Locker (DVD screen capture, The Hurt Locker).

\section{Seeing Sergeant James as a Combat-affected Veteran}

The first two hours of The Hurt Locker draw a picture of the intense, unpredictable and continuous stresses of war. It begins with the death of Thompson, a likeable and respected character whose role of bomb tech James fills in the unit. From the beginning, we know how quickly death can occur for James and that, whether or not he is a likeable character, he can die unexpectedly. This is also true for the other supporting characters in the film. In addition to Thompson, the camp psychologist, Cambridge, is also killed suddenly when Eldridge dares Cambridge to join them in the field and he rides along on the body-bomb mission. In addition to Thompson and Cambridge, three of the contractors with whom they quickly develop a friendly rapport, are killed in the ambush segment.

James' post-war story takes place in four and a half minutes and consists of five main scenes: James in the grocery store, cleaning the gutters, awake in the middle of the night, in 
the kitchen with his girlfriend, and talking to his son. The scenes portray James' failure to experience a sense of family intimacy or sense of satisfaction in ordinary civilian life. He appears out of his element or trapped in a mundane routine. He exhibits PTSD symptomlike behaviors and responses of avoidance/numbing and hyperarousal. The first two fastpaced, intense hours of the film contrast with the few screen minutes of James at home. The audience has been prepared by the deployment portion of the film to get a sense of what avoidance/numbing and hyperarousal might feel like after leaving the intensity of the combat experience, and this serves to underscore the tension, conflict, and tragedy of the film's conclusion.

\section{Avoidance/Numbing, Hyperarousal, and Reliving/Reexperiencing}

The first image of James returned home is a reflection in the glass of a supermarket freezer (Figure 4.9). The technique suggests his feeling detached from himself, a type of numbing, and the effect has additional impact because the audience is unable to see James directly until the camera angle changes to show him pushing a grocery cart. James looks out of place doing an activity that is tedious and unremarkable compared to disarming bombs.

At the sound of a baby's babbling, the audience shares James' view as he turns to locate his son. This point of view shot reinforces the idea that we are meant to share his perspective and not only watch him. For the previous two hours of the film, the audience was treated to increasing levels of suspense and unpredictability and now that a high degree of intensity has been eliminated. Similar to James, we needed a hyped-up, alert, ready for anything state of mind to appreciate the drama and intensity of the combat portion of the film, and to mentally process the sudden firefights, deaths and chaos that occurred repeatedly from the beginning of the film until this grocery store scene. The hyped up 
attitude, appropriate moments ago in the film's narrative feels out of place for experiencing the ordinariness of the grocery store.

Contrast is frequently used in The Hurt Locker and the technique jolts the audience to draw attention to James' PTSD symptom-like responses. Some contrasts, such as the shift from the war zone to the grocery store, are striking and glaring, and others are subtle undercurrents, such as James' interaction with his girlfriend in the store. When they meet up he says, "Wow. You've done some shopping." Her cart is nearly overflowing and he has only a few items. He continues, "I got some soda," and then asks, "We done?" This phrase emphasizes the turnaround in James' experiences: when he disarmed bombs, he would declare to his unit, "We're done!" But as a civilian, his words indicate a questioning of his post-war situation rather than the successful conclusion of a mission.

The conversation between James and his girlfriend is always small talk. James' role at home feels painfully insignificant. As the audience, we are again prompted to identify with James in feeling disjointed, out of sync, and as though we must squelch the energetic and frenzied pace required to let ourselves get caught up in the film's wartime narrative. As their conversation in the store continues, she replies to James question, asking "You wanna get us some cereal, and we'll meet you at the checkout?" He turns to ask where the cereal is, but she has already hurried away. The film cuts to a long shot of James standing in a seemingly endless cereal aisle. The position of the camera creates the sense that the task to get cereal is so ordinary yet so complicated, necessary yet pointless; regardless of what he does, which cereal he selects, his involvement has no significance. Again, through point of view and reaction shots, the audience is invited to feel the emptiness and the contradiction rather than simply watch James experience it. He selects a box of cereal, tosses it in the cart and solves 
the meaningless problem. As he moves down the aisle, he strikes out at a display. This behavior can be seen as indicating James' state of hyperarousal manifesting as frustration.

Another sudden cut takes us to a cold rainy day. James stands on a ladder scooping soaked autumn leaves from the rain gutters of the house. The environmental contrast between the war zone and home is emphasized in this scene. Iraq was very hot and dry; at home it is cold and raining. The difference in the weather is symbolic of the difference for James of all things. The tedious quality of James' task makes this scene, which lasts only seventeen seconds, feel much longer.

The next scene is shorter, only six seconds. A close-up profile shot of James' face fills nearly half the frame. It is the middle of the night and the room is lit by the television's white, static-filled screen. James is fully awake, looking at nothing. He expression suggests he is troubled, enduring the quiet of the night, which is barely tolerable.

The scene cuts again to James and his girlfriend making dinner. He appears interested and happier. He is animated and invigorated as he tells a story of a man who drove his truck into an Iraqi market, saying "He starts passing out free candies. All the kids come runnin' up, families and stuff." He smiles as he talks and glances at his girlfriend, perhaps to gauge her interest or to see her reaction. "He detonates." he says. He watches her. “They're sayin' fiftynine are dead." He has reached the end of his story but has not yet made his point: to tell her he wants to go back. "You know they need more bomb techs," he says quietly. She responds, "You wanna chop those up for me?" as she hands him some carrots. James' avoidance can be inferred from this exchange in different ways. He could be avoiding returning to the dullness of civilian life or returning to war as a means for him to put off committing to her and/or their son. Both of these interpretations help explain James' 
eventual decision to redeploy. The conversation leads directly into the next and final scene of James at home.

The last scene at home explains why James decides to return to combat. In the scene, he is playing with his young son and his comments reveal his decision-making process. His feelings for what used to be special to him have dissipated due to his war experiences, manifesting as numbing/avoidance, but James attributes it to growing up. "As you get older," he acknowledges to himself, "some of the things that you love might not seem so special anymore.” He continues, “The older you get, the fewer things you really love.” He looks at his son as though he has "outgrown" his feelings for him, too. Steeling himself for what he is about to say and numbing himself emotionally to any residual feelings for his son, James admits, " then, I think it's one."

As James contemplates what he just said the sound of helicopters slowly grows louder on the soundtrack. His facial expression (Figure 4.10) says he knows this is a loss, but also that it is his truth. This ends the film's story of James at home. The film cuts to a scene showing two large cargo helicopters landing on an airstrip. James disembarks along with the other soldiers. He is greeted by a soldier and is presumably taken to his new unit, the only one who receives this individual treatment. Whereas what James did or said back home seemed to him to have little significance; what he does in combat not only saves lives, but gives him satisfaction.

\section{Veteran Myth from Sergeant James Representation}

A possible veteran myth begins to develop from the Sergeant James representation from the first moments of the film, one that the audience then expects the narrative to ultimately and reasonably reinforce: war is like drug addiction. The lead-in to the first scene shows a 
quote by Chris Hedges, a Pulitzer Prize winning journalist: "The rush of battle is often a potent and lethal addiction, for war is a drug." Introduced by the quote, fed by increasing "doses" of combat trauma with "good" and "bad" highs, the metaphor is reinforced, for example when Eldridge accuses James of needing his "adrenalin fix." James reaches a personal crisis/hits bottom when neither he nor Sanborn know why James is the way he is. He goes home and is cut off from his drug but is plagued by withdrawal. He then relapses, succumbing to his addiction and returns to "the rush of war." The ideas associated with the addiction metaphor do not build up properly to myth because the film closes the metaphor's logical loop. James is addicted and acts accordingly, and while the metaphor, similar to myth, hides nothing — addiction is the film's argument — unlike myth, the metaphor implies there is nothing left to reveal—addiction explains James' behavior both in and out of combat. However, the addiction metaphor and associated physiological and psychological withdrawal symptoms do pose a question as to whether James has any real choice in his decision to return to war; at the same time, the resolved metaphor ignores PTSD as an outcome of combat trauma and restates PTSD symptom-like responses and behaviors as drug withdrawal.

Looking at the James representation through a lens of the combat-affected veteran exhibiting PTSD-like symptoms, a complex, untidy conclusion awaits James. While the addiction metaphor allows a resolution of the narrative, the ideas associated with James' war experiences, PTSD symptom-like behaviors and responses, and reenlistment suggest reasoning that makes sense to a combat-affected James. His psychological numbing, avoidance, hyperarousal and reliving/reexperiencing (through redeployments rather than flashbacks) are ignored as possible combat-related PTSD and, as such, are left unaddressed, 
undiagnosed and untreated. Further, they are experienced only by James and are essential components of the dilemma posed by civilian life. Neither Eldridge (a young, inexperienced soldier) nor Sanborn (an experienced soldier) become addicted.

James, out of sorts in ordinary civilian society, admits his rationale for redeploying in the post-war scenes with his girlfriend and son; a reasoning that seems at once understandable and circular if not contradictory. James attempts to escape his posttraumatic stress by, essentially, equating his disordered state of mind with growing up, maturity and love. The question of James' choice combined with an unaddressed combat-related PTSD can be seen as the beginning of a veteran myth that disrupts the metaphor and disguises PTSD among other ideas of social dysfunction and personal idiosyncrasies that persist beyond the end of the film; and, presumably, for some soldiers who return.

Thus the meaning that addiction suggests in terms of James' responses, behaviors, and decisions is complicated by the introduction of PTSD symptom-like responses and behaviors into his decision-making process. Both addiction and PTSD throw into question whether or not the combat-affected veteran, addicted to war and/or mentally disordered by trauma, is able to make choices that preserve their own security or to recognize combatrelated trauma. The conclusion of the film highlights a complex set of sociocultural conditions in which combat-affected veterans struggle to define their lives, a resolution that remains unresolved. 


\section{Veteran Representations: HBO Documentary Wartorn: 1861-2010}

HBO's Wartorn: 1861-2010 is a documentary released in 2010, thirty years after PTSD was included in the DSM. The documentary's stated objective is "to bring urgent attention to the invisible wounds of war" (DVD back cover). The film is structured around individual stories of veterans who struggle with these wounds after returning to civilian life and is interspersed with interviews by James Gandolfini of contemporary military personnel. The film "examines occurrences of PTSD” (DVD back cover) and shows the long-lasting psychological struggle that combat veterans experience after the war. The film contains interviews with both active military personnel and veterans from wars going back to WWII. The purpose of the film seems to be to legitimize or clarify the significant effects of combat trauma for popular audiences - in other words, to bring PTSD out of clinical discourse and into popular discourse and the homes and vocabulary of soldiers and veterans suffering with "invisible wounds of war" and their families. However, although the film tells the viewer about great suffering and loss both during military service and after, it stops there, revealing little about the possibility or methods of treatment. I therefore argue that, although a history is recognized, the injury process is acknowledged, and diagnostics and treatments exist, this film constructs a veteran myth of psychostasis where the psychological, invisible wounds remain in a type of stasis or equilibrium and recovery remains out of reach.

\section{Film Synopsis: Wartorn: 1861-2010, 2011}

The film begins with a quote from Homer's The Odyssey. The white lettering reads: "Must you carry the bloody horror of combat in your heart forever?" The quote is suddenly replaced with video of cannon blasts and footage of WWII combat, of dead and maimed 
soldiers, and film clips from the Army's documentary Let There be Light showing military doctors talking to soldiers dramatically affected by their combat experiences.

The first story in the film is of a Civil War veteran, Angelo Crapsey. His story is derived and told from letters he had written to friends and family during his service from 1861 until 1863 when he writes to his brother that he is not well, noting, "I am clear off the hooks." His letters begin soon after he enlists and document not only the events of his combat experiences but also the way combat was affecting his state of mind. According to the letters, early in the war, Crapsey considered combat-affected soldiers as cowardly but by the time he was discharged his perspective was much different. He and his family coped with his paranoia and rage as best they could but sometime resorted to tying him down to control his outburst. A few months after returning home, Angelo committed suicide at age 21 .

The film cuts to a scene of Gandolfini interviewing military doctors at Walter Reed Army Medical Center. He begins the interview by asking "There is a lot of confusion about posttraumatic stress. What are some of the physical manifestations?" One doctor shares an analogy to explain hyperarousal, a mythology of the warrior that says, "The only thing you should feel when you shoot an insurgent is recoil." He counters it by asserting that a person "has no compassion for human life" if they are not affected by killing someone. The doctors talk about hypervigilance as the more prominent symptom of PTSD, or at least the easiest for other to see, noting also that anger is more evident than numbing, rage than avoidance. The Chief of Psychiatry at Walter Reed Army Medical Center attempts a brief explanation of PTSD: he notes, “As a soldier says, 'I'm just jacked up, I'm ready for a fight, I'm ready to save somebody's life" and continues by commenting that "the problem with PTSD is those symptoms don't go away when we come back home." Another doctor remarks, "It's almost 
like a seizure, where they don't have control of it, they don't know when it's going to happen."

The film cuts suddenly to grainy video footage of a convoy of US military vehicles. There is a huge explosion in the line of vehicles followed by scenes of wounded soldiers being taken from the field. As these images are shown, a voiceover explains a soldier's firsthand experience of an IED explosion. This is followed by a series of combat veterans describing traumatic (stressor) events and their responses to combat trauma, including nightmares, flashbacks and surprise over how dramatically they were affected. One veteran says, "Never in a million years did I think I would lose my mind."

\section{Seeing Noah, Jason, Nathan and Billy as Combat-affected Veterans}

\section{Noab's Suicide}

The first in-depth contemporary veteran representation is of Noah, who served two tours in Iraq. His story, told by his mother, is titled "The Suicide of Noah Pierce," revealing at the start the tragic outcome of his PTSD. She describes her son's suicide and shows us the objects he had with him and the note he wrote. She shows the gun he used to kill himself, the knife he used to stab his identification cards through his face and subsequently plunged into the dashboard, and his room, which she maintains as a memorial to Noah. His military awards, pictures, funeral flag and personal pictures are most prominently on display. She explains that the Army trained her son to kill, but "they forgot to untrain him; to take that urge to kill away from him." She shows a picture of Noah and describes the anger she sees in his face. "My son has started dying slowly from the inside," she comments, adding that eventually, he "killed the outside as well." She reads his suicide note out loud. Noah wrote that he thought things would get better, but they didn't; there is no indication that he sought 
help or if he was aware that help was available. The film shows us the end of his handwritten note as his mother reads it aloud:

I'm getting drunk now so, I'm more opened up. I have been planning this a long time. Times finally up. I am not a good person, I have done bad things. I have taken lives, now it's time to take mine.

Noah's story ends as the image of the letter fades out.

The film jumps back to WWII and the captions describe General Patton’s reaction to “a young soldier who was hospitalized with nervous exhaustion.” The captions reveal that it was reported that the General slapped the young man and sent "that yellow son of a bitch back to the front line."

The film flashes forward to a group of aging men remembering WWII. Al Maher talks about his service as a B-24 co-pilot. He talks about the missions he was on with a flight of four planes. His descriptions of the other planes being shot down are vivid and detailed: "and you know that ten men went down and then you would count the [para]chutes ... if nothin' came out you knew it was an awful loss." He describes men dying on the ground, commenting, "I hate to even talk about it." Other WWII veterans talk about "battle fatigue" and the "lack of intestinal fortitude" that was used to describe their conditions. Some talk about guilt and rage and how difficult the readjustment was to do on their own. "It just goes inside, you can't get it out," says Maher; “it's like you have a camera inside.” Some men are overcome with emotion as they describe the memories that sound as though they could have happened yesterday instead of five decades earlier. The men not speaking appear still and introspective; some seem to be comparing their own experiences to those of the speaker.

One of the WWII veterans describes the "awful lot of guilt" that he carried with him after the war and admits that, after fifty years, "I still have bad nightmares." The man 176 
becomes keyed-up talking about his nightmares, commenting that, "it takes all god damn night to kill somebody," a statement that is not further explained. The next veteran, wearing a WWII Veteran cap tells us, 'You weren't the same once you went away ... you were not normal in any aspect at all." He says that he came back "a raving lunatic" and that sociocultural norms meant little to him. He explains that he had a bad marriage and three sons whom he has not seen in 25 years.

Another veteran tells of his grandson serving in Iraq and how he relives his own war experiences whenever his grandson is deployed. He explains, "Whenever [my grandson] goes off into the field for two weeks and I don't hear from him, I'm landing again. All the bad that can come up, comes up. I know. But how can I tell my grandson that he's not coming home the same person that left?" The comments of these veterans make it clear that their lives continued after the war, but that the horrors were not left behind. The images of war continue to shape the perspective the veterans have of themselves and their relationships with their families and society.

The documentary moves next to a Marine Corps Vietnam War veteran artist, Akinsanya Kambon, whose job was to "be in a combat zone and draw everything that I saw." He saw bodies, and they would "just keep coming," he says. He describes the animal-like mindset and attitudes that were necessary to fight, commenting, "I don't know how to get rid of it, you know.... It like, it's all full in my head." As he talks, his intonation recreates the growls and aggression of the fight, giving the impression that reexperiencing the trauma of the war is very close to the surface. In one scene he stands and looks at one of his own paintings. His posture, gaze and quiet suggest to us he is reliving the event that lead to the painting. He describes a scene that gives him his worst nightmares, from which he wakes screaming. In 
his nightmare and in his painting a fellow soldier is stuck in a tree branches. A close-up of the painting shows the soldier's frightened facial expression. He appears as though he could be standing, an onlooker of a horrific combat scene. The camera pans down, exposing more of the painting, and reveals that the soldier's lower body from the waist down is torn away. Kambon notes that the soldier is still alive- "his eyes were blinkin', they were blinkin' really fast." The painting tells us the horrible physical details of the soldier's body having been torn away and the story triggers a vivid reliving response from Kambon, revealed in a close up of his face as he reexperinces the traumatic event. Throughout the segment, Kambon talks with a matter-of-fact delivery that is not overly descriptive, but is broken by introspective and reflective recollections about his presence in the war.

The film cuts to Gandolfini interviewing Gen. Odierno when he was Commander of U.S. Forces in Iraq. The general suggests that there is a greater awareness of PTSD, noting, "Vietnam has helped that ... there have been so many Vietnam veterans who have had posttraumatic stress ... and we have never dealt with that problem." Odierno goes on to say that military training is "about being mentally and physically tough so it becomes difficult for some of these individuals to admit they have a problem." When asked if he himself experienced any posttraumatic stress, he avoids answering by telling about his own son being injured. Gandolfini also interviews National Guardsmen who describe the ways their lives have changed since serving in the war and how they continue "days upon days living at such a high alert level."

\section{Jason's Evaluation}

Jason Sheuerman's story is told by his father. After showing signs of major depression while still in the military, Jason seeks help from military sources. One of the evaluators tells 
Jason he is "faking" and instructs him to "be a man." Jason commits suicide a short time later. The father tells how Jason's suicide has devastated the family and about his own feelings of guilt for not being able to help his son. Jason's brother explains, "It is not the soldier that's in combat that comes down with PTSD, it's the entire family."

Jason's story is followed by Gandolfini interviewing General Chiarelli at Walter Reed Army Medical Center. The General is charged with changing Army personnel's attitudes toward PTSD and suicide. Chiarelli describes a fight against a culture that finds it difficult to accept that psychological injuries have serious consequences. He notes that the "science behind [PTSD] and how we treat [it] is not as mature" as it is for physical injury, but that progress is being made inside the military. His interview concludes with the statement that, whether a soldier has PTS or TBI (Traumatic Brain Injury) or anything else, "only bad things happen when you wait to treat an injury."

\section{Nathan's Sentencing}

"The Sentencing of Nathan Damigo" is a segment of the film that documents events in the life of a young marine who returns from Iraq (Figure 4.12).

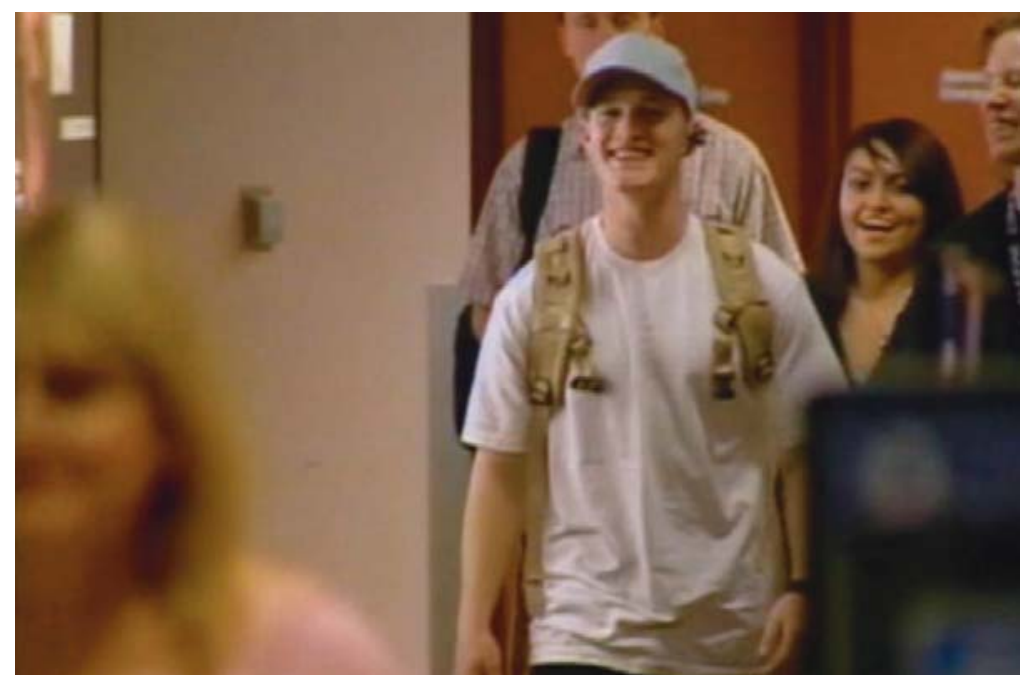

Figure 4.12: Nathan at the airport as he returns from Iraq in "The Sentencing of Nathan Damigo" (DVD screen capture, Wartorn: 1861-2010). 
In the segment, Nathan's family describes his post-war behaviors as "out of character" for him. His nightmares were so severe they were waking other family members. A month after his return, Nathan got arrested for attacking a man at gunpoint. Nathan's mother tells us a psychologist who worked with Nathan explained the crime was a flashback in which Nathan went into combat mode. He had been drinking, was probably suicidal, and thought he was just "doing his job" like he did in Iraq. At the time of the film's interviews, Nathan was about to leave for a six-year prison sentence. In one segment he explains that he didn't expect to end up in prison when he signed up for the Marine Corp. Throughout the segment, Nathan and his family state they know he was not himself after he returned. As Nathan tattoos his brother the day before the sentencing hearing, the brother asks, "Do you know if it was PTSD, Nate?” The answer comes quickly: "I know it was PTSD.” This young man who entered the Marines at 18 years old looks much older. When emotion does threaten to break through Nathan's subdued, disciplined persona, he represses it. His mother asks him, “You okay?” and he answers, "No. I'm okay as I can be.” The following day, Nathan is sentenced and taken into custody (Figure 4.13).

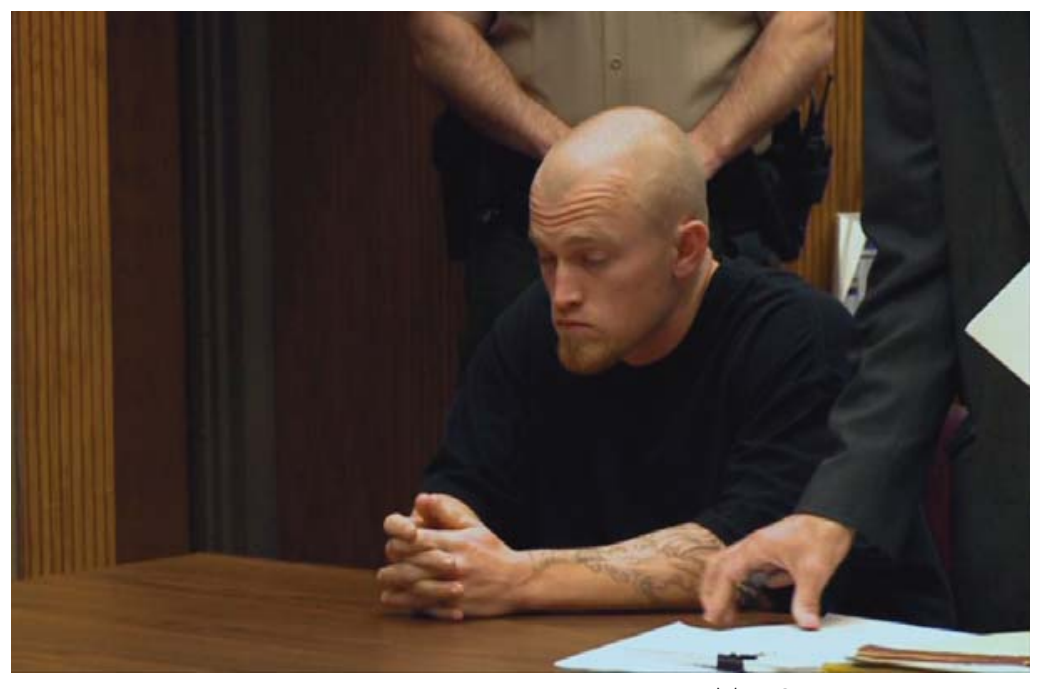

Figure 4.13: Nathan at his sentencing hearing from "The Sentencing of Nathan Damigo" (DVD screen capture, Wartorn: 1861-2010). 
When we first see Nathan he looks like any other young man walking through an airport (Figure 4.12). The last time we see Nathan, a matter of months later, he is being sentenced,. He looks very different: older, broken and betrayed (Figure 4.13).

\section{Billy's War in Pictures}

In "Billy's War Comes Home," we first see Billy at a computer looking at pictures from his tour in Iraq. The pictures we are shown are of dead, bloody bodies and blown up vehicles. He appears dedicated to looking at them again and again (Figure 4.14).

His wife expresses confusion as to why he would want those memories refreshed by looking at the photos. He explains, "It's still part of my life." Reliving and reexperiencing the war are dominant symptoms for Billy to the extent that his interaction with his family is suffering. His wife and son describe how they want more interaction with Billy, who spends so much time looking at the pictures: "He's home, but he's not home" says his wife. His son adds, "it sucks, and he knows it sucks." Billy describes how he becomes violent at times and shows a hole in the wall that he made with his fist. "I've never hit you though," he says to his wife. He comments that was he going to fix the wall but the viewer is left with the idea that, as with the photos, he would rather keep the hole there. He too has nightmares and wants to avoid places where too many people are present. 


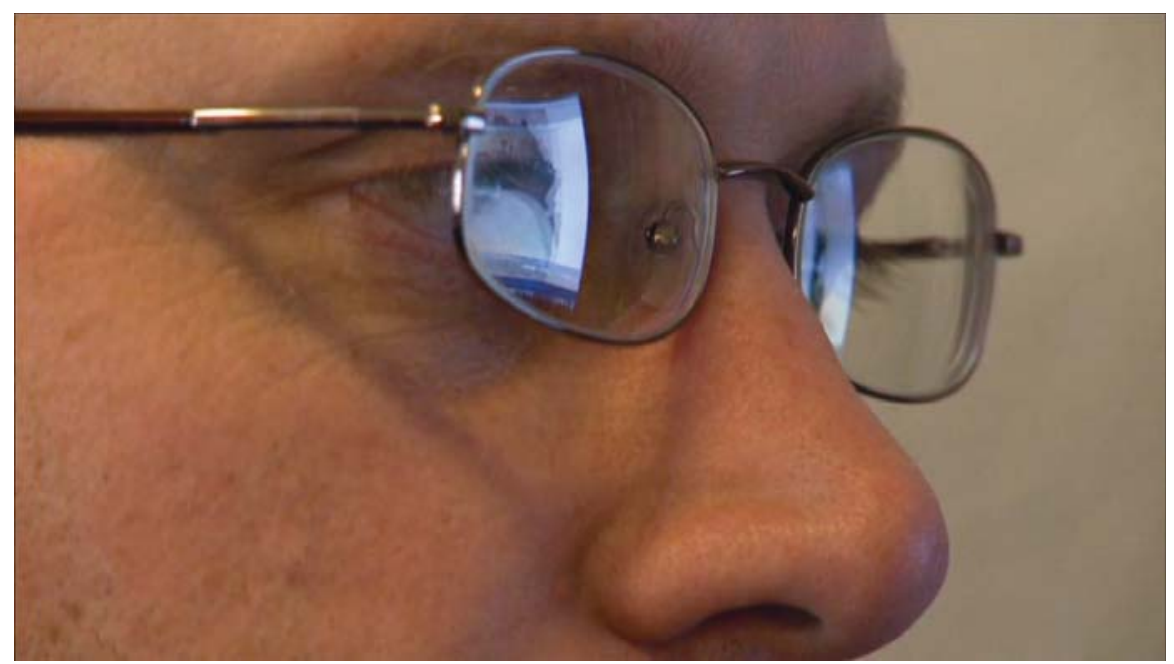

Figure 4.14: Billy looking at his war pictures in "Billy's War Comes Home" (DVD screen capture, Wartorn: 1861-2010).

All indications are that Billy's war did come home with him. His wife and kids are confused by the behaviors he struggles with "on a daily basis." In a comment that is echoed by Sgt. James in The Hurt Locker, Billy notes that his son “... would like to know why I am the way I am." The family goes shopping and they talk about his nightmares. Billy knows, as they approach the store, that he will be highly anxious there ("my head's gonna be, I call it, 'on-a-swivel"'). In the store, he is very anxious. He calls his young daughter over to him and she helps him by being near him as they push the cart. The longer they are in the store, the more dramatic his stress responses, and he begins stuttering when he speaks.

In the second to last scene of his story, the family is in the car, returning from a Walmart store. Billy's wife is driving. She comments, “It's been two years, after the fact, since he's been home." Seemingly talking to the camera, she adds, "So how long does it take?" The camera cuts from her to capture Billy's reaction. A pained response appears on his face. The camera remains on him as layers of turmoil seem to be trapped behind a mask of bewilderment. He does not attempt to answer her question, and it seems an answer is as unknown to him as it is to her. 
When the interview resumes at home with Billy, he says, "I've done some terrible, terrible things." He reflects and pauses, then explains that people tell him "you just have to get over it" or "you were just doing you job." His comment, "those are just words," makes it clear that Billy feels very misunderstood. His segment closes with Billy reflecting on his time in combat: "I've seen humanity at its worst, and I struggle with that, struggle with that on a, on a, on a, on a, um, on a daily basis," he manages to say.

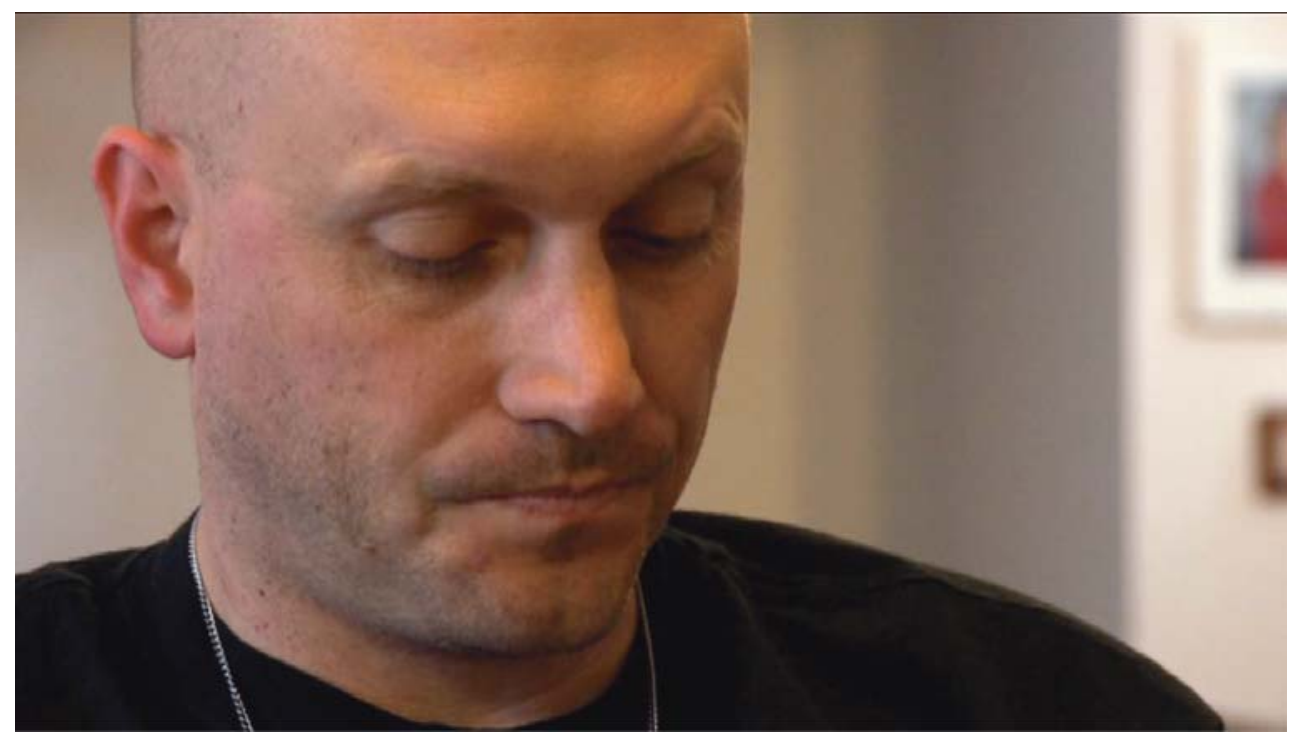

Figure 4.15: Final image of Billy from the "Billy's War Comes Home" (DVD screen capture, Wartorn: 1861-2010).

The last minutes of the film show a series of still images and video of combat, wartime soldiers, and civilians caught up in war zones, but mostly it show the faces of soldiers near or at emotional breaking points. The final image before the credits is the image of the soldier in Figure 4.1 above. It is this image that fades to a black screen. On this screen appears a phone number and web site for "information on treatment for service members, veterans and military families" and a phone number and web address for the National Suicide Prevention Lifeline. 


\section{Veteran Myth from Wartorn Representations}

My analysis of the collection of veterans in Wartorn parallels my approach to the Life magazine pictorial in Chapter 2 (see pages 59-65) where veteran myth is an accumulation of the representations in the film. A clinical diagnosis of a mental disorder is an undercurrent of all of the stories of veterans in Wartorn. Specific references to diagnosing and treating PTSD are mostly absent other than noted above as the military begins to recognize the problem of PTSD.

The veterans presented and represented in this film are in it because their stories are consistent with the theme of this documentary. Nightmares, hypervigilance, emotional numbness, angry outbursts, avoidance and vividness of the memories accumulate throughout the film. Each veteran's wartime experiences are vivid, powerful and damaging to them and their families. Billy's story at the end the film shows an exchange between him and his wife. Their conversation is indicative of the degree to which information about PTSD is slow to reach popular audiences.

The segments of documentary that separate the veterans' stories and the final segment of the film show a series of images of soldiers_-fighting, mangled, dead—-throughout visual media history. Photographs from the Civil War through the war in Iraq of soldiers and combat zones provide evidence of the stresses and traumas endured by the soldiers. These segments also include images of distraught soldiers in emotionally broken down moments of anguish.

Wartorn documents a problematic condition that has been informally recorded for generations, as Angelo Crapsey's letters show, and formally recognized in clinical fields for decades as the PTSD diagnosis. The film informs popular audiences of the severity of 
psychological wounds and resulting tragedies that PTSD-affected veterans and their families face by documenting real people suffering and dying from posttraumatic stress and PTSD. The film also points to a long history of combat-affected veterans. Yet the film and the combat-affected veteran's stories it shares fail to document or even allude to current developments in PTSD treatment. Although it demonstrates that invisible wounds are serious and very real, it withholds existing knowledge about getting help for PTSD. We are shown Noah's mother, who keeps the artifacts Noah had with him when he killed himself and we are shown Billy who struggles to function in ordinary civilian life and is unable to establish a comfortable relationship with his wife or a nurturing one with his children.

The last we see of Nathan is his leaving the courtroom in custody of guards as he is taken to prison. We do not know or learn what becomes of him in a postscript, a common trope of documentary. Caught up in the legal system, both Nathan and his family are shown as they wait for his sentencing hearing. His trial had already concluded, and any efforts to pursue alternate measures of psychological/psychiatric counseling and/or probation or community service as an alternative option to incarceration did not appear in the film. Nathan's life after the war and in prison is a direct result of his PTSD symptom-like behaviors and responses that take place in sociocultural practices carried out in the criminal courts of the justice system. Without proper psychological and/or psychiatric help, Nathan seems headed towards a life eerily similar to that of James Allen evoked by the criminality myth of I am a Fugitive from a Chain Gang. Because these veterans and their families are inadvertently caught up in the outcomes of behaviors directly linked to PTSD, their military service continues to dominate their lives and deaths. Jason knows he needs help dealing with the post-combat, inner conflicts that torment him, but cannot get the help he needs from 
military sources. Instead, military evaluators send him back to his post and he commits suicide. Billy appears obsessed with looking at pictures he acquired while deployed in a combat zone. The photographs of maimed, dead and dying men and children seem to be the most compelling images that draw Billy away from his family and back to the computer to view them. All of these veterans are unable to reengage in their lives or with their families. They know they are stuck in their combat-trauma experiences and situations, but there is no way out.

Wartorn was released thirty years after the PTSD diagnosis was formalized in the DSM, and the military is portrayed as just beginning to recognize the impact war takes on soldiers and that combat veterans take home their wartime experiences and mindsets along with pictures and mementos. The veterans in $W$ artorn are left suffering at the end of the film, as are the families. The dominant theme of the film is the continuing struggle and inability to escape or disengage from the lasting effects of combat trauma. These effects are clearly knowable and documented in the film and perhaps are more visible than the phrase "invisible wounds" suggests. For this reason, I propose that a veteran myth emerging from this film is one of psychostasis in which the question posed at the beginning of the film, "Must you carry the bloody horror of combat in your heart forever?" seems to be "yes."

Despite the fact that PTSD and treatment options have existed for decades and continue to develop and evolve due to clinical practice and scholarly and clinical research, the veteran representations in the film remain unresolved, trapped in a limbo of suffering and given only two options: to seek more information on their own or suicide prevention. 
EPILOGUE

\section{Functions of Veteranness in Sociocultural Discourse}

Dying is easy. Living's the hard part.

-Shane Parham 


\section{Project Synopsis}

In the "Method and Framework" of my research in Chapter 1 (pages 22-38) I explain my role as a reader of veteran myths drawing on Barthes' notion of myth and Foucault's concept of discursive unities. I selected a sampling of veteran representations from popular films for close examination: James Allen from I am a Fugitive from a Chain Gang, $\mathrm{Al}$ and Fred from The Best Years of Our Lives, Michael from The Deer Hunter, Eriksson from Casualties of War, Sgt. James from The Hurt Locker, as well as a collection of veterans from the documentary Wartorn: 1861-2010. I locate these films within three time periods and sociocultural contexts: World Wars I and II (1930s-50s), the Vietnam War (1970s-90s), and post 9/11 (2001-present). I refer to the American Psychiatric Association's Diagnostic and Statistical Manual of Mental Disorders (4th and 5th editions) and the web site of National Center for PTSD for clinical information about PTSD diagnostic criteria (see Chapter 1).

My analysis in Chapters 2, 3, and 4 focuses specifically on each combat-affected veteran's behaviors and responses and correlations between these representations and PTSD that motivate the story and are thereby appropriate for the narrative. This analysis identifies several veteran myths such as criminality, psychosimplicity and unrecoverability that develop through PTSD symptom-like behaviors and responses such as reliving/reexperiencing, numbing/avoidance and hyperarousal. At the conclusion of each chapter I discuss what these veteran representations reveal about the dominant veteran discourse of each period.

This project is grounded in sociocultural contexts (see "Exigency of this Study," page 8) that in effect, help maintain a naturalized set of shared sociocultural practices that benefit society yet are often problematic for veterans, specifically PTSD- or combat-affected veterans. These combat-affected veteran constructs go on to influence broadly shared ideas 
about all veterans that I argue have the status of myth but assume the shape of truth, essentially transforming connotative meanings into natural seeming, common sense meanings. As such, veteran representations circulating as variations of myths ultimately converge in an overarching idea of veteranness as a discursive unity that informs and is informed by dominant sociocultural discourse and practices that unwittingly perpetuate these veteran myths.

\section{Summary: Veteran Myths after WWI and WWII}

I begin my analysis in Chapter 2, the period of World War I and World War II visual media, in which veteran myths of monumentality (Life pictorial), criminality and psychosimplicity appear in popular print and film media. The James Allen representation from I am a Fugitive from a Chain Gang demonstrates that Allen's combat experiences had changed him enough that his personal goals become incompatible with the post-war life his family and society expect for him. Allen's PTSD symptom-like behaviors and responses of avoidance, hyperarousal and reexperiencing show what appears to be a reasonable narrative development in which the once-capable returning soldier ends up on the margins of society, but still on the right side of the law. Allen then moves to the wrong side of the law by being forced to participate in an armed robbery and being sentenced to hard labor. Allen's PTSD symptom-like responses continue and intensify in prison where none of his soldierly characteristics are recognized. The conduct that earned him military medals goes against the grain of prison life. After escaping the chain gang and assuming an alias, he succeeds professionally for years as a fugitive, but his hyperarousal responses lead to his being turned over to the police. Caught in a battle for his freedom, a veteran myth of criminality appears that has no use or place for the bravery, selflessness and competence he displayed as a newly 
returned veteran. Ultimately, it is his criminality that leads to his total marginalization at the end of the film as he runs off into the darkness as a fugitive not only from justice but also from society and from his personal potential.

The Fred and Al representations from The Best Years of Our Lives show veterans struggling with being "nervous out of the service" but ultimately able to "get over" the persistent PTSD symptom-like behaviors they exhibit during and after their return from war simply by choosing to do so, creating a veteran myth of psychosimplicity. Fred lets go of his war and the combat experiences that lead to his nightmares of reliving/reexperiencing by purging them from his mind, as seen in the warplane graveyard flashback scene. Only then does he exercise the ability to create an opportunity for gainful employment by insisting on leaving the war in the past.

Al's avoidance/numbing responses lead to his excessive drinking and exacerbate his hyperarousal responses to the banking practices that underappreciate the human-integrity "collateral" that he sees in the men he served with in combat. His drinking allows him to overcome his personal dilemma after he becomes fed up with his own avoidance/numbing and he cleverly combats a traditional banking system in a way that allows the bank administrators to recognize its endemic faults. Both Fred and $\mathrm{Al}$ suddenly recover from their post-war dilemmas in climactic break-through scenes and are freed from the PTSD symptom-like responses that held them back from contributing to society's war recovery. Once they make the simple choice to "get over it" they not only begin to thrive in their personal lives but also in their public lives as they morph from their post-war struggles into contributing members in the nation's economic recovery after the Depression. While PTSDaffected veterans do need to make personal choices in their post-war lives relating to 
posttraumatic stress behaviors and responses, the oversimplified way in which this film constructs their successful reintegration to civilian life ignores both the underlying disorderliness of PTSD and the process of recovery in a myth of psychosimplicity.

\section{Summary: Veteran Myths after the Vietnam War}

My analysis continues in Chapter 3 with representations selected from the era of the Vietnam War veteran where a veteran myth of unrecoverability appears. While bearing a striking resemblance to the psychosimplicity myth, it is also significantly different in terms of the implied future of the veteran. The Michael representation is constructed as PTSD is being developed as a formal diagnosis, two years before it is added to the DSM. The Eriksson representation is constructed nine years after the diagnosis appeared in the DSM.

Michael from The Deer Hunter is a representation of a soldier returned from the war with all three of the persistent PTSD symptom-like behaviors and responses: hyperarousal, reliving/reexperiencing and avoidance/numbing. In the third, post-war, segment of the film, the narrative positions Michael as the deer hunter who must fight a personal war and complete his mission to bring his buddies home. Before he is able to do so, he first struggles with an internal conflict between making it home safely but without his friends, one who is AWOL in Vietnam and the other who insists Michael promise not take him out of the veteran's hospital. Michael's internal conflict eventually spills over into a violent and dangerous confrontation while on a hunting trip with other, non-veteran friends. The confrontation peaks at a moment of highly charged conflict symbolized by the collision of the deer hunter's “one shot" philosophy of life with the combat veteran's will to survive and

get back home. After this climactic scene, Michael wages a personal battle and brings both of his buddies home. However, the final scene shows Michael in uniform and exhibiting a 
personal stoicism in contrast to his friends' mourning of Nick's death, implying that his soldier's strength allows him to internalize and fight back against his traumatic experiences, as he had the torture of the POW camp. His determination to survive traps him in the internal fight, his PTSD symptom-like responses and behaviors, which then make it possible for him to make the decisions that allow him and his friends to survive the war, are symbolized by the image of him as the perpetual soldier. This internal strength enables him to function, although differently than before the war, satisfactorily within society's conventions and norms. Because the lasting image is of the soldier-winning-out-over-hisdilemmas, he will never successfully overcome his soldier identity, resulting in a veteran myth of unrecoverability. In this way, Michael remains soldierly and will carry his war with him. Both his outward appearance (military dress) and his frame of mind (internalized trauma and determination to survive) point to this unrecoverability myth.

The Eriksson representation from Casualties of $W$ ar is released from his posttraumatic stress by, essentially, waking up from a bad dream that takes the form of reexperiencing/reliving and finally being able to look outward and upward while, presumably, rejoining society. In this representation, the PTSD symptom-like behaviors and responses work in sequence. Although he is unable to act to help the young woman victim, Eriksson's flashback ends at the sentencing hearing of his fellow soldiers initiated by his charges against them. His PTSD symptom-like responses conclude at a peaceful park after a young Vietnamese-looking woman's words help him understand the war is over for him. Nearly the entire film occurs in Eriksson's dreaming-state-of-mind as he reexperiences/relives the traumatic mission through the flashback-dream-sequence. Similar to $\mathrm{Al}$ and Fred, Eriksson "gets over it" by accepting the opportunity the chance meeting of 
the woman grants him. "It's over now," she says, and the traumatic war-time mental weight is lifted from him. Although his future is unclear, the implication is that it will be more promising now that his posttraumatic stress is alleviated after his encounter with the woman.

The veteran myths of both Michael and Eriksson are similar to the psychosimplicity that develops from the representations of Fred and Al from The Best Years of Our Live. All four veterans, essentially, decide to act in way that results in overcoming their post-war dilemmas. However, both Fred's and Al's stories conclude with a definite sense of happily-ever-after. The veteran myth of unrecoverability resembles psychosimplicity in that the veterans make choices to confront their dilemmas, but differs in that the future is uncertain for the Vietnam War veteran, reflecting a social discourse that, although it recognizes that there is a lasting impact of combat on the veterans, is unsure about what that impact is, how to deal with it, and what the veteran's future looks like. Both Michael and Eriksson rejoin society and that is the last the audience sees of them; one is unrecovered, giving the appearance of psychological recovery by repressing his symptom-like responses and behaviors, the other presumably cured.

\section{Summary: Veteran Myths Post 9/11}

Finally, the post 9/11 period veteran representations discussed in Chapter 4 present complex and unresolved dilemmas. Sgt. James returns to combat even though he has an opportunity to return to his young son and girlfriend who want to be with him, but he is unable to connect emotionally with them or to function effectively in society. The veterans in $W$ artorn continue to suffer with the effects of their war experiences, which also remain unresolved in each of their stories. 
As a combat-affected veteran representation, Sgt. James draws attention to complex sets of sociocultural conditions surrounding military service, redeployment and the individuals who enlist and find themselves in overwhelming and traumatizing situations. The film attempts to convey ideas about military trauma by means of metaphor and in doing so poses questions about the similarities and differences between combat addiction and posttraumatic stress. Through the accumulation of difficult and compelling challenges, the narrative ultimately articulates an unresolved and ambivalent psyche for PTSD-affected veterans.

A type of psychostasis myth coheres from the veteran representations from the HBO documentary $W$ artorn. PTSD is presented as a recognizable problem, but the film portrays the disorder as though there is no treatment. The film concludes with a screen displaying a phone number and web site for veterans to get " more information" and a number and web site dedicated to suicide prevention, but does not address PTSD treatment or therapy. The film reinforces a soldier/veteran entanglement that blurs the distinction between experiencing combat trauma and the "post" and persistent aspects of PTSD. Further, the film show families also dramatically impacted by the soldier's/veteran's invisible wounds but unable to provide support, ostensibly because there are also no support systems for them. Because the film's presentation is limited to the tragedy of invisible wounds and the minimal information about resources appears only after the last film images fades, the problem of recovering invisible wounds seems impenetrable and solutions out of reach. The veteran representations are thus caught up in a myth of psychostasis from which there is no relief. 


\section{Veteranness as a Discursive Unity}

The veteran myths I argue are constructed in these representations include:

- monumentality, which sets aside the individual veteran for the social and symbolic value of patriotism, sacrifice and honor that war veterans readily provide

- criminality, which relies on symptom-like behaviors and responses to take the veteran down a road to complete marginalization from society

- psychosimplicity, which over-simplifies the means by which veterans can choose to overcome posttraumatic stress

- unrecoverability, which leaves the veteran unrecovered from his war trauma and the audience uncertain about his future

- combativeness, which suggests the veteran's posttraumatic stress indicates a readiness to resort to combative outbursts

- psychostatis, which leaves the veteran trapped in his war experiences and without access to treatment

The veteran myths revealed through my analysis suggest that the use of PTSD symptom-like behaviors and responses exhibited by the veteran representation are either a necessary or convenient interpretation of veteran in these contexts of popular visual media. Whether requisite for the drama of the veteran stories or effective ways to create character continuity throughout the overall narrative, the usage of PTSD symptom-like behaviors and responses in popular media suggests the veteran representations are informed by a broadly shared discourse of veteran that sees these behaviors and responses as appropriate and valid for the constructs.

\section{Sociocultural Functions of Veteranness}

Findings from my analysis suggest that the dominant discourse about veterans, a discursive unity that I call veteranness, circulates a variety of veteran myths through popular visual media. Realist veteran constructs are indicative of the naturalized dimension of veteran 
discourse. Prior to the Mt. Rainier shooting, Benjamin Barnes could reasonably be identified as an Iraq war veteran and subsumed into a discourse of "Support the Troops" that became widely prevalent after the U.S. went to war in Afghanistan. However, the media representation of Barnes analyzed in Chapter 1 introduced him as an Iraq War veteran and as a criminal suspect. In the sociocultural context of journalism and popular discourse, it seemed reasonable to select the veteran identity over other possible identities, for example, simply a suspected gunman. The characterization of Barnes thus demonstrates the ease of associating his criminal behavior with his veteran status. Indeed, after the death of Margaret Anderson, the criminal discourse was inescapable for Barnes and implied for other veterans.

During the era of the World Wars, visual media veterans either fail miserably to reintegrate (Allen) or succeed in ways that help society's progress (Al and Fred) and that help them to recuperate; veteran recovery goes hand in hand with society's recovery. During the Vietnam War period, visual media veterans have to make a choice between personal psychological failure and success (Michael and Eriksson); veteran survival or recovery occurs on an individual level. Post 9/11 popular visual media veterans (Sgt. James and the collection from $W$ artorn) allow audiences to see the powerful, complex yet irresolvable dilemmas veterans face.

That a veteran of combat returns home somehow "different" or "changed" has been a consistent theme in popular media renditions of veteran characters and narratives. I Am a Fugitive From a Chain Gang from the 1930s, one of the earliest film representations of a combat veteran in a popular U.S. film, and the more recent 2008 veteran representation in The Hurt Locker both present men who are significantly affected by their war experiences and for whom familial and sociocultural contexts pose disastrous outcomes. The stories and 
narratives are very different; however, their outcomes are much the same, and both veterans end up living outside of mainstream society. The veterans themselves are, in a sense, collateral damage. The Best Years of Our Lives and Casualties of War present equally affected veterans who simply put their wartime pasts behind them. The Deer Hunter presents a veteran both dramatically changed by his war experiences and also coping by applying those experiences to his civilian life. Wartorn presents a series of examples and perspectives (including soldiers, veterans, military doctors, families of veterans) to introduce the dilemma of psychological wounds to popular audience. All of these representations of combataffected veterans are constructed with ideas and concepts that overlay what we today call PTSD and coalesce in veteranness.

Veteranness is the dominant veteran discourse that facilitates a seemingly natural, common sense way to think and talk about veterans. My project demonstrates, however, that veteran myths function in ways that hide the negative effects of combat trauma among acceptable sociocultural practices and expectations: criminals go to prison, monuments honor fallen soldiers, war veterans "get over it" or stay in it (they can choose which they want to do), and "invisible wounds" gain recognition as legitimate adverse effects of the trauma of combat.

Veteranness also functions to effectively and reasonably appropriate the tragic outcomes suffered by fallen soldiers and combat-affected veterans to substitute and foreground other meanings such as patriotism, heroism, and valor. These new connotations make it possible to maintain a place of honor for soldiers and veterans through sociocultural practices ranging from the establishment of holidays (e.g. Memorial Day, Veterans Day, etc.) to the building of physical structures (e.g. monuments and memorials) to the creation of visual 
media (e.g. print and film) that are designed to draw attention to the soldiers sacrificed and soldier's sacrifice.

Veteranness can also function to maintain a collective obligation to continue sacrificing soldiers in what we consider "necessary" wars and allows society to make these sacrifices though rendering the combat-affected veteran as myth.

As stated in Chapter 1, a basic premise of my research is to support our ability to fulfill our responsibilities to war veterans in general and combat-affected veterans in particular by revealing veteran myths circulating in sociocultural contexts in a dominant veteran discourse. I argue we need to learn about all of the lasting effects of war and the trauma inherent to combat, including the sometimes tragic, catastrophic, yet unseen PTSD-related effects that, if go unchallenged, hinder and undermine our efforts. This study reveals veteran myths that influence the ways we think about and respond to our combat veteran's unseen injuries and examines the ways we collectively understand posttraumatic stress, PTSD and post-war experiences of actual veterans affected by war trauma. It also challenges a dominant veteran discourse of veteranness that includes within it many different veteran myths that risks normalizing or naturalizing sociocultural expectations of all veterans and rendering them voice-less, invisible, and, ultimately, disposable. 


\section{Works Cited \& Referenced}

Affron, Charles and Mirella Jona Affron. Best Years: Going to the Movies, 1945-1946. Jew Jersey: Rutgers University Press. 2009. Print.

“Alone.” Iraq and Afghanistan Veterans of America/Ad Council. PSA. IAVAVids. Web. <www.youtube.com/watch?v=z_CYLYyvxWk. Uploaded Nov. 20, 2008.

Anderegg, Micheal, ed. Inventing Vietnam: The War in Film and Television. Philadelphia: Temple University Press, 1991. Print.

Apocalypse Now. Dir. Francis Ford Coppola. Perf. Martin Sheen, Marlon Brando and Robert Duvall. Film. 1979. United Artists. DVD.

Baker, Mike. "Benjamin Colton Barnes, Iraq War Veteran Suspected Of Killing Park Ranger, Reportedly Found Dead" Huffingtonpost.com. <www.huffingtonpost.com/2012/ 01/02/benjamin-colton-barnes-_n_1179815.html> 2 Jan. 2012. Web. Accessed 3 Jan. 2012.

Barthes, Roland. Mythologies. New York: Hill \& Wang. 1972. Print.

Belsaw, Jim. “An Image Crystallized: Lee Teter's Gift to Veterans.” The VVA Veteran. March/April 2004. Web. <www.vva.org/archive/TheVeteran/ 2004_03/feature_teter.htm>

Bently, Steve. "A Short History of PTSD: From Thermopylae to Hue, Soldiers Have Always Had a Disturbing Reaction to War." The VVA Veteran 1991. Reprinted online March/April, 2005.<www.vva.org/archive/TheVeteran/2005_03/ feature_HistoryPTSD.htm> Accessed August 18, 2010.

Bergman, Paul and Michael Asimow. Reel Justice: The Courtroom Goes to the Movies. Kansas City: McMeel Publishing, LLC. 2006. Print. 
The Best Years of Our Lives. Dir. William Wyler. Perf. Myrna Loy, Fredric March, Dana Andrews, Teresa Wright, Virginia Mayo. Film. 1946. MGM, 2000. DVD.

The Big Lebowski. Dir. Joel Coen. Perf. Jeff Bridges, John Goodman, Steve Buscemi, John Turturro. Film. 2005. Universal, 2005. DVD.

Black, Gregory D. Hollywood Censored: Morality Codes, Catholics, and the Movies. New York: Cambridge University Press . 1994. Print.

Blankinship, Donna Gordon. "Benjamin Colton Barnes, Iraq War Veteran Suspected Of Killing Park Ranger, Reportedly Found Dead" Associated Press. www.huffingtonpost.com, U.S. Edition. January 2, 2012. Web. Accessed 01 Feb 2012.

Born on the Fourth of July. Dir. Oliver Stone. Perf. Tom Cruise, Kyra Sedgwick, Raymond J. Barry, Jerry Levine, Frank Whaley, Caroline Kava and Willem Dafoe. Film. 1989. Universal Studios. DVD.

Broderick, Ned. Hi, Mom. I'm Home 1994. Oil on hardboard. The National Vietnam Veterans Art Museum; reproduced inVietnam: Relfexes and Reflections. Front dustcover, color; page 33, b/w. Harry N. Abrams, Inc: New York. 1989. Print

Burns, Robert E. I Am a Fugitive from a Georgia Chain Gang! Athens, GA: University of Georgia Press. 1997. Foreword by Matthew J. Mancini, 1997. Print. (Originally published by The Macfadden Publications, Inc, 1932)

Casualties of War. Dir. Brian DePalma. Perf. Michael J. Fox, Sean Penn. Film. 1989. Columbia Tristar Home Entertainment, 2001. DVD.

Coming Home. Dir. Hal Ashby. Perf. Jane Fonda, Jon Voight and Bruce Dern. 1978. MetroGoldwyn-Mayer Studios Inc. DVD.

Couvares, Francis G. Ed. Movie Censorship and American Culture. Second edition. Amherst, MA: University of Massachusetts Press. 2006. Print. 
Dean, Eric T. Jr. "The Myth of the Troubled and Scorned Vietnam Veteran”. Journal of American Studies, Vol. 26, No. 1 (Apr., 1992), pp. 59-74. Published by: Cambridge University Press on behalf of the British Association for American Studies. Article Stable URL: http://www.jstor.org/stable/27555590

The Deer Hunter. Dir. Michael Cimino. Perf. Robert De Niro, John Cazele, John Savage, Meryl Streep, Christopher Walken. Film. 1978. Universal, 2006. DVD.

Devine, Jeremy M. Vietnam at 24 Frames a Second: A Critical and Thematic Analysis of over 400 Films About the Vietnam War. Austin: University of Texas Press, 1999. Print.

Diagnostic and Statistical Manual of Mental Disorders: DSM-IV-TR. Washington, DC: American Psychiatric Association, 2000. Print.

Diagnostic and Statistical Manual of Mental Disorders, Fifth Edition. Arlington, VA, American Psychiatric Association, 2013. Web. <dsm.psychiatryonline.org>Accessed 1 June 2013.

Doherty, Thomas. Hollywood's Censor: Joseph I. Breen \& The Production Code Administration. New York: Columbia University Press, 2007. Print.

Early, Emmett. The War Veteran in Film. Jefferson, NC: McFarland \& Company, Inc., 2003. Print.

Fagelson, William. "Nervous Out of the Service: 1940s American Cinema, World War II Veteran Readjustment, and Postwar Masculinity," American Studies, University of Texas at Austin, May 2004

Foucault, Michel. The Archaeology of Knowledge and The Discourse on Language. Trans. A. M. Sheridan Smith. New York: Tavistock Publications Limited, 1972.

Full Metal Jacket. Dir. Stanley Kubrik. Perf. Matthew Modine, Adam Baldwin, Lee Ermey, Vincent D’Onofrio, Dorian Harewood, Arliss Howard and Kevyn Major Howard. Film. 1987. Warner Bros. DVD. 
Gast, Phil and Michael Pearson. "Troubled picture emerges of suspect in park ranger's slaying." CNN.com. U.S. Edition. January 5, 2012. Web. <www.cnn.com/2012/01/ 03/justice/washington-ranger-killed> Accessed 01 Feb 2012.

Green, Howard J., John E. O'Connor, Brown Holmes and Sheridan Gibney. I Am a Fugitive From a Chain Gang. Wisconsin/Warner Bros. Screenplay Series. Ed. Balio, Tino. Wisconsin: The University of Wisconsin Press, 1981. Print.

Hale, Barbara S. "The Representation of the Veteran in American Film, 1945-1950." 1996. Print.

Hall, Stuart. Representation: Cultural Representations and Signifying Practices. London: Sage Publications Ltd. 1997. Print.

Hayes, Ashley. "Experts: Vets’ PTSD, violence a growing problem” CNN.com. <www.cnn.com/2012/01/17/us/veterans-violence/index.html?iref=allsearch> January 17, 2012. Web. Accessed 1 Feb. 2012.

Herbison, Chauncey C. "B(l)ack to the World: Explorations of Race, Trauma Illness, and Healing in Selected Vietnam War Films." Diss. University of Kansas, 2006. DAI 67, no. 06A (2006): AAI3222180.

Horton, Alex. "The Mt. Rainier Shooting and PTSD: How the Media Got It Wrong” <http://www.blogs.va.gov/VAntage/5650/the-mt-rainier-shooting-and-ptsd-howthe-media-got-it-wrong/>

Hotakainen, Rob. "Concern grows over 'epidemic' veteran suicide rate” The News Tribune. Tacoma, Washington. May 26, 2011. Web. <www.thenewstribune.com/2011/05/ 26/1680716/concern-grows-over-epidemic-veteran.html>.

The Hurt Locker. Dir. Kathryn Bigelow. Perf. Anthony Mackie Jeremy Renner, Brian Geraghty, Evangeline Lilly. Film. 2008. Summit Entertainment, 2010. DVD.

I am a Fugitive from a Chain Gang. Dir. Mervyn LeRoy. Perf. Paul Muni, Glenda Farrell, Helen Vinson, Preston Foster. Film. 1932. Warner Brothers Home Video, 2005. DVD. 
Internet Move Database. imdb.com. Web.

Jewell, Richard B. The Golden Age of Cinema: Hollywood, 1929-1945. Malden, MA: Blackwell Publishing. 2007. Print.

---. Special features: "Commentary by Richard B. Jewell". I am a Fugitive from a Chain Gang. Dir. Mervyn LeRoy. Perf. Paul Muni, Glenda Farrell, Helen Vinson, Preston Foster. Film. 1932. Warner Brothers Home Video. 2005. DVD.

Karner, Tracy X. “ Masculinity, Trauma, and Identity: Live Narratives of Vietnam Veterans with Post Traumatic Stress Disorder (Posttraumatic Stress Disorder). Diss. University of Kansas, 1994. DAI 55, no 09A: item AAG9504027.

Leff, Leonard J. and Jerold L. Simmons. Dame in the Kimono: Hollywood, Censorship, and the Production Code. Revised edition. Lexington: University Press of Kentucky. 2001. Print.

Let There Be Light. United States Department of Defense; Army. 1946. US National Archives. Film. January 22. 2013. < www.youtube.com/watch?v=lQPoYVKeQEs> Web.

Life Magazine. "Speaking of Pictures." May 30, 1949, pages 8-10. Time, Inc. Google books. Web. 26 Nov. 2012.

Make the Connection. Web <maketheconnection.net>

Minchew, Kaye Lanning. "How Hollywood Reformed The Georgia Prison System" Georgia Journal. Spring 1992. Troup County Archives; Troup County History. Web. <www.cobbles.com/simpp_archive/linkbackups/chain-gang.htm>

Mirzoeff, Nicholas. Ed. The Visual Culture Reader. 2nd. Ed. London: Routledge. 2002. Print.

Moss, Alfred P. “About Lee Teter: Reflections.” Vietnam Veterans of America, Inc., Chapter 172.

Web. 6 April 2014. <vietnamreflections.com/contents/view/lee_teter>

National Center for PTSD. “About Us.” Web. <www.ptsd.va.gov/about/index.asp> 
--. "About Face” Web. <www.ptsd.va.gov/apps/AboutFace/>

---. Announcement. "Diagnostic Criteria: DSM-5." Web. < professional/pages/diagnostic_ criteria_dsm-5.asp> Accessed April 2013.

---. "Professional Section." Web < professional/pages/dsm-iv-tr-ptsd.asp> Accessed April 2013.

---. "PTSD Overview." < ptsd.va.gov/public/PTSD-overview/what-is-ptsd.asp> 28 Jan. 2013.

--.. "Public Section Home." www.ptsd.va.gov/public/index.asp

---. Public Section. "Symptoms of PTSD." Web. <www.ptsd.va.gov/public/PTSDoverview/basics/symptoms_of_ptsd.asp> Accessed April 2013.

---. Public Section. “Treatment of PTSD.” Web. <www.ptsd.va.gov/public/treatment/ therapy-med/treatment-ptsd.asp> Accessed April 2013.

"Park ranger fatally shot at Mount Rainier National Park" Seattlepi.com. $<$ www.seattlepi.com/default/article/Park-ranger-fatally-shot-at-Mount-Rainier2435973.php\#photo-1988015> 1 Jan. 2012.

Platoon. Dir. Oliver Stone. Perf. Tom Berenger, Willem Dafoe and Charlie Sheen. Film. 1986. Orion Pictures Corporation. DVD.

Schrader, Paul. The Internet Movie Script Database. Screenplay. Web. <www.imsdb.com/scripts/Taxi-Driver.html> 3 Aug. 2014.

Scott, Wilbur J. "PTSD in DSM-III: A Case in the Politics of Diagnosis and Disease." Social Problems. Vol. 37, No. 3. August 1990, pp 294-310. University of California Press. <www.jstor.org/stable/800744> Accessed April 4, 2012.

Scurfield, Raymond Monsour. A Vietnam Trilogy, Veterans and Post Traumatic Stress: 1968, 1989, 2000. New York: Algora Publishing, 2004. Print. 
Sinaiko, Eve. Ed. Vietnam: Reflexes and Reflections. The National Vietnam Veterans Art Museum. New York: Harry N. Abrams, Inc..1998. Print

Suarez, Benjamin. "Self-Portrait: The Vietnam Vet" Acrylic on canvas. The National Vietnam Veterans Art Museum; reproduced inVietnam: Relfexes and Reflections. Vietnam: Relfexes and Reflections. Page 183. Harry N. Abrams, Inc: New York. 1989. Print.

Taxi Driver. Dir. Martin Scorsese. 1976. Perf. Robert De Niro, Jodie Foster, Albert Brooks, Harvey Keitel, Leonard Harris, Peter Boyle and Cybill Shepherd. Film. Sony Pictures Home Entertainment, Inc. 2007. DVD.

Teter, Lee. Reflections. 1988. Oil painting. Web Site. <leeteter.com> 23 April 2014.

--- “About Reflections.” Artist Statement. May 26, 2010. Oak Gallery \& Frame Shop. Web. $<$ www.oakgalleryandframe.com/teter_about_reflections.htm>

Tropic Thunder. Dir. Ben Stiller. Perf. Jack Black, Ben Stiller, Robert Downey Jr. Film. 2008. Dreamworks, 2008. DVD.

United States Department of Commerce; Census Bureau. “A Snapshot of Our Nation’s Veterans" Web. <www.census.gov/how/infographics/veterans.html> 3 Aug. 2014.

United States Department of Veterans Affairs. “About Us.” Web. <www.ptsd.va.gov/about/index.asp> 27 Feb. 2014.

Walker, Mark. Vietnam Veteran Films. Metuchen, New Jersey: The Scarecrow Press, Inc., 1991. Print.

Wartorn: 1861-2010. Dir. John Alpert and Ellen Goosenberg Kent. HBO Documentary Films. Film. 2011. DVD. 